Third Meeting, January 11th, 1895.

WM. Prddie, Esq, D.Sc., F.R.S.E., Vice-President, in the Chair.

\begin{abstract}
Properties connected with the Angular Bisectors of a Triangle.
\end{abstract}

By J. S. Mackay, M.A., LL.D.

Notetion.

When points and lines are not specitically designated in the course of the following pages it will be understood that the notation for them is that recommended in the Proceedings of the Edinburgh Mathematical Society, Vol. I. pp. 6-11 (1894). It may be convenient to repeat all that is necessary for the present purpose.

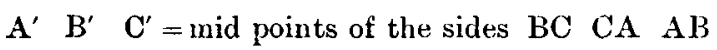

D E $\quad F=$ points of contact of sides with incircle

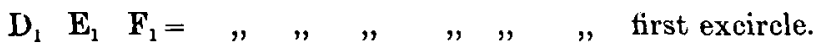

And so on.

$\mathrm{H} \quad=$ orthocentre of $\mathrm{ABC}$

$\mathrm{I}=$ incentre of $\mathrm{ABC}$

$I_{1} \quad I_{2} \quad I_{3}=1$ st 2 nd $3 \mathrm{rd}$ excentres of $\mathrm{ABC}$

L. M $\mathbf{N}=$ feet of interior angular bisectors of $A B C$

$\mathbf{L}^{\prime} \quad \mathbf{M}^{\prime} \quad \mathbf{N}^{\prime}=$, , exterior $, \quad, \quad$,

$\mathrm{O}=$ circumcentre of $\mathrm{ABC}$

U $\quad U^{\prime}=$ ends of that diameter of the circumcircle which is perpendicular to $\mathrm{BC} . \quad \mathrm{U}$ is on the opposite side of $\mathrm{BC}$ froin $\mathrm{A}$.

Similarly for $\mathrm{V} \mathrm{V}^{\prime}$ and $\mathrm{W} \mathrm{W}^{\prime}$.

$X \quad Y \quad \%=$ feet of the perpendiculars from A B C. 
The various points

$\mathrm{K} \mathbf{K}^{\prime}, \mathbf{P} \mathrm{P}^{\prime}, \quad \mathbf{Q} \mathbf{Q}^{\prime}, \mathbf{S} \mathbf{S}^{\prime}, \mathrm{T} \mathbf{T}^{\prime}$

are defined as they occur.

$$
\begin{aligned}
& \begin{array}{llllll}
a & \beta & \gamma & =\mathrm{AI} & \mathrm{BI} & \mathrm{CI}
\end{array} \\
& \begin{array}{llllll}
\alpha_{1} & \beta_{1} & \gamma_{1} & =\mathrm{AT}_{1} & \mathrm{BI}_{1} & \mathrm{CI}_{1}
\end{array} \\
& \begin{array}{llllll}
\alpha_{2} & \beta_{2} & \gamma_{2} & =\mathrm{AI}_{2} & \mathrm{BI}_{2} & \mathrm{CI}_{2}
\end{array} \\
& \begin{array}{lllllll}
\boldsymbol{a}_{3} & \beta_{3} & \gamma_{3} & =\mathbf{A I}_{3} & \mathbf{B I}_{3} & \mathrm{CI}_{3}
\end{array} \\
& \begin{array}{lllll}
a_{1}-\alpha & \beta_{2}-\beta & \gamma_{3}-\gamma=\mathrm{I}_{1} \mathrm{I} & \mathrm{I}_{2} \mathrm{I} & \mathrm{I}_{3} \mathrm{I}
\end{array} \\
& a_{.3}+\alpha_{3} \quad \beta_{3}+\beta_{1} \quad \gamma_{1}+\gamma_{2}=I_{2} I_{3} \quad I_{3} I_{1} \quad I_{1} I_{2} \\
& h_{1} \quad h_{2} \quad h_{3} \quad=\text { the perpendiculars AX BY CZ }
\end{aligned}
$$

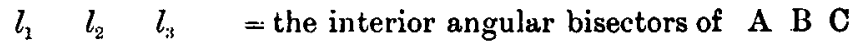

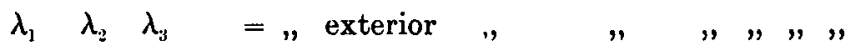

$$
\begin{aligned}
& r \quad=\text { radius of the incircle } \\
& \begin{array}{rlll}
r_{1} & r_{2} & r_{3} \quad=\text { radii of the } 1 \text { st } 2 \text { nd } 3 \text { rd excircles }
\end{array} \\
& \mathrm{R} \quad \text { = radius of the circumcircle } \\
& s \quad=\text { semiperimeter of } \mathrm{ABC} \\
& \begin{array}{llllll}
s_{1} & s_{2} & s_{3} & =s-a & s-b & s-c
\end{array} \\
& \begin{array}{llllll}
u_{1} & v_{1} & u_{1} & =\mathrm{BL} & \mathrm{CM} & \mathrm{AN}
\end{array} \\
& \begin{array}{lllll}
u_{1}^{\prime} & v_{1}^{\prime} & w_{1}^{\prime} & =\mathrm{BL}^{\prime} & \mathrm{CM}^{\prime} \quad \mathrm{AN}^{\prime}
\end{array} \\
& u_{2} \quad v_{2} \quad w_{2} \quad=\mathrm{CL} \quad \mathrm{AM} \quad \mathrm{BN} \\
& u_{2}^{\prime} \quad v_{2}^{\prime} \quad u_{2}^{\prime} \quad=\mathrm{CL}^{\prime} \quad \mathrm{AM}^{\prime} \quad \mathrm{BN}^{\prime}
\end{aligned}
$$

$\$ 1$.

If from either end of the base of a triangle a perpendicular be drawn to the bisector of the interior or exterior vertical angle, the distance of the foot of this perpendicular from the mid point of the base is equal to half the difference or half the sum of the sides of the triangle.*

\section{Figure 7.}

Let $\mathrm{BP} . \mathrm{BP}^{\prime}$, the perpendiculars from $\mathrm{B}$ on $\mathrm{AL} \mathrm{AL}^{\prime}$, the interior and the exterior bisectors of $\angle A$, meet $A C$ in $B_{1} B_{2}$.

* Compare Leybourn's Mathematical Kepusitury, old series, I. 284 (1799), II. $24(1801)$. 
$\begin{array}{lll}\text { Then } & \mathrm{BP}=\mathrm{B}_{1} \mathrm{P} & \mathrm{BP}^{\prime}=\mathrm{B}_{2} \mathrm{P}^{\prime} \\ \text { and } & \mathrm{CB}_{1}=\mathrm{AC}-\mathrm{AB} & \mathrm{CB}_{2}=\mathrm{AC}+\mathrm{AB} .\end{array}$

Now since $\mathrm{PP}^{\prime}$ are the mid points of $\mathrm{BB}_{1} \mathrm{BB}_{2}$ and $\mathrm{A}^{\prime}$ the wid point of $\mathrm{BC}$,

therefore

$$
\begin{aligned}
A^{\prime} \mathrm{P} & =\frac{1}{2} \mathrm{CB}_{1} & \mathrm{~A}^{\prime} \mathrm{P}^{\prime} & =\frac{1}{2} \mathrm{CB}_{2} \\
& =\frac{1}{2}(\mathrm{AC}-\mathrm{AB}) & & =\frac{1}{2}(\mathrm{AC}+\mathrm{AB})
\end{aligned}
$$

Similarly if $Q Q^{\prime}$ be the feet of the perpendiculars from $\mathrm{C}$ on AL AL',

$$
A^{\prime} Q=\frac{1}{2}(A C-A B) \quad A^{\prime} Q^{\prime}=\frac{1}{2}(A C+A B)
$$

It is not easy to assign authorities to the properties given in the following pages. Some of these properties occur incidentally in the solutions of problems on the construction of triangles, and are there spoken of, or assumed without being spoken of, as well known theorems. A large collection of them will be found in four articles entitled "Useful Propositions in Geometry" by M. A. Harrison, which appeared in Leybourn's Mathematical Repository, old series, I. 283-5, 367-9, II. 23-5, 234-7 (1799-1801). In these articles no mention is made of properties connected with the bisector of the exterior vertical angle.

It has been conjectured that "M. A. Harrison" is a pseudonym, adopted either by J. H. Swale or John Lowry.

$$
\begin{aligned}
\therefore \mathrm{ABB}_{1}=\mathrm{AB}_{1} \mathrm{~B} & =\mathrm{BAL}^{\prime}=\mathrm{B}_{2} \mathrm{AL}^{\prime}=\mathrm{AP}^{\prime} \mathrm{A}^{\prime}=\mathrm{AQ}^{\prime} \mathrm{A}^{\prime} \\
& =\frac{1}{2}(\mathrm{~B}+\mathrm{C}) \\
\angle \mathrm{CBB}_{1}=\mathrm{BL}^{\prime} \mathrm{A} & =\frac{1}{2}(\mathrm{~B}-\mathrm{C})
\end{aligned}
$$

(2) $\mathrm{A}^{\prime} \mathrm{PP}^{\prime}$ is a straight line parallel to $\mathrm{AC}$. Hence $\mathrm{P} \mathrm{P}^{\prime}$ are situated on $\mathrm{C}^{\prime} \mathrm{A}^{\prime}$ one of the sides of the triangle $\mathrm{A}^{\prime} \mathrm{B}^{\prime} \mathrm{C}^{\prime}$, which is complementary to ABC.

Similarly, if from B perpendiculars be drawn to the bisectors of the interior and exterior angles at $\mathrm{C}$, the feet of these perpendiculars will also be situated* on $\mathrm{C}^{\prime} \mathrm{A}^{\prime}$.

(3) If perpendiculars be drawn from each vertex of a triangle to the interior and the exterior bisectors of the angles at the other vertices, the twelve points of intersection thus obtained will range, four

* Arthur Lascases in the Nouvelles Anmules, XVIII. 171 (1859). 
and four, on three straight lines, which by their mutual intersections will form the triangle complementary to the given triangle. *

The proof of this is obvious enough from what precedes; but the following demonstration will be found interesting.

\section{Figuae 8.}

Let $A B C$ be a triangle, $I I_{1} I_{2} I_{3}$ the incentre and the ex. centres.

The four lines $I_{2} B \quad I_{3} I_{1} \quad I_{3} C \quad I_{1} I_{2}$ are the interior and the exterior bisectors of the angles $\mathrm{B}$ and $\mathrm{C}$. Now these four lines, taken three and three, form the four triangles

$$
\mathrm{I}_{3} \mathrm{I}_{1} \mathrm{C} \quad \mathrm{I}_{2} \mathrm{IC} \quad \mathrm{I}_{2} \mathrm{I}_{2} \mathrm{~B} \quad \mathrm{I}_{3} \mathrm{IB}
$$

Hence, by a theorem due to Wallace, $\uparrow$ the circuncircles of these four triangles all pass through the sawe point $A$; and by one of Steiner's theorems $\ddagger$ the feet of the perpendiculars let fall from $A$ on the four straight lines are collinear.

Let $A_{1} \quad A_{2} \quad A_{3} \quad A_{4}$ be the feet of the perpendiculars. Then $\mathrm{AA}_{1} \mathrm{BA}_{2}$ is a rectangle; therefore $A_{1} A_{2}$ passes through $C^{\prime}$ the mid point of $A B$. Similarly $\mathrm{A}_{3} \mathrm{~A}_{+} \quad, \quad, \quad \mathrm{B}^{\prime}, \quad, \quad, \quad, \quad \mathbf{A C}$; therefore the straight line $A_{1} A_{2} A_{3} A_{4}$ bisects $A B$ and $A C$.

$$
\begin{array}{lll}
A_{3} A_{4}=l, & A_{1} A_{2}=c, & A_{2} A_{4}=s \\
A_{1} A_{3}=s_{3}, & A_{2} A_{3}=s ., & A_{1} A_{4}=s_{3}
\end{array}
$$

(5) The four points $A_{1} A_{2} A_{;} A_{4}$ lie, two and two, on the circumferences of the six circles which have for diameters the distances of $A$ from $I \quad I_{1} I_{2} I_{3} B$ C.

(6) If the circles be denoted by their diameters, the circles AI $\mathrm{AI}_{1}$ touch each other at $\mathrm{A}$, and have $\mathrm{I}_{32} \mathrm{I}_{; ;}$for common tangent; they also touch the circle $I_{1}$ the former at $I$ and the latter at $I_{1}$.

* T. T. Wilkinson in the Lady's artd Gentleman's Dirtry for 1862, p. 74. The demonstration given is also due to him, as well as part of (4). See the Dicury for 1863, pp. 54-5.

† Leybourn's Mathematical Repository, new series, Vol. I., p. 22 of the Questions (1804).

† Gergonne's Aunceles X VIII. 302(1828) or Steiner's Gcsenmelte Werkc, I. 223 
The circles $\mathrm{AI}_{2} \mathrm{AI}_{i j}$ touch each other at $\mathrm{A}$, and have $\mathrm{AI}_{1}$ for common tangent ; they also touch the circle $I_{2} I_{3}$ the former at $I_{2}$ and the latter at $I_{3}$.

(7) The radical axis of the circles

$$
\begin{array}{lllll}
\mathrm{AB} & \mathrm{AI} & \mathrm{AI}_{2} & \text { is } & \mathbf{A A _ { 1 }} \\
\mathrm{AB} & \mathrm{AI}_{3} & \mathrm{AI}_{1} & , & \mathrm{AA} \\
\mathrm{AC} & \mathrm{AI} & \mathrm{AI} & , & \mathrm{AA}_{:} \\
\mathrm{AC} & \mathrm{AI}_{1} & \mathrm{AI} & , & \mathrm{A} \mathrm{A}_{4} \\
\mathrm{AP}: \mathrm{AL}=\frac{1}{2}(\mathrm{AC}+\mathrm{AB}): \mathrm{AC} \\
\mathrm{AQ}: \mathbf{A L}=\frac{1}{2}(\mathrm{AC}+\mathrm{AB}): \mathrm{AB}
\end{array}
$$

\section{Figuke 9 .}

Since $\mathrm{PA}^{\prime}$ is parallel to $\mathrm{AC}$, therefore triangles ACL $P A^{\prime} \mathrm{L}$ are similar; therefore $\mathrm{AL}: \mathrm{PL}=\mathrm{AC}: \mathrm{P} \Lambda^{\prime}$

$$
=A C: \frac{1}{2}(\mathrm{AC}-\mathrm{AB})
$$

therefore

$$
A L-P L: A L=\frac{1}{2}(A C+A B): A C
$$

$$
\begin{gathered}
A P^{\prime}: A L^{\prime}=2(A C-A B): A C \\
A Q^{\prime}: \Lambda L^{\prime}=2(A C-A B): A B \\
P Q: A L=A C^{2}-A B^{\prime 2}: 2 A C \cdot A B \\
P^{\prime} Q^{\prime}: A L^{\prime}=A C^{2}-A B^{2}: 2 A C \cdot A B
\end{gathered}
$$

FigURE 9.

Since triangles ACL PA'L are similar therefore

$$
\begin{aligned}
\mathrm{PL}: \mathrm{AL} & =\mathrm{PA}^{\prime}: \mathbf{A C} \\
& =!(A C-A B): A C
\end{aligned}
$$

Since triangles ABL $Q^{\prime} L$ are similar therefore

$$
\begin{aligned}
\mathrm{QL}: \mathrm{AL} & =\mathrm{QA}^{\prime}: \mathbf{A B} \\
& =\frac{1}{2}(\mathbf{A C}-\mathbf{A B}): \mathbf{A B}
\end{aligned}
$$


therefore $\quad \frac{\mathrm{PL}+\mathrm{QL}}{\mathrm{AL}}=\frac{\mathrm{AC}-\mathrm{AB}}{3 \mathrm{AC}}+\frac{\mathrm{AC}-\mathrm{AB}}{2 \mathrm{AB}}$

$$
\begin{aligned}
& =\frac{\mathrm{AC} \cdot \mathrm{AB}-\mathrm{AB}}{2 \mathrm{AC} \cdot \mathrm{AB}}+\frac{\mathrm{AC}^{2}-\mathrm{AC} \cdot \mathrm{AB}}{2 \mathrm{AC} \cdot \mathrm{AB}} \\
& =\frac{\mathrm{AC}^{2}-\mathrm{AB}^{2}}{2 \mathrm{AC} \cdot \mathrm{AB}}
\end{aligned}
$$

$(11)^{*}$

$$
\begin{aligned}
\mathbf{A B C} & =\mathbf{A Q} \cdot \mathbf{B P}=\mathbf{A P} \cdot \mathbf{C Q} \\
& =\mathbf{A} \mathbf{Q}^{\prime} \cdot \mathbf{B} \mathbf{P}^{\prime}=\mathbf{A} \mathbf{P}^{\prime} \cdot \mathbf{C} \mathbf{Q}^{\prime}
\end{aligned}
$$

For triangles $\mathrm{AXL}, \mathrm{BPL}$ are similar therefore

$$
\begin{aligned}
\mathrm{AX}: \mathrm{BP} & =\mathrm{AL}: \mathrm{BL} \\
& =\mathrm{QL}: \mathbf{A}^{\prime} \mathrm{L} \\
& =\mathrm{AQ}: \mathrm{BA}^{\prime} \\
\mathrm{AQ} \cdot \mathrm{BP} & =\mathrm{AX} \cdot \mathrm{BA}^{\prime} \\
& =\mathrm{ABC}
\end{aligned}
$$

therefore

The last two expressions for ABC may be derived from the first two, since

$$
\mathrm{AP} \cdots B \mathrm{P}^{\prime} \quad \mathrm{AQ}=\mathrm{CQ}^{\prime} \quad \mathrm{BP}=\mathrm{A} \mathrm{P}^{\prime} \quad \mathrm{CQ}=\mathrm{AQ} \mathrm{Q}^{\prime} .
$$

(12) The values of the following ingles may be registered for reference :

$$
\begin{aligned}
& A B P=A C Q=90^{-}-\underset{2}{1} A \\
& \mathrm{BDF}=\mathrm{BFD}=\mathrm{BD}_{22} \mathrm{~F}_{2}=\mathrm{BF}_{2} \mathrm{D}_{2}=90^{\circ}-{ }_{2}^{1} \mathrm{~B} \\
& \mathrm{CDE}=\mathrm{CED}=\mathrm{CD}_{3} \mathrm{E}_{: \mathrm{i}}=\mathrm{CE}_{; ;} \mathrm{D}_{: 3}=90^{\circ}-\frac{1}{2} \mathrm{C} \\
& \mathrm{AB} \mathrm{P}^{\prime}=\mathrm{ACQ}^{\prime}=\mathrm{A} \\
& \left.\mathrm{BD}_{1} \mathrm{~F}_{1}=\mathrm{BF}_{1} \mathrm{D}_{1}=\mathrm{BD}_{3} \mathrm{~F}_{3}=\mathrm{BF}_{3} \mathrm{D}_{3 ;}=\right]_{2} \mathrm{~B} \\
& \mathrm{CD}_{1} \mathrm{E}_{1}=\mathrm{CE}_{1} \mathrm{D}_{1}=\mathrm{CD}_{2} \mathrm{E}_{2}=\mathrm{CE}_{2} \mathrm{D}_{2}=\frac{\mathrm{l}}{2} \mathrm{C}
\end{aligned}
$$

In triangles $\mathrm{BDP}$ CQD

$$
\begin{aligned}
& \left.\mathrm{PBD}=\frac{1}{2}(\mathrm{~B}-\mathrm{C}), 131\right) \mathrm{P}=90^{\circ}+{ }_{2}^{1} \mathrm{C}, \quad \mathrm{DPB}=90^{\circ}-1_{2}^{1} \mathrm{~B} \\
& =\mathrm{DCQ} \quad=\mathrm{CQD} \quad=\mathrm{QDC}
\end{aligned}
$$

* Part of (11) is given in Hind's Triyonometry, 4th ed., p. $30 \pm(18+1)$. 
In triangles $\mathrm{BD}_{1} \mathrm{P} \quad \mathrm{CQD}_{1}$

$$
\begin{aligned}
& \mathrm{PBD}_{1}=\frac{1}{2}(\mathrm{~B}-\mathrm{C}), \mathrm{BD}_{1} \mathrm{P}=\frac{1}{2} \mathrm{C}, \quad \mathrm{D}_{1} \mathrm{~PB}=180^{\circ}-\frac{1}{2} \mathrm{~B} \\
& =\mathrm{D}_{1} \mathrm{CQ} \quad=\mathrm{CQD} \mathrm{D}_{1} \quad=\mathrm{QD}_{1} \mathrm{C}
\end{aligned}
$$

In triangles $\mathrm{BD}_{2} \mathrm{P}^{\prime} \quad \mathrm{CQ}^{\prime} \mathrm{D}_{2}$

$$
\begin{aligned}
& \mathrm{P}^{\prime} \mathrm{BD}_{2}=\frac{1}{2} \mathrm{~A}+\mathrm{B}, \quad \mathrm{BD}_{2} \mathrm{P}^{\prime}=\frac{1}{2} \mathrm{C}, \quad \mathrm{D}_{2} \mathrm{P}^{\prime} \mathrm{B}=90^{\circ}-\frac{1}{2} \mathrm{~B} \\
& =\mathrm{D}_{2} \mathrm{CQ}^{\prime} \quad=\mathrm{CQ}^{\prime} \mathrm{D}_{3} \quad=\mathrm{Q}^{\prime} \mathrm{D}_{2} \mathrm{C}
\end{aligned}
$$

In triangles $\mathrm{BD}_{3} \mathrm{P}^{\prime} \mathrm{CQ}^{\prime} \mathrm{D}_{i ;}$

$$
\begin{aligned}
& \mathrm{P}^{\prime} \mathrm{BD}_{3}=\frac{1}{2} \mathrm{~A}+\mathrm{C}, \quad \mathrm{BD}_{3} \mathrm{P}^{\prime}=90^{\circ}-\frac{1}{2} \mathrm{C}, \mathrm{D}_{3} \mathrm{P}^{\prime} \mathrm{B}=\frac{1}{2} \mathrm{~B} \\
& =\mathrm{D}_{i j} \mathrm{CQ}^{\prime} \quad=\mathrm{CQ}^{\prime} \mathrm{D}_{i j} \quad=\mathrm{Q}^{\prime} \mathrm{D}_{i j} \mathrm{C}
\end{aligned}
$$

$\triangle \mathrm{E} P=\mathrm{A} F \mathrm{P}=\mathrm{A} Q \mathrm{E}_{1}=\mathrm{A} Q \mathrm{~F}_{1}=90^{\circ}+\frac{1}{2} \mathrm{C}$

A P E $=A P F=\Lambda E_{1} Q=A F_{1} Q=\prod_{2}^{1} B$

$A E_{.:} P^{\prime}=A F_{3} P^{\prime}=A Q^{\prime} F_{s i}=A Q^{\prime} F_{3 ;}=\frac{1}{2} C$

A $P^{\prime} E_{2}=A P^{\prime} F_{2}=A E_{3} Q^{\prime}=A F_{3} Q^{\prime}={ }_{2}^{1} B$

$(13)^{*}$

$$
\begin{aligned}
& \mathrm{AP} \cdot \mathrm{AQ}=\mathrm{BP}^{\prime} \cdot \mathrm{CQ}^{\prime}=s s_{1} \\
& \mathbf{B P} \cdot \mathbf{C Q}=\mathbf{A P}^{\prime} \cdot \mathbf{A Q}^{\prime}=s_{i} s_{i}
\end{aligned}
$$

The similar triangles $\mathrm{AEP} A Q E_{\text {, give }}$

$$
A E: A P=A Q: A E_{1}
$$

therefore

$$
\begin{aligned}
\mathrm{AP} \cdot \mathrm{AQ} & =\mathrm{AE} \cdot \mathrm{AE}_{1} \\
& =s s_{1} ;
\end{aligned}
$$

and

$$
\mathrm{AP}=\mathrm{BP}^{\prime} \quad \mathrm{AQ}=\mathrm{CQ}^{\prime}
$$

The other equalities may be derived from the similar triangles BDP CQD, and the fact that

$$
\begin{aligned}
& \mathbf{B P}=\mathbf{A P}^{\prime} \quad \mathbf{C Q}=\mathbf{A} \mathbf{Q}^{\prime} . \\
& \mathrm{AP} \cdot \mathrm{AQ} \cdot \mathrm{BP} \cdot \mathrm{CQ}=\mathrm{AP}^{\prime} \cdot A \mathrm{Q}^{\prime} \cdot \mathrm{BP}^{\prime} \cdot \mathrm{CQ}^{\prime} \\
& =\Delta^{*}
\end{aligned}
$$

* (13) Half of this is given in Hind's Trifonometr!", thed., p. 304 (1841). 
(15) Let $\mathrm{D}, \mathrm{D}_{1}, \mathrm{D}_{2}, \mathrm{D}_{3}$ be the points where the incircles and the excircles touch BC.

\section{FigURE 9.}

It is known that

$$
A^{\prime} D=A^{\prime} D_{1}=\frac{1}{2}(A C-A B), A^{\prime} D_{2}=A^{\prime} D_{3}=\frac{1}{2}(A C+A B) ;
$$

hence $\quad D \quad D_{1} \quad P \quad Q \quad$ lie on a circle with centre $A^{\prime}$

and $\quad \mathrm{D}_{z} \quad \mathrm{D}_{\mathfrak{z}} \mathrm{P}^{\prime} \quad \mathrm{Q}^{\prime}$

(16) The incircle and first excircle of $\mathrm{ABC}$ cut the circle $D P D_{1} Q$ orthogonally, and the second and third excircles cut $D_{2} Q^{\prime} P^{\prime} D_{3}$ orthogonally.

For $D D_{1}$ is perpendicular to $I D$ and $I_{1} D_{1}$; and $\quad \mathrm{D}_{2} \mathrm{D}_{3}, \quad, \quad, \quad \mathrm{I}_{2} \mathrm{D}_{2} \quad, \quad \mathrm{I}_{3} \mathrm{D}_{3}$.

$$
\begin{array}{ll}
\mathrm{J} \mathrm{P} \cdot \mathrm{I} \mathbf{Q}=r^{2}, & \mathrm{I}_{1} \mathrm{P} \cdot \mathrm{I}_{1} \mathrm{Q}=r_{1}{ }^{2} \\
\mathrm{I}_{3} \mathrm{P}^{\prime} \cdot \mathrm{I}_{2} \mathrm{Q}^{\prime}=r_{3}^{\prime \prime}, & \mathrm{I}_{3} \mathrm{P}^{\prime} \cdot \mathrm{I}_{3} \mathbf{Q}^{\prime}=r: r^{\prime}
\end{array}
$$

(18) If $I_{1} I_{1}$ be considered as one pair of a system of coaxal circles, then $P Q$ are the limiting points of the system; and $P^{\prime} Q^{\prime}$ are the limiting points of the coaxal system of which $I_{2} I_{3}$ form one pair.

For $\mathrm{DD}_{1}$ is a common tangent to the circles $\mathrm{I}_{1}$, and $\mathrm{A}^{\prime}$ is its mid point ; therefore the radical axis of $I I_{1}$ passes through $A^{\prime}$.

Now since the circie whose diameter is $\mathrm{DD}_{1}$ has its centre at $A^{\prime}$ and cuts $I I_{1}$ orthogonally, therefore it passes through the limiting points of the system $I_{1} I_{1}$; and the limiting points of the system $I I_{1}$ are situated on the line $I_{1}$.

(19) $A P B P^{\prime}$ is a rectangle, and $\mathrm{PP}^{\prime}$ bisects $\mathrm{AB}$. Hence if $\mathrm{AX}$ be perpendicular to $\mathrm{BC}$, the circle on $\mathrm{AB}$ as diameter passes through* $\mathrm{P} \mathrm{P}^{\prime} \mathrm{X}$.

Similarly the circle on $\mathrm{AC}$ as diameter * passes through Q $Q^{\prime} \mathbf{X}$.

* W. H. Levy in the Lady's and Gentleman's Diary for 1856, p. 49. 
(20) Triangles $X P Q, X P^{\prime} Q^{\prime}$ are inversely similar* to $A B C$.

Figitie 9.

Since A P B X are concyclic

therefore

$\angle \mathrm{APX}=\angle \mathrm{ABX}$

therefore

$\angle X P Q=\angle A B C$

Since A $\mathrm{C} \quad \mathrm{Q} X$ are concyclic

therefore

$\angle \mathrm{AQX}=\angle \mathrm{ACX}$

therefore triangle $\mathrm{XPQ}$ is similar to $\mathrm{ABC}$

In like manner $X P^{\prime} Q^{\prime}$ is similar to $A B C$

(21) The directly similar triangles $X P Q \quad X P^{\prime} Q^{\prime}$ have their homologous sides mutually perpendicular.

(22) The incentre and the excentres of triangles $X P Q X P^{\prime} Q^{\prime}$ are situated on $\mathrm{BX}$ and $\mathrm{AX}$.

Sirce A P B X are concrclic

therefore

$$
-B X P=\angle B A P=\frac{1}{2} A
$$

Since $\mathrm{A}$ C $\mathrm{Q} X$ are concyclic

therefore

$$
\therefore \mathrm{CXQ}=\angle \mathrm{CAQ}=\frac{1}{2} \mathrm{~A}
$$

therefore $\mathrm{BX}$ bisects $\angle \mathrm{PXQ}$

therefore $\mathrm{BX}$ contains the incentre and one excentre of $\mathrm{XPQ}$.

Now AX is perpendicular to $\mathrm{BX}$

therefore AX contains the other excentres.

In like manner it may be proved that $\mathrm{AX}$ contains the incentre and one excentre of triangle $X P^{\prime} Q^{\prime}$, and that $\mathrm{BX}$ contains the other excentres.

- W. H. Ievy in the Lady's and Gentleman's Diury for 1856, p. 49. The first part of the theorem, however, is given in Leybourn's Mathematical Repository, old series, II. 25 (1801). 
(23) To determine the incentre and the excentres of the triangles XPQ X I'Q'.

Since AX ID are parallel

therefore

$\mathrm{AL}: \mathrm{IL}=\mathrm{XL}: \mathrm{DI}$.

But in the similar triangles $\mathrm{ABC} \mathrm{XPQ}$

$\mathrm{AL}$ and $\mathrm{XL}$ are homologous lines;

therefore $1 \mathrm{~L}$ and $\mathrm{DL}$ are homologous lines,

and I D homologous points;

therefore $\mathrm{D}$ is the incentre of $\mathrm{XPQ}$.

Since $\angle D P D_{1}$ is right, $D_{1}$ is the first excentre.

The other excentres are the points where DP and $D Q$ intersect AX.

In like manner it may be proved that $D_{3}$ and $D_{2}$ are the third and second excentres of triangle $X P^{\prime} Q^{\prime}$ and that the incentre and first excentre are the points where $D_{3} Q^{\prime}$ and $D_{3} P^{\prime}$ intersect $\mathrm{AX}$.

(24) The circumcircles* of $X P Q X P^{\prime} Q^{\prime}$ pass through $\mathbf{A}^{\prime}$.

Since

$$
\begin{aligned}
-\angle A^{\prime} \mathrm{XQ} & =-\mathrm{CAQ} \\
& =\angle \mathrm{A}^{\prime} \mathrm{PQ}
\end{aligned}
$$

because $A^{\prime} P$ and $\mathbf{C A}$ are parallel;

therefore $A^{\prime} \mathbf{P} \quad \mathbf{Q} \quad \mathbf{Q}$ are concyclic.

In like manner $A^{\prime} \quad Q^{\prime} \quad P^{\prime} X$ are concyclic.

(25) The diameters* of the circles $\mathrm{XPQ} X \mathrm{P}^{\prime} \mathrm{Q}^{\prime}$ are respectively equal to $\mathrm{AU}^{\prime} \mathrm{AU}$.

For the diameter of $\mathrm{XPQ}$ is the perpendicular drawn from $\mathrm{A}^{\prime}$ to $\mathrm{PQ}$ and terminated by $\mathrm{AX}$; and this perpendicular along with $A^{\prime} U^{\prime} U^{\prime} A$ AX produced forms a parallelogram.

(26) The diameters of the circles $X P Q X P^{\prime} Q^{\prime}$ coincide with the radical axes of the circles $I I_{1}$ and $I_{2} I_{3}$.

* The first parts of (24) and (25) are found in Leybourn's Mathematical Repository, old series, II. 24, 235 (1801). 
(27) The circle $\mathrm{XPQ}$ cuts orthogonally the system of circles I $I_{1}$; and the circle $X P^{\prime} Q^{\prime}$ cuts orthogonally the system $I_{2} I_{3}$.

For the circle $\mathrm{XPQ}$ passes through the limiting points $\mathrm{P} Q$ of the system $I I_{1}$ and has its centre on the radical axis of the same system.

(28) The centres of the circles $X P Q$ and $X P^{\prime} Q^{\prime}$ and the ninepoint centre of triangle $A B C$ are collinear.

For they are situated on the straight line which bisects $A^{\prime} X$ perpendicularly.

(29) The sum of the areas of the circles $X P Q X P^{\prime} Q^{\prime}$ is equal to the area of the circle ABC.

For the areas of circles are proportional to the squares of their diameters

and

$$
A U^{\prime 2}+A U^{2}=U^{\prime 2}
$$

$$
\mathrm{XPQ}+\mathrm{XP}^{\prime} \mathrm{Q}^{\prime}=\mathrm{ABC} \text {. }^{*}
$$

$$
A B C: X P Q=U U^{\prime}: U^{\prime} K
$$$$
A B C: X P^{\prime} Q^{\prime}=U U^{\prime}: U K
$$

For

$$
\begin{aligned}
A B C: X P Q & =U C^{\prime 2}: A U^{\prime} \\
& =U U^{\prime}: U^{\prime} K
\end{aligned}
$$

For another proof see $\$ 4,(11)$.

$$
\begin{array}{llll}
X P & X P^{\prime} & X Q & X Q^{\prime}
\end{array}
$$

are respectively parallel to

$$
\mathrm{CU} \quad \mathrm{CU}^{\prime} \mathrm{BU} \quad \mathrm{BU}^{\prime}
$$

For

$$
\begin{aligned}
\angle \mathrm{XPQ} & =-\mathrm{ABC} \\
& =\angle \mathrm{AUC} .
\end{aligned}
$$

* W. H. Levy in the Lady's and Gentleman's Diary for 1855, p. 71.

+ Parts of (28), (29), (30), (31), are found in Leybourn's Mathematical Repository, old series, II. 236, 25 (1801). 
(3) The triangles

\section{$\mathrm{A}^{\prime} \mathrm{BP} \quad \mathrm{A}^{\prime} \mathrm{CQ} \quad \mathrm{A}^{\prime} \mathrm{BP}^{\prime} \quad \mathrm{A}^{\prime} \mathrm{CQ}^{\prime}$}

are respectively similar to

$$
\text { QAX PAX Q'AX P'AX }
$$

For $\mathbf{A}^{\prime} \mathbf{P}$ is parallel to $\mathbf{C A}$;

$$
\begin{aligned}
& \text { therefore } \quad \angle \mathrm{BA}^{\prime} \mathrm{P}=\mathrm{C} \\
& =-\mathrm{AQX} \text {; } \\
& \angle \mathrm{BPA}^{\prime}=90^{\circ}+\frac{1}{2} \mathrm{~A} \\
& =-\mathbf{A X Q} \text {. }
\end{aligned}
$$

Or it may be proved that

$$
-\mathbf{A}^{\prime} \mathbf{B P}=-\mathbf{Q A X}
$$

since the sides of the one are perpendicular to the sides of the other.

(34) The triangles

$$
\begin{array}{llll}
\mathbf{A}^{\prime} \mathrm{UP} & \mathbf{A}^{\prime} \mathrm{UQ} & \mathbf{A}^{\prime} \mathrm{U}^{\prime} \mathbf{P}^{\prime} \quad \mathbf{A}^{\prime} \mathbf{U}^{\prime} \mathbf{Q}^{\prime}
\end{array}
$$

are respectively similar to

$$
\text { QCX PBX Q'CX P'BX. }
$$

For

$$
\angle \mathrm{A}^{\prime} \mathrm{UP}=\llcorner\mathrm{QCX}
$$

since the sides of the one are perpendicular to the sides of the other;

and

$$
\begin{aligned}
\angle \mathbf{A}^{\prime} \mathbf{P U} & =\frac{1}{2} \mathbf{A} \\
& =\angle \mathbf{Q X C} .
\end{aligned}
$$

(35) The following triads of points are collinear :*

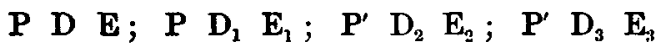

$$
\begin{aligned}
& \text { Q D F ; Q } D_{1} F_{1} ; Q^{\prime} D_{2} F_{2} ; Q^{\prime} D_{3} F_{3} \text {. }
\end{aligned}
$$

* W, H. Lovy in the Lady's and Gentleman's Diary for 1857, p. 51. 
Figure 10.

The points B D P I are concyclic; therefore $\angle B D P$ is the supplement of $\angle B T P$. Because the isosceles triangles CDE, UBI have

$$
-\mathrm{C}=\llcorner\mathrm{U}
$$

therefore

$$
\angle \mathrm{CDE}=\angle \mathrm{BIU} \text {; }
$$

therefore $\angle \mathrm{BDP}$ is the supplement of $\angle \mathrm{CDE}$;

therefore $\mathrm{DP}$ coincides with $\mathrm{DE}$.

(36) The following quintets of points are concyclic:

$$
\begin{array}{llllllllll}
\mathbf{B} & \mathbf{D} & \mathbf{I} & \mathbf{F} & \mathbf{P} ; & \mathbf{C} & \mathbf{D} & \mathbf{I} & \mathbf{E} & \mathbf{Q} \\
\mathbf{B} & \mathbf{D}_{1} & \mathbf{I}_{1} & \mathbf{F}_{1} & \mathbf{P} ; & \mathbf{C} & \mathbf{D}_{1} & \mathbf{I}_{1} & \mathbf{E}_{1} & \mathbf{Q} \\
\mathbf{B} & \mathbf{D}_{2} & \mathbf{I}_{2} & \mathbf{F}_{2} & \mathbf{P}^{\prime} ; & \mathbf{C} & \mathbf{D}_{2} & \mathbf{I}_{2} & \mathbf{E}_{2} & \mathbf{Q}^{\prime} \\
\mathbf{B} & \mathbf{D}_{3} & \mathbf{I}_{3} & \mathbf{F}_{3} & \mathbf{P}^{\prime} ; & \mathbf{C} & \mathbf{D}_{3} & \mathbf{I}_{3} & \mathbf{E}_{:} & \mathbf{Q}^{\prime}
\end{array}
$$

the diameters of the various circles being

$\begin{array}{llll}\mathrm{B} \mathrm{I} & \mathrm{B} \mathrm{I}_{1} & \mathrm{~B} \mathrm{I}_{2} & \mathrm{~B} \mathrm{I}_{3} \\ \mathrm{C} \mathrm{I} & \mathrm{CI}_{1} & \mathrm{CI}_{2} & \mathrm{CI}_{3}\end{array}$

(37) Since C L B L' form a harmonic range, and $\mathrm{CQ}$ BP $A L^{\prime}$ are parallel, therefore Q L P A form a harmonic range.*

\section{Figure 9.}

Similarly for $Q^{\prime}$ A $P^{\prime} L^{\prime}$.

(38) If at $L$ a perpendicular be drawn to $A L$ meeting $A B A C$ at $P Q$, then $A P$ or $A Q$ is a harmonic meant between $\mathrm{AB}$ AC.

* Fuhrmann's Synthctische Bewcise planimetrischer Sätse, pp. 58-9 (1890).

+ Rev. R. Townsend in Mathcmatical Qucstions from the Educational Timcs, XIV. $76(1870)$. 
Figure 11.

If $B_{1}$ be the image of $B$ in $A L$, then $\mathrm{AL}$ bisects $\angle \mathrm{BLB}_{1}$;

therefore $\mathrm{LQ}$ bisects $-\mathrm{CLB}_{1}$;

therefore $\mathrm{L}\left(\mathrm{BAB}_{1} \mathrm{Q}\right)$ is a harmonic pencil.

Now this pencil is cut by the transversal $A C$;

therefore $A \quad B_{1} Q \quad C$ form a harmonic range

and $\mathrm{AQ}$ is the harmonic mean between $\mathrm{AB}_{1} \mathrm{AC}$.

Similarly for $L^{\prime}$.

$$
A U: I U=A B+A C: B C
$$

Figune 12.

Draw IP IQ parallel to AB AC.

The quadrilaterals ABUC IPUQ are similar: therefore $A U: I U=A B+A C: I P+I Q$.

Now $\angle \mathrm{UBL}=\angle \mathrm{UAC}=\angle \mathrm{UAB}=\angle \mathrm{UIP}$; and $\mathrm{UB}=\mathrm{UI}$;

therefore triangles UBL UIP are congruent, and $\quad B L=I P$.

Similarly $\mathrm{CL}=\mathrm{IQ}$;

therefore $\quad A U: I U=A B+A C: B L+C L$.

(40) If on $A^{\prime} K$ as diameter a circle is described, and from $O$ the circumcentre of $\mathrm{ABC}$ a perpendicular is drawn to $\mathrm{A}^{\prime} \mathrm{K}$ meeting this circle at $\mathbf{P}$, then*

$$
\mathrm{AB}^{2}+\mathrm{AC}^{2}=4 \mathrm{PU}^{2}
$$

* John Whitley in the Gentleman's Mathematical Companion for 1803, p. 38. 


\section{Ficture 13.}

The trimgle PUU' is isosceles;

$$
\begin{aligned}
& \text { therefore } \\
& \mathrm{PA}^{\prime 2}=\mathrm{PU}^{\prime 2}-\mathrm{UA}^{\prime} \cdot \mathrm{A}^{\prime} \mathrm{U}^{\prime} \\
& =\mathrm{PU}^{\prime 2}-\mathrm{A}^{\prime} \mathbf{H}^{\prime \prime} \text {; } \\
& \text { and } \\
& \mathrm{PK}^{2}=\mathrm{PU}^{2}-\mathrm{UK}^{+} \cdot \mathrm{KU}^{\prime} \\
& =P U^{\prime}-A K \% \\
& \mathrm{AB}^{2}+\mathrm{AC}^{2}=2 \mathrm{~A}^{\prime} \mathrm{B}^{2}+2 \mathrm{~A}^{\prime} \mathrm{A}^{2} \\
& =2 \mathrm{~A}^{\prime} \mathrm{B}^{2}+2 \mathrm{AK}^{2}+2 \mathrm{~A}^{\prime} \mathrm{K}^{2} \\
& =2 \mathrm{~A}^{\prime} \mathrm{B}^{2}+2 \mathrm{AK}^{2}+2 \mathrm{PA}^{\prime 2}+2 \mathrm{PK}^{2} \\
& =4 \mathrm{PU}^{2}
\end{aligned}
$$

\section{$\$ 2$.}

If from the mid point of the base of a triangle a perpendicular be drawn to the bisector of the interior or exterior vertical angle, this perpendicular will cut off from the sides segments equal to half the sum* or half the difference of the sides.

\section{Figure 14.}

Let the perpendiculars from $\mathrm{A}$ to $\mathrm{AU} \mathrm{AU}^{\prime}$ meet $\mathrm{AC}$ at $\mathrm{S} \mathrm{S}^{\prime}$, and $\mathrm{AB}$ at $\mathrm{T} \mathrm{T}^{\prime}$.

Draw $\mathrm{BB}_{1} \mathrm{BB}_{2}$ parallel to the perpendiculars.

Because $A^{\prime}$ is the mid point of $B C$, therefore $\mathrm{S},,,, \quad, \quad, \quad \mathrm{B}_{1} \mathrm{C}$. Now $\mathrm{B}_{1} \mathrm{C}=\mathrm{AC}-\mathrm{AB}$; therefore $\quad \mathrm{CS}=\frac{1}{2}(\mathrm{AC}-\mathrm{AB})$; therefore $\quad A S=\frac{1}{2}(A C+A B)$.

- Part of this is found in Leybourn's Mathenuatical Rcpository, old series, I. 284 (1799). 


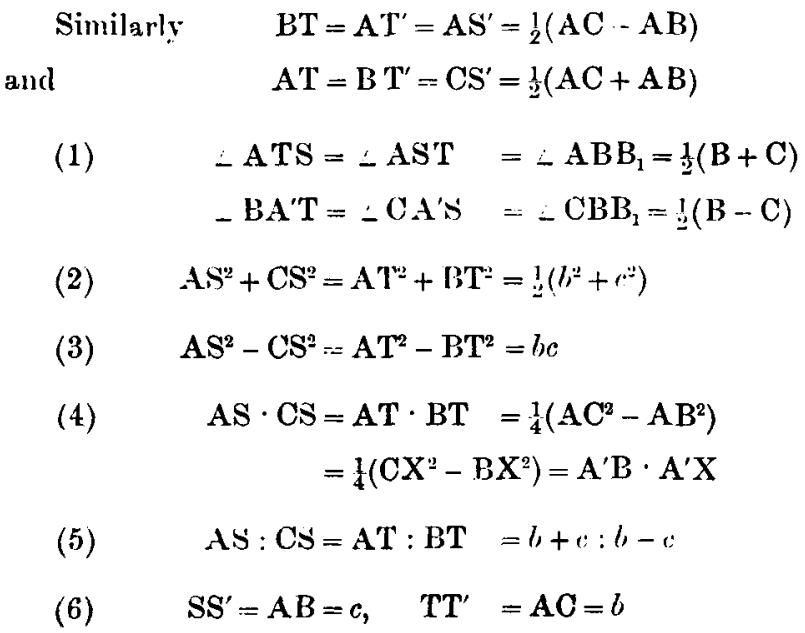

Instead of drawing perpendiculars to the two bisectors of the vertical angle either from the ends of the two sides or from the mid point of the base, if perpendiculars be drawn to the sides from certain points in the two bisectors of the vertical angle, values will be obtained for half the sum and half the difference of the sides.

Figure 9.

From $U U^{\prime}$ let the perpendiculars US $U^{\prime} S^{\prime}$ be drawn to $\mathrm{AC}$, and $\mathrm{UT} \mathrm{U}^{\prime} \mathrm{T}^{\prime}$ to $\mathrm{AB}$.

$(7)^{*} \quad \mathrm{AS}=\mathrm{AT}^{\mathrm{T}}=\mathrm{CS}^{\prime}=\mathrm{BT}^{\prime}=\frac{1}{2}(\mathrm{AC}+\mathrm{AB})$

For the right-angled triangles UAS UAT are congruent; therefore $\quad A S=A T \quad U S=U T$.

Hence the right-angled triangles UCS UBT are congruent, and $\mathrm{CS}=\mathrm{BT}$.

- Parts of (7) and (8) are found in Leybourn's Mfethermatical Repository, old spries, I. 283-4 (1799). 
Similarly $\quad \mathrm{AS}^{\prime}=\mathrm{AT}^{\prime} \quad \mathrm{CS}^{\prime}=\mathrm{BT}^{\prime}$.

Now

$$
\begin{aligned}
\frac{1}{2}(A C+A B) & =\frac{1}{2}\{(A S+C S)+(A T-B T)\} \\
& =\frac{1}{2}(A S+A T)=A S=A T
\end{aligned}
$$

and also

$$
\begin{aligned}
& =\frac{1}{2}\left\{\left(\mathrm{CS}^{\prime}+\mathrm{AS^{ \prime }}\right)+\left(\mathrm{BT}^{\prime}-\mathbf{A T ^ { \prime }}\right)\right\} \\
& =\frac{1}{2}\left(\mathrm{CS}^{\prime}+B \mathrm{BT}^{\prime}\right)=\mathrm{CS}^{\prime}=\mathrm{BT}^{\prime}
\end{aligned}
$$

$$
\mathrm{CS}=\mathrm{B}^{\prime} \mathrm{T}=A \mathrm{~S}^{\prime}=A \mathrm{~T}^{\prime}={\underset{y}{j}}_{(\mathrm{A}}(\mathrm{AC}-\mathrm{AB})
$$

For

$$
\begin{aligned}
\frac{1}{2}(\mathrm{AC}-\mathrm{AB}) & =\frac{1}{2}\{(\mathrm{AS}+\mathrm{CS})-(\mathrm{AT}-\mathrm{BT})\} \\
& =\frac{1}{2}(\mathrm{CS}+\mathrm{BT})=\mathrm{CS}=\mathrm{BT} ;
\end{aligned}
$$

and also

$$
\begin{aligned}
& =\frac{1}{2}\left\{\left(C \mathbf{S}^{\prime}+A \mathbf{S}^{\prime}\right)-\left(B T^{\prime}-A \mathbf{T}^{\prime}\right)\right\} \\
& =\frac{1}{2}\left(A \mathbf{S}^{\prime}+A \mathbf{T}^{\prime}\right)=A \mathbf{S}^{\prime}=A \mathbf{T}^{\prime} .
\end{aligned}
$$

$$
\begin{aligned}
-U^{\prime} B \mathbf{C} & =\mathbf{U}^{\prime} \mathbf{C} B=U^{\prime} \mathbf{U}^{\mathbf{B}}=\mathbf{U}^{\prime} \mathbf{U}^{\mathbf{C}} \\
=\mathrm{U}^{\prime} \mathbf{A} \mathbf{S}^{\prime} & =\mathbf{U}^{\prime} \mathbf{A} \mathbf{T}^{\prime}=\mathbf{A} \mathbf{U}=\mathbf{A} \mathbf{U}^{\mathbf{T}} \\
& =\frac{1}{2}(\mathbf{B}+\mathbf{C})
\end{aligned}
$$

(10) $\angle U^{\prime} B A=U^{\prime} C A=U^{\prime} U^{\prime} A=B$ U T $=\mathbf{C} U \mathbf{S}$

$$
=\frac{1}{5}(\mathrm{~B}-\mathrm{C})
$$

For half the sum of two magnitudes increased by half their difference gives the greater.

(11) If $\mathrm{BP} C \mathrm{Q}$ be drawn perpendicular to $\mathrm{AU}$.

$$
-\mathrm{ABP}=90^{-}-\frac{1}{2} \mathrm{~A}=\frac{1}{2}(\mathrm{~B}+\mathrm{C}) \text {. }
$$

But

$$
\therefore \mathrm{AUS} \quad=\frac{1}{2}(\mathrm{~B}+\mathrm{C}) ;
$$

therefore BP US intersect* on the circle ABC . Similarly CQ UT

A like statement holds good for $\mathrm{BP}^{\prime} \mathrm{U}^{\prime} \mathrm{S}^{\prime}$, and for $\mathrm{CQ}^{\prime} \mathrm{U}^{\prime} \mathrm{T}^{\prime}$.

* Leylourn's Mat/cinuticul Reposetory, old series, 1. 285 (1799). 
$\left.\begin{array}{rll}(12)^{*} \text { If } & \mathrm{BP} & \mathrm{US} \\ \mathrm{CQ} & \mathrm{UT} \\ \mathrm{BP} & \mathrm{U}^{\prime} \mathrm{S}^{\prime} \\ \mathrm{CQ} & \mathrm{U}^{\prime \prime} \mathrm{T}^{\prime}\end{array}\right\}$ meet on the circumcircle at $\left\{\begin{array}{l}\mathrm{B}_{2} \\ \mathrm{C}_{2} \\ \mathrm{~B}_{2}^{\prime} \\ \mathrm{C}_{2}{ }^{\prime}\end{array}\right.$

$4 \mathrm{US} \cdot \mathrm{S} \mathrm{B}_{2}=4 \mathrm{UT} \cdot \mathrm{T} \mathrm{C}_{2}$

$=4 \mathrm{U}^{\prime} \mathrm{S}^{\prime} \cdot \mathrm{S}^{\prime} \mathrm{B}_{2}{ }^{\prime}=4 \mathrm{U}^{\prime \prime} \mathrm{T}^{\prime} \cdot \mathrm{T}^{\prime} \mathrm{C}_{2}{ }^{\prime}=\mathrm{AC}^{2}-\mathrm{AB}^{2}$

For $\quad \mathrm{US} \cdot \mathrm{SB}_{2}=\mathrm{AS} \cdot \mathrm{SC}$

$$
=\frac{1}{2}(A C+A B) \cdot \frac{1}{2}(A C-A B)
$$

(13) The incentre I of $A B C$ is situated on $A U$.

If with centre $U$ and radius $U I$ a circle be described, it will pass through $B$ and $C$ and will cut $A C A B$ again at $B_{1} C_{1}$ such that $\quad B_{1} S=C S \quad C_{1} T=B T$.

Hence $\quad \mathrm{B}_{1} \mathrm{C}=\mathrm{BC}_{1}=\mathrm{AC}-\mathrm{AB}$;

and $\quad B \quad P \quad B_{1}$ are collinear, and so are $\quad \mathrm{C} \quad \mathrm{C}_{1}$.

$$
\begin{aligned}
& \mathrm{U}^{\prime} \mathrm{B}_{2}=\mathrm{UB}_{2}^{\prime}=\mathrm{AB}_{1}=\mathrm{AB} \\
& \mathrm{U}^{\prime} \mathrm{C}_{2}=\mathrm{UC}_{2}^{\prime}=\mathrm{AC}_{1}=\mathrm{AC}
\end{aligned}
$$

(15) $B_{2} B_{2}^{\prime}$ are symmetrically situated with respect to 0 , and so are $\mathrm{C}_{2} \mathrm{C}_{2}$ '

(16) By reference to $\$ 1,(12)$ it will be seen that

$$
-\mathrm{AEP}=\mathrm{AQF}_{1} \text {; }
$$

hencè $\quad \mathrm{E} \mathrm{E}_{1} \mathbf{P} \mathrm{Q}$ are concyclic.

Similarly $\quad$ F $F_{1} P$ Q , ,

The diameters of these two circles are $\mathrm{EE}_{1} \mathrm{FF}_{1}$, and their centres are $\mathrm{S} \mathbf{T}$.

(17) In like manner $E_{2} E_{3} P^{\prime} Q^{\prime}$ are concyclic, and also $\mathbf{F}_{2} \quad F_{3} \mathbf{P}^{\prime} Q^{\prime} \quad, \quad$,

The diameters of these two circles are $\mathbf{E}_{2} \mathbf{E}_{3} \mathbf{F}_{2} \mathbf{F}_{3}$, and their centres are $\mathbf{S}^{\prime} \mathbf{T}^{\prime}$.

* Leybourn's Mathemulical Rcpusitury, old series, I. 360 (1799). 
(18) All the four circles are equal to each other, and their diameters are equal to $\mathrm{BC}$.

The first two cut the circles I $I_{1}$ orthogonally, and the second I., $I_{\text {: }}$

Compare $\$ 1,(16)$.

\section{$\$ 3$.}

To find values for the rectangles contained by various segments of the base $B C$.

\section{Figure 9.}

The values of the segments here given will be found useful in the verification of properties (1)-(12).

$$
\begin{aligned}
& \mathrm{BX}=\frac{a^{2}-b^{2}+c^{2}}{2 a} \quad \mathrm{CX}=\frac{a^{2}+b^{2}-c^{2}}{2 a} \quad \mathrm{~A}^{\prime} \mathrm{X}=\frac{b^{2}-c^{2}}{2 a} \\
& \mathrm{~A}^{\prime} \mathrm{D}=\mathrm{A}^{\prime} \mathrm{D}_{1}=\frac{b-c}{2} \\
& \mathrm{~A}^{\prime} \mathrm{D}_{2}=\mathrm{A}^{\prime} \mathrm{D}_{3}=\frac{b+c}{2} \\
& \mathrm{~B} \mathrm{~L}=\frac{c a}{b+c} \quad \mathrm{~B} \mathrm{~L}^{\prime}=\frac{c a}{b-c} \\
& \mathrm{CL}=\frac{a b}{b+c} \quad \mathrm{CL}^{\prime}=\frac{a b}{b-c} \\
& \mathrm{~A}^{\prime} \mathrm{L}=\frac{a(b-c)}{2(b+c)} \quad \mathrm{A}^{\prime} \mathrm{L}^{\prime}=\frac{a(b+c)}{2(b-c)} \\
& \mathrm{L} \mathrm{D}=\frac{s_{1}(b-c)}{b+i} \quad \mathrm{I}, \mathrm{D}_{1}=\frac{s(b-c)}{b+c} \\
& \mathrm{~L}^{\prime} \mathrm{D}_{2:}=\frac{s_{:}(b+c)}{b-c} \quad \mathrm{~L}^{\prime} \mathrm{D}_{3: 3}=\frac{s_{2}(b+c)}{b-c} \\
& \mathrm{DX}=\frac{s_{1}(b-c)}{a} \quad \mathrm{D}_{1} \mathrm{X}=\frac{s(b-c)}{a} \\
& \mathrm{D}_{2} \mathrm{X}=\frac{s_{3}(b+c)}{a} \quad \mathrm{D}_{33} \mathrm{X}=\frac{\varepsilon_{0}(b+c)}{a} \\
& \mathrm{~L} \mathrm{X}=\frac{2 s s_{1}(b-c)}{a(b+c)} \quad \mathrm{L}^{\prime} \mathrm{X}=\frac{2 s_{2} s_{3}(b+c)}{a(b-c)}
\end{aligned}
$$


(1)

$$
\mathbf{A}^{\prime} \mathbf{X} \cdot \mathbf{A}^{\prime} \mathbf{L}=\mathbf{A}^{\prime} \mathrm{D}^{2}=\mathbf{A}^{\prime} \mathrm{D}_{1}{ }^{2}=\frac{1}{4}(b-c)^{2}
$$

Because A C Q $X$ are concyclic

therefore

$$
\angle \mathbf{A}^{\prime} \mathbf{X Q}=\frac{1}{2} \mathbf{A}=\angle \mathrm{A}^{\prime} \mathbf{Q L} \text {; }
$$

therefore triangles $\mathbf{A}^{\prime} X Q \mathrm{~A}^{\prime} \mathrm{QL}$ are similar;

therefore

$A^{\prime} X: A^{\prime} Q=A^{\prime} Q: A^{\prime} L$;

therefore

$A^{\prime} X \cdot A^{\prime} \mathbf{L}=A^{\prime} Q^{2}$

$$
=\mathrm{A}^{\prime} \mathrm{D}^{2}
$$

$$
\mathbf{A}^{\prime} \mathbf{X} \cdot \mathbf{A}^{\prime} \mathbf{L}^{\prime}=\mathbf{A}^{\prime} \mathbf{D}_{2}{ }^{2}=\mathbf{A}^{\prime} \mathrm{D}_{3}{ }^{2}=\frac{1}{4}(b+c)^{2}
$$

This follows, in a manner analogous to the preceding, from the similarity of triangles $\mathbf{A}^{\prime} \mathbf{X} \mathbf{Q}^{\prime} \mathbf{A}^{\prime} \mathbf{Q}^{\prime} \mathbf{L}^{\prime}$.

The following method may be used for proving (1) and (2).

Since the points A I L I $I_{2}$ form a harmonic range, therefore their projections on $\mathrm{BC}$ will form a harmonic range ; that is, $\mathrm{X} \mathrm{D} \mathrm{L} \mathrm{D}_{1}$ is a harmonic range.

Hence, since $\mathrm{DD}_{1}$ is bisected at $\mathrm{A}^{\prime}$,

$$
A^{\prime} X \cdot A^{\prime} L=A^{\prime} D^{2}=A^{\prime} D_{1}^{\prime \prime} .
$$

Similarly, since $I_{2} \quad A_{3} I_{3} \quad$ form a harmonic range, so also will $\mathrm{D}_{2} \mathrm{X} \quad \mathrm{D}_{3}, \mathrm{~L}^{\prime}$.

Hence, since $\quad D_{2} D_{3}$ is bisected at $A^{\prime}$,

$$
A^{\prime} \mathbf{X} \cdot A^{\prime} L^{\prime}=A^{\prime} D_{i:}{ }^{2}=A^{\prime} D_{i:}{ }^{2}
$$

For

$$
\mathrm{A}^{\prime} \mathrm{X} \cdot \mathrm{LX}=\mathrm{DX} \cdot \mathrm{D}_{1} \mathrm{X}=\frac{s \mathrm{x}_{1}(b-c)^{2}}{a^{2}}
$$

(5)

For

$$
\begin{aligned}
\mathrm{A}^{\prime} \mathrm{X} \cdot \mathrm{L} \mathrm{X} & =\mathrm{A}^{\prime} \mathrm{X}^{2}-\mathrm{A}^{\prime} \mathrm{X} \cdot \mathrm{A}^{\prime} \mathrm{L} \\
& =\mathrm{A}^{\prime} \mathrm{X}^{2}-\mathrm{A}^{\prime} \mathrm{D}^{2} \\
& =\mathrm{DX} \cdot \mathrm{D}_{1} \mathrm{X}
\end{aligned}
$$$$
\mathrm{A}^{\prime} \mathrm{X} \cdot \mathrm{L}^{\prime} \mathrm{X}=\mathrm{D}_{2} \mathrm{X} \cdot \mathrm{D}_{3} \mathrm{X}=\frac{s_{2} s_{3}(b+c)^{2}}{a^{2}}
$$

$$
\begin{aligned}
A^{\prime} X \cdot L^{\prime} X & =A^{\prime} X \cdot A^{\prime} L^{\prime}-A^{\prime} X^{2} \\
& =A^{\prime} D_{3}{ }^{2}-A^{\prime} X^{2} \\
& =D_{2} X \cdot D_{; 3} X
\end{aligned}
$$


(5)

For

For

For

For

For

For

$$
\mathrm{A}^{\prime} \mathrm{X} \cdot \mathrm{LD}=\mathrm{A}^{\prime} \mathrm{D} \cdot \mathrm{DX}=\frac{s_{1}(b-c)^{2}}{2 a}
$$

$$
\begin{aligned}
A^{\prime} X \cdot L D & =A^{\prime} X^{\prime} \cdot A^{\prime} D-A^{\prime} X \cdot A^{\prime} L \\
& =A^{\prime} X \cdot A^{\prime} D-A^{\prime} D^{2} \\
& =A^{\prime} D \cdot D X
\end{aligned}
$$

$$
\mathrm{A}^{\prime} \mathrm{X} \cdot \mathrm{LD}_{1}=\mathrm{A}^{\prime} \mathrm{D}_{1} \cdot \mathrm{D}_{1} \mathrm{X}=\frac{8(b-c)^{2}}{2 a}
$$

$$
\begin{aligned}
A^{\prime} X \cdot L_{1} & =A^{\prime} X \cdot A^{\prime} D_{1}+A^{\prime} X \cdot A^{\prime} L \\
& =A^{\prime} X \cdot A^{\prime} D_{1}+A^{\prime} D_{1}{ }^{-2} \\
& =A^{\prime} D_{1} \cdot D_{1} X
\end{aligned}
$$

$$
\begin{aligned}
\mathrm{A}^{\prime} \mathrm{X} \cdot \mathrm{L}^{\prime} \mathrm{D}_{: ;} & =\mathrm{A}^{\prime} \mathrm{D}_{2} \cdot \mathrm{D}_{22} \mathrm{X}=\frac{s_{3}(b+c)^{2}}{2 a} \\
\mathrm{~A}^{\prime} \mathrm{X} \cdot \mathrm{L}^{\prime} \mathrm{D}_{3} & =\mathrm{A}^{\prime} \mathrm{X} \cdot \mathrm{A}^{\prime} \mathrm{L}^{\prime}+\mathrm{A}^{\prime} \mathrm{X} \cdot \mathrm{A}^{\prime} \mathrm{D}_{2} \\
& =\mathrm{A}^{\prime} \mathrm{D}_{2}{ }^{2}+\mathrm{A}^{\prime} \mathrm{X} \cdot \mathrm{A}^{\prime} \mathrm{D}_{2} \\
& =\mathrm{A}^{\prime} \mathrm{D}_{2} \cdot \mathrm{D}_{2} \mathrm{X}
\end{aligned}
$$

$$
\mathrm{A}^{\prime} \mathrm{X} \cdot \mathrm{L}^{\prime} \mathrm{D}_{3}=\mathrm{A}^{\prime} \mathrm{D}_{3} \cdot \mathrm{D}_{3} \mathrm{X}=\frac{s_{2}(b+c)^{2}}{2 a}
$$

$$
\begin{aligned}
A X \cdot L^{\prime} D_{i z} & =A^{\prime} X \cdot A^{\prime} L^{\prime}-A^{\prime} X \cdot A^{\prime} D_{z} \\
& =A^{\prime} D_{i}{ }^{2}=A^{\prime} X \cdot A^{\prime} D_{;} \\
& =A^{\prime} D_{s} \cdot D_{i ;} X
\end{aligned}
$$

$\mathrm{A}^{\prime} \mathrm{L} \quad \mathrm{LX}=\mathrm{DL} \cdot \mathrm{LD}_{1}=\frac{s s_{1}(b-c)^{2}}{(b+c)^{2}}$

$A^{\prime} L \quad L X=A^{\prime} L \cdot A^{\prime} X-A^{\prime} L^{3}$

$$
\begin{aligned}
& =\mathbf{A}^{\prime} \mathrm{D}^{2}-\mathrm{A}^{\prime} \mathrm{L}^{\prime} \\
& =\mathrm{DL} \cdot \mathbf{L D}_{1}
\end{aligned}
$$

$$
\mathrm{A}^{\prime} \mathrm{L}^{\prime} \cdot \mathrm{L}^{\prime} \mathrm{X}=\mathrm{D}_{2} \mathrm{~L}^{\prime} \cdot \mathbf{L}^{\prime} \mathrm{D}_{3}=\frac{s_{x^{3}} s_{3}(b+c)^{2}}{(b-c)^{2}}
$$

$$
\begin{aligned}
A^{\prime} L^{\prime} \cdot L^{\prime} X & =A^{\prime} L^{\prime 2}-A^{\prime} L^{\prime} \cdot A^{\prime} \mathbf{X} \\
& =A^{\prime} L^{\prime 2}-A^{\prime} D_{3}{ }^{\prime 2}
\end{aligned}
$$$$
=\mathrm{D}_{2} \mathrm{~L}^{\prime} \cdot \mathrm{L}^{\prime} \mathrm{D}_{;}
$$ 


$$
\mathrm{DX} \cdot \mathrm{D}_{1} \mathrm{X}=\mathrm{BD} \cdot \mathrm{DC}-\mathrm{BX} \cdot \mathrm{XC}
$$

For

$$
\begin{aligned}
B D \cdot D C-B X \cdot X C & =\left(A^{\prime} B^{2}-A^{\prime} D^{2}\right)-\left(A^{\prime} B^{2}-A^{\prime} X^{2}\right) \\
& =A^{\prime} X^{2}-A^{\prime} D^{2} \\
& =D X \cdot D_{1} X
\end{aligned}
$$

$$
\mathrm{D}_{2} \mathrm{X} \cdot \mathrm{D}_{3} \mathrm{X}=\mathrm{BD}_{2} \cdot \mathrm{D}_{2} \mathrm{C}+\mathrm{BX} \cdot \mathrm{XC}
$$

$$
\text { For } \begin{aligned}
\mathrm{BD}_{2} \cdot \mathrm{D}_{2} \mathrm{C}-\mathrm{BX} \cdot \mathrm{XC} & =\left(\mathrm{A}^{\prime} \mathrm{D}_{2}{ }^{2}-\mathrm{A}^{\prime} \mathrm{C}^{2}\right)+\left(\mathrm{A}^{\prime} \mathrm{C}^{2}-\mathrm{A}^{\prime} \mathrm{X}^{\prime \prime}\right) \\
& =\mathrm{A}^{\prime} \mathrm{D}_{2}{ }^{2}-\mathrm{A}^{\prime} \mathrm{X}^{2} \\
& =\mathrm{D}_{2} \mathrm{X} \cdot \mathrm{D}_{3} \mathrm{X}
\end{aligned}
$$

In Mathematical Qucstions from the Educational Times, XIII. 34 (1870), T. T. Wilkinson says regarding (1):

"This is one of the properties of Halley's diagram, which was partially discussed in the four numbers of the Student, published at Iiverpool from 1797 to 1800. It there forms Prop. 8, and is due to Non Sibi, a name assumed by the first editor, Mr John Knowles. In the diagram as there considered, the properties of one side only are given; but when all the sides are considered, there seems to be no limit to the relations between the different parts of the figure. Sone time ago I considered the 'angular properties' only; and after writing down about 130 of them, they seemed to arise more abundantly than ever."

Halley's diagram somewhat resemblez Figure 15, and it obtained that name, among the nun-academic geometers of England, from the statement of W. Jones in his Synopsis Palmariorum Mathesces, p. 24. (1706), that he received it "from the learned Mr Halley." Jones Bays that an endless variety of useful theorem. may be deduced from it, and that by inspection only.

The property (1), however, is older than the Student; for it is spoken of as a well-known theorem in the Laulies' Diary for $\mathbf{1 7 8 5}$.

(3) and (7) occur in M'Dowell's Exercises on Euclid, $\$ 154$ (1863); (9) and (11) are found in Leybourn's Mathemutical Repository, old series, I. 369 (1799). 
$\$ 4$.

To find values for the rectangles contained by various segments of the diameter $\mathrm{UU}^{\prime}$.

\section{Figure 15.}

$$
\mathbf{A}^{\prime} \mathbf{U} \cdot \mathbf{U K}^{\prime}=\mathbf{A}^{\prime} \mathbf{X} \cdot \mathbf{A}^{\prime} \mathbf{L}=\frac{1}{4}(b-c)
$$

From the similar triangles $\mathrm{UA}^{\prime} \mathrm{L} A K \mathrm{U}^{\prime}$

$$
\mathbf{A}^{\prime} \mathbf{L}: \mathbf{A}^{\prime} \mathbf{U}^{\prime}=\mathbf{K} \mathbf{U}^{\prime}: \mathbf{K A}
$$

that is,

$$
A^{\prime} L: A^{\prime} U=U K^{\prime}: A^{\prime} X
$$

$$
\mathrm{A}^{\prime} \mathrm{U}^{\prime} \cdot \mathrm{U}^{\prime} \mathrm{K}^{\prime}=\mathbf{A}^{\prime} \mathrm{X} \cdot \mathrm{A}^{\prime} \mathrm{L}^{\prime}=\frac{1}{4}(b+c)^{\prime 2}
$$

From the similar triangles $\mathrm{UA}^{\prime} \mathrm{I}^{\prime} \mathrm{AKU}$

$$
\mathbf{A}^{\prime} \mathbf{L}^{\prime}: \mathbf{A}^{\prime} \mathbf{U}^{\prime}=\mathbf{K} \mathbf{U}: \mathbf{K A}
$$

that is,

$$
A^{\prime} L^{\prime}: A^{\prime} U^{\prime}=U^{\prime} h^{\prime}: A^{\prime} X
$$

$$
\mathrm{A}^{\prime} \mathrm{K} \cdot \mathrm{K} \mathrm{U}^{\prime}=\mathrm{A}^{\prime} \mathrm{X} \cdot \mathrm{EX}
$$

For

$$
\begin{aligned}
\mathbf{A}^{\prime} \mathrm{X} \cdot \mathrm{LX} & =\mathrm{DX} \cdot \mathrm{D}_{1} \mathrm{X} \\
& =\mathbf{A}^{\prime} \mathbf{X}^{2}-\mathbf{A}^{\prime} \mathbf{D}^{2} \\
& =\mathbf{K} \mathbf{A}^{2}-\mathbf{A}^{\prime} \mathbf{D}^{2} \\
& =\mathbf{U K}^{\prime} \mathbf{K} \mathbf{U}^{\prime}-\mathbf{A}^{\prime} \mathrm{U} \cdot \mathbf{K} \mathbf{U}^{\prime} \\
& =\mathbf{A}^{\prime} \mathbf{K} \cdot \mathbf{K} \mathbf{U}^{\prime}
\end{aligned}
$$

$$
\begin{aligned}
\mathbf{A}^{\prime} \mathbf{K} \cdot \mathbf{K U} & =\mathbf{A}^{\prime} \mathbf{X} \cdot \mathbf{L}^{\prime} \mathbf{X} \\
\mathbf{A}^{\prime} \mathbf{X} \cdot \mathbf{L}^{\prime} \mathbf{X} & =\mathrm{D}_{2} \mathbf{X} \cdot \mathrm{D}_{3} \mathbf{X} \\
& =\mathbf{A}^{\prime} \mathbf{D}_{2}{ }^{2}-\mathbf{A}^{\prime} \mathbf{X}^{2} \\
& =\mathbf{A}^{\prime} \mathbf{D}_{2}{ }^{2}-\mathbf{K} \mathbf{A}^{2} \\
& =\mathbf{A}^{\prime} \mathbf{U}^{\prime} \cdot \mathrm{U}^{\prime} \mathbf{K}^{\prime}-\mathrm{UK} \cdot \mathbf{K} \mathbf{U}^{\prime} \\
& =\mathbf{A}^{\prime} \mathbf{K} \cdot \mathrm{KU}
\end{aligned}
$$


(5)

For

For

For

For

$$
\begin{aligned}
& \mathrm{A}^{\prime} \mathrm{K} \cdot \mathrm{A}^{\prime} \mathrm{U}^{\prime}=\mathrm{BD}_{\mathbf{2}} \cdot \mathrm{D}_{2} \mathrm{C} \\
& \mathrm{BD}_{2} \cdot \mathrm{D}_{2} \mathrm{C}=\mathrm{A}^{\prime} \mathrm{D}_{2}{ }^{2}-\mathrm{A}^{\prime} \mathrm{C}^{2} \\
& =\mathrm{A}^{\prime} \mathrm{U}^{\prime} \cdot \mathrm{U}^{\prime} \mathrm{K}^{\prime}-\mathrm{A}^{\prime} \mathrm{U} \cdot \mathbf{A}^{\prime} \mathrm{U}^{\prime} \\
& =\mathbf{A}^{\prime} \mathbf{K} \cdot \mathbf{A}^{\prime} \mathbf{U}^{\prime}
\end{aligned}
$$

$$
\begin{aligned}
\mathrm{A}^{\prime} \mathrm{K} \cdot \mathrm{A}^{\prime} \mathrm{K}^{\prime} & =\mathrm{BX} \cdot \mathrm{XC} \\
\mathrm{BX} \cdot \mathrm{XC} & =\mathrm{AX} \cdot \mathrm{XR} \\
& =\mathrm{A}^{\prime} \mathrm{K} \cdot \mathrm{A}^{\prime} \mathrm{K}^{\prime}
\end{aligned}
$$

$\mathrm{A}^{\prime} \mathrm{U} \cdot \mathrm{UK}=\mathrm{US}^{2}$

$$
\begin{aligned}
\mathrm{US}^{2} & =\mathrm{CU}^{2}-\mathrm{CS}^{2} \\
& =\mathbf{A}^{\prime} \mathbf{U} \cdot \mathrm{UU}^{\prime}-\mathbf{A}^{\prime} \mathbf{U} \cdot \mathbf{U K}^{\prime} \\
& =\mathbf{A}^{\prime} \mathbf{U} \cdot \mathbf{U}^{\prime} \mathbf{K}^{\prime} \\
& =\mathbf{A}^{\prime} \mathbf{U} \cdot \mathbf{U K}
\end{aligned}
$$

Since ID IL are respectively perpendicular to $\mathrm{AK} \mathrm{AU}$, therefore the right-angled triangles $A K U^{\prime}$ IDL are similar; therèfore $\mathrm{U}^{\prime} \mathrm{K}: \mathrm{AK}=\mathrm{LD}: \mathrm{ID}$ therefore$$
\mathrm{U}^{\prime} \mathrm{K} \cdot \mathrm{ID}=\mathrm{AK} \cdot \mathrm{LD}
$$$$
=\mathrm{A}^{\prime} \mathrm{X} \cdot \mathrm{LD}
$$$$
=\mathrm{A}^{\prime} \mathrm{D} \cdot \mathrm{DX}
$$

$(10) \dagger$

$$
\mathrm{U}^{\prime} \mathrm{K} \cdot \mathrm{I}_{1} \mathrm{D}_{1}=\mathrm{A}^{\prime} \mathrm{D}_{1} \cdot \mathrm{D}_{1} \mathrm{X}
$$

The proof of this is similar to the preceding.

* For (1), (2), (3), (5), (8) see Leybourn's Mathematical Repository, old series, I. $285,368,367,369,368(1799)$.

$+(9)$ and $(10)$ are given by T. T. Wilkinson in Mathematical Questions from the Educational Tincs, XXIV. 28 (1875). 
$A B C: X P Q=U^{\prime}: U^{\prime} K$

and

A B C : $X P^{\prime} Q^{\prime}=U^{\prime} U^{\prime}: U K$

Figure 9.

Draw $A^{\prime} X^{\prime}$ perpendicular to $P Q$;

then $X^{\prime}$ is the mid point of $P Q$.

Because $\quad-\mathrm{UCA}^{\prime}=\frac{1}{2} \mathrm{~A}=\angle \mathrm{A}^{\prime} \mathbf{P X} \mathbf{X}^{\prime}$,

therefore the right-angled triangles $\mathrm{UA}^{\prime} \mathrm{C} \mathrm{A}^{\prime} \mathrm{X}^{\prime} \mathrm{P}$ are similar;

therefore

$\mathrm{A}^{\prime} \mathrm{C}^{2}: \mathrm{X}^{\prime} \mathrm{P}^{2}=\mathrm{U}^{2}: \mathbf{A}^{\prime} \mathrm{P}^{2}$.

But

$\mathrm{ABC}: \mathrm{XP}=\mathrm{B} \mathrm{C}^{2}: \mathrm{PQ}^{2}$

$$
=\mathrm{A}^{\prime} \mathrm{C}^{2}: \mathrm{X}^{\prime} \mathrm{P}^{2} \text {; }
$$

therefore

$$
\begin{aligned}
\mathbf{A B C}: \mathbf{X P Q} & =\mathbf{U} \mathbf{C}^{2}: \mathbf{A}^{\prime} \mathbf{P}^{2} \\
& =\mathbf{A}^{\prime} \mathbf{U} \cdot \mathbf{U U}^{\prime}: \mathbf{A}^{\prime} \mathbf{U} \cdot \mathbf{U K}^{\prime} \\
& =\mathbf{U} \mathbf{U}^{\prime}: \mathbf{U} \mathbf{K}^{\prime} \\
& =\mathbf{U U}^{\prime}: \mathbf{U}^{\prime} \mathbf{K}
\end{aligned}
$$

For another proof see $\$ 1,(28)$.

In a similar manner it may be shown that

$$
\text { ABC: } X P^{\prime} Q^{\prime}=U^{\prime}: U K \text {. }
$$

(12) Because

$$
\mathbf{U}^{\prime} \mathbf{K}+\mathbf{U K}=\mathbf{U U}^{\prime}
$$

snother proof is obtained of the theorem that

$$
A B C=X P Q+X P^{\prime} Q^{\prime}
$$

(13) If the base $\mathrm{BC}$ and the vertical angle $\mathrm{A}$ be given, and if in $\mathrm{AU} \mathrm{AU}^{\prime}$ the bisectors of the interior and exterior angles at $A$, there be taken AP equal to half the sum, and $A Q$ equal to half the difference of the sides, the loci of $\mathbf{P}$ and $\mathbf{Q}$ are two circles. If their radii be denoted by $r^{\prime} r^{\prime \prime}$ and the radius of the circle inscribed in $\mathrm{CUU} \mathrm{U}^{\prime}$ by $\boldsymbol{r}^{\prime \prime \prime}$, then

$$
\mathrm{R}=r^{\prime}+r^{\prime \prime}+r^{\prime \prime}
$$

Mr G. Robinson, jun., Hexham, in the Lady's and Gentleman's Diary for 1862 p. 74. Two solutions will be found in the Diary for 1863, pp. 49-50. 
If through $A^{\prime}$ a perpendicular is drawn to $B C$, then AD $A D, A D, A D:$ will intersect this perpendicular at

R, II $R_{::} R_{2}$ such that*

$$
\mathbf{A}^{\prime} \mathbf{R}=\gamma^{\prime} \quad \mathbf{A}^{\prime} \mathbf{R}_{1}=r_{1} \quad \mathbf{A}^{\prime} \mathbf{R}_{.2}=r_{2} \quad \mathbf{A}^{\prime} \mathbf{R}_{: 1}=r_{: ;}
$$

Figure 16.

Let $\mathrm{DI}$ produced meet $\mathrm{AD}_{1}$ at $\mathrm{D}^{\prime}$.

Since the line joining the extremities of two parallel and similarly directed radii of two circles passes through their external homothetic centre; and since $A$ is the external homothetic centre of the circles $I_{1}$ and $I$, and $I_{1} D_{1} I^{\prime}$ are parallel; therefore II ${ }^{\prime}$ is in radius of the incirele $\mathrm{I}$, and 1$) \mathrm{D}^{\prime}=2 r$.

Now since $A^{\prime} D=A^{\prime} D_{1}$, and $A^{\prime} R$ is pariallel to $D^{\prime} D^{\prime}$, therefore $\quad A^{\prime} R=! D^{\prime} D D^{\prime}=r$.

Similarly for the other equalities.

(1) Through B', the nid point of CA, a perpendicular to $\mathrm{CA}$ is drawn, and this perpendicular is intersected by

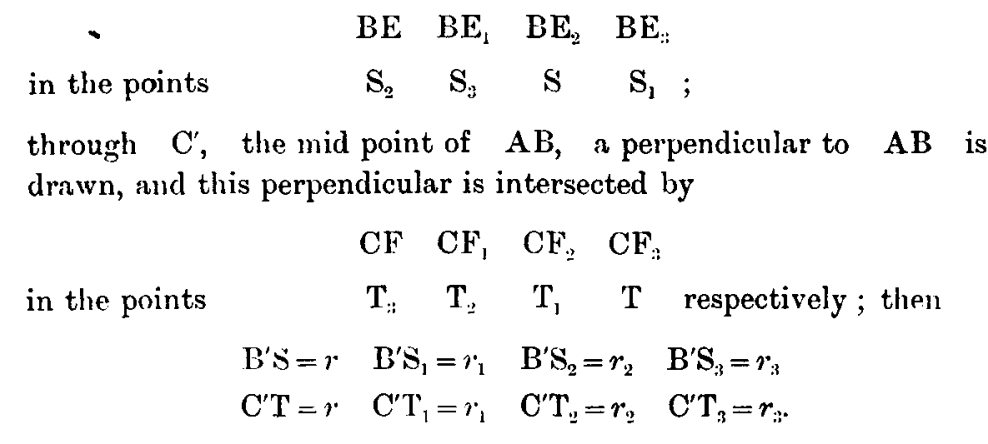

* W. IT. Levy in the Lady's and Gentleman's Diary for 1863, p. 77, and for 1864, pp. 54-i). 
(2) The four triangles RST $\mathrm{R}_{1} \mathrm{~S}_{1} \mathrm{~T}_{1} \mathrm{R}_{2} \mathrm{~S}_{2} \mathrm{~T}_{2} \quad \mathrm{R}_{3} \mathrm{~S}_{;}^{\prime} \mathrm{T}_{:}$are inver'sely similar to $A B C$; they have $O$, the circumcentre of $\mathrm{ABC}$, for their common centre of homology, and $\mathrm{OI} \mathrm{OI}_{1} \mathrm{OI}_{2} \mathrm{OI}_{3 ;}$ for the diameters of their circumcircles.

\section{Figure 17}

Since

$$
A^{\prime} R_{1}=r_{1}=I_{1} D_{1}
$$

therefore $\quad I_{1} R_{1} A^{\prime}$ is right.

Similarly $\angle I_{1} S_{1} B^{\prime}$ and $\angle I_{1} T_{1} C^{\prime}$ are right;

therefore the circle whose diameter is $\mathrm{OI}_{1}$

passes through $R_{1} S_{1} T_{1}$.

Since $R_{1} S_{1} O_{1} T_{1}$ are concyclic,

therefore

$$
\begin{aligned}
-\mathrm{S}_{1} \mathrm{R}_{1} \mathrm{~T}_{1} & =180^{\circ}--\mathrm{S}_{1} O \mathrm{TT}_{1} \\
& =180-\angle \mathrm{B}^{\prime} \mathrm{OC} \\
& =\mathrm{A}:
\end{aligned}
$$

and

$$
-\mathrm{R}_{1} \mathrm{~S}_{1} \mathrm{~T}_{1}=-\mathrm{R}_{1} \mathrm{OT} \mathrm{T}_{1}=\mathrm{B}
$$

since $T_{1} O R_{1} O$ are respectively perpendicular to $A B$ BC : therefore triangle $R_{1} S_{1} T_{1}$ is similar to $A B C$.

(3) Let the mid points of $\mathrm{OI} \mathrm{OI}_{1} \mathrm{OI}_{2} \mathrm{OI}_{3}$ be denoted by

$$
I^{\prime} \quad I_{1}^{\prime} \quad I_{2}^{\prime} \quad I_{3}^{\prime}
$$

then $\mathrm{I}_{1} \mathrm{I}_{2}{ }^{\prime} \mathrm{I}_{3}{ }^{\prime} \mathrm{I}^{\prime}$ is an orthic tetrastigm, similar and similarly situated to the tetrastigm $I_{1} I_{2} I_{3} I$, and the radius of the circumcircle of any of its four triangles is $R$.

For the radius of the circumcircle of any of the four triangles of the orthic tetrastigm $I_{1} I_{2} I_{: ;} I$ is $2 R$.

(4) Let AI BI CI meet the circumcircle of ABC in $\mathrm{U} \mathrm{V} \mathrm{W}$, and let the points diametrically opposite to $\mathrm{U} V \mathrm{~W}$ be $\mathrm{U}^{\prime} \mathrm{V}^{\prime} \mathrm{W}^{\prime}$.

Then I is the orthocentre of the triangle UVW. Now since $O$ is the circumcentre of UVW, therefore $I^{\prime}$ is the nine-point centre of the four triangles of the orthic tetrastigm UVWI. 
In like manner since $I_{1}$ is the orthocentre, and $O$ the circumcentre of the triangle $U V^{\prime} W^{\prime}, \quad I_{1}^{\prime}$ is the nine-point centre of the four triangles of the orthic tetrastigm $U V^{\prime} W^{\prime} I_{1}$; and similarly for $I_{2}^{\prime} I_{3}^{\prime}$.

See Proceedings of the Edinhurgh Mathematical Society, Vol. I., pp. 54-5 (1894).

(5) The sum of the circumcircles of the four RST triangles is three times the circumcircle of $\mathrm{ABC}$.

Since circles are proportional to the squares of their diameters, the circumcircle of $\mathrm{ABC}$ is to the sum of the four RST circles as $4 \mathrm{R}^{2}$ is to $\mathrm{OI}^{2}+\mathrm{OI}_{1}{ }^{2}+\mathrm{OI}_{2}{ }^{2}+\mathrm{OI}_{3}{ }^{2}$.

$$
\text { Now } \quad \begin{aligned}
\mathrm{\Sigma}\left(\mathrm{OI}^{2}\right) & =4 \mathrm{R}^{2}+2 \mathrm{R}\left(r_{1}+r_{2}+r_{3}-r\right) \\
& =4 \mathrm{R}^{2}+2 \mathrm{R} \cdot 4 \mathrm{R} \\
& =12 \mathrm{R}^{2} .
\end{aligned}
$$

$\$ 6$.

If UD UD $\mathrm{U}^{\prime} \mathrm{D}_{2} \mathrm{U}^{\prime} \mathrm{D}_{3}$ intersect $\mathrm{AX}$ at $\mathrm{X}_{0} \mathrm{X}_{1} \mathrm{X}_{2} \mathrm{X}_{\text {; }}$ then* $\quad \mathrm{XX}_{0}=r \quad \mathrm{XX}_{1}=r_{1} \quad \mathrm{XX}_{2}=r_{2} \quad \mathrm{XX}_{3}=r_{3}$

\section{Figure 18.}

Through I draw a parallel to $\mathrm{BC}$ meeting $\mathrm{UU}^{\prime}$ in $\mathrm{K}_{0}$ and $\mathrm{AX}$ in $\mathrm{X}_{0}$; join $\mathrm{UD} \mathrm{DX}_{0}$.

Because

$$
A^{\prime} D^{2}=A^{\prime} X \cdot A^{\prime} L
$$

therefore

$$
A^{\prime} D: A^{\prime} X=A^{\prime} L: A^{\prime} D
$$

that is

$$
\begin{aligned}
\mathbf{A}^{\prime} \mathbf{D}: \mathrm{K}_{0} \mathbf{X}_{0} & =\mathbf{A}^{\prime} \mathrm{L}: \mathrm{K}_{0} \mathrm{I} \\
& =\mathbf{U A}^{\prime}: \mathbf{U} \mathbf{K}_{0}
\end{aligned}
$$

therefore the points $\mathrm{U} \mathrm{D} \mathrm{X}$ are collinear.

* The first of these properties is given by W. Dixon Rangeley in the Gentleman's Diary for 1822, p. 47; the first and second (without any hint as to the third and fourth) by W. H. Levs in the Lady's and Gentleman's Diary for 1849, p. 75. 
Similarly, if through $I_{1}$ a parallel be drawn to BC meeting $A X$ in $X_{1}$, it may be proved that $U D_{1} X_{1}$ are collinear.

Through $I_{3}$ draw a parallel to $B C$ meeting $U^{\prime}$ in $K_{3}$ and $A X$ in $X_{3} ;$ join $U^{\prime} D_{3} D_{3} X_{3}$.

$\begin{array}{rlrl}\quad \text { Because } & \mathbf{A}^{\prime} \mathbf{D}_{3}{ }^{2} & =\mathbf{A}^{\prime} \mathbf{X} \cdot \mathbf{A}^{\prime} \mathbf{L}^{\prime} \\ \text { therefore } & \mathbf{A}^{\prime} \mathbf{D}_{3}: \mathbf{A}^{\prime} \mathbf{X} & =\mathbf{A}^{\prime} \mathbf{L}^{\prime}: \mathbf{A}^{\prime} \mathbf{D}_{: ;} \\ \text {that is } & \mathbf{A}^{\prime} \mathbf{D}_{3: 3}: \mathbf{K}_{\mathbf{3}} \mathbf{X}_{3} & =\mathbf{A}^{\prime} \mathbf{L}^{\prime}: \mathbf{K}_{\mathbf{3}} \mathbf{I}_{3} \\ & & & =\mathbf{U}^{\prime} \mathbf{A}^{\prime}: \mathbf{U}^{\prime} \mathbf{K}_{3} ;\end{array}$

therefore the points $U^{\prime} D_{3} X_{3}$ are collinear.

Similarly for the points $U^{\prime} \mathrm{D}_{2} \mathrm{X}_{2}$

$$
\begin{aligned}
& \begin{array}{llllll}
V E & V^{\prime} E_{1} & V E_{2} & V^{\prime} E_{3} & \text { intersect } & B Y
\end{array} \\
& \begin{array}{llll}
Y_{0} & Y_{1} & Y_{2} & Y_{3} ; \text {; and }
\end{array} \\
& \text { WF } W^{\prime} F_{1} \quad W^{\prime} F_{2} \quad W_{3} \text { intersect } C Z \text { at } \\
& \begin{array}{lllll}
Z_{0} & Z_{1} & Z_{2} & Z_{3} & \text { such that }
\end{array} \\
& \mathrm{YY}_{0}=r \quad \mathrm{YY}_{1}=r_{1} \quad \mathrm{YY}_{2}=r_{2} \quad \mathrm{YY}_{3}=r_{3} \\
& Z_{1} Z_{0}=r \quad Z Z_{1}=r_{1} \quad Z Z_{2}=r_{2} \quad Z_{3}=r_{3} \text {. }
\end{aligned}
$$

(2) The four triangles $\mathrm{X}_{0} \mathrm{Y}_{0} Z_{0} \mathrm{X}_{1} \mathrm{Y}_{1} Z_{1} \mathrm{X}_{2} \mathrm{Y}_{2} Z_{2} \quad \mathrm{X}_{3} \mathrm{Y}_{3} \mathrm{Z}_{3}$ are inversely similar to $\mathrm{ABC}$; they have $H$, the orthocentre of $\mathrm{ABC}$, for their coummon centre of homology, and $\mathrm{HI} \mathrm{HI}_{1} \mathrm{HI}_{2} \mathrm{HI}_{\text {; }}$ for the diameters of their circumcircles.

\section{Figure 19.}

Since

$$
\left.\mathrm{XX}_{1}=r_{1}=\mathrm{I}_{1} \mathrm{D}\right)_{1}
$$

therefore $-\mathrm{I}_{1} \mathrm{X}_{1} \mathrm{X}$ is right.

Similarly $-I_{1} Y_{1} Y$ and $-I_{2} Z_{1} Z$ are right;

therefore the circle whose diameter is HI

passes through $X_{1} Y_{1} Z_{1}$. 
Since $\quad \mathrm{X}_{1} \mathrm{Y}_{1} \mathrm{H} \quad \mathrm{Z}_{1}$ are concyclic

therefore

$$
\begin{aligned}
\angle \mathrm{Y}_{1} \mathrm{X}_{1} \mathrm{Z}_{1} & =180^{\circ}-\angle \mathrm{Y}_{1} \mathrm{HZ}_{1} \\
& =\mathrm{A} ;
\end{aligned}
$$

and

$$
\angle \mathrm{X}_{1} \mathrm{Y}_{1} \mathrm{Z}_{1}=\angle \mathrm{X}_{1} \mathrm{HZ}_{1}=\mathrm{B}
$$

since $Z_{1} \mathrm{H} \mathrm{X} \mathrm{X}_{1} \mathrm{H}$ are respectively perpendicular to $\mathrm{AB} \mathrm{BC}$; therefore triangle $X_{1} Y_{1} Z_{1}$ is similar to $A B C$.

(3) The mid points of $\mathrm{HI} \mathrm{HI} \mathrm{HI}_{2} \mathrm{HI}_{3}$ form an orthic tetrastigm sinilar and similarly situated to the tetrastigm $I_{1} I_{2} I_{3} I$, and the radius of the circumcircle of any of its four triangles is $R$.

(4) The sum of the circumcircles of the four triangles $X_{0} Y_{0} Z_{0} \ldots$. is four times the sum of the circumcircles of the three triangles

\section{AYZ XBZ XYC.}

It will be seen from a subsequent Section that the values * of $\mathrm{HI}^{2} \ldots$ may be written

$$
\begin{aligned}
& \mathrm{HI}^{2}=4\left(\mathrm{R}^{2}-2 \mathrm{R} r\right)+b c+c a+a b-\left(a^{2}+b^{2}+c^{2}\right) \\
& \mathrm{HI}_{1}{ }^{2}=4\left(\mathrm{R}^{2}+2 \mathrm{R} r_{1}\right)+b c-c a-a b-\left(a^{2}+b^{2}+c^{2}\right) \\
& \mathrm{HI}_{2}{ }^{2}=4\left(\mathrm{R}^{2}+2 \mathrm{R} r_{2}\right)-b c+c a-a b-\left(a^{2}+b^{2}+c^{2}\right) \\
& \mathrm{HI}_{3}{ }^{2}=4\left(\mathrm{R}^{2}+2 \mathrm{R} r_{3}\right)-b c-c a+a b-\left(a^{2}+b^{2}+c^{2}\right)
\end{aligned}
$$

Hence

$$
\begin{aligned}
\Sigma\left(\mathrm{HI}^{2}\right) & =4\left(12 \mathrm{R}^{2}-a^{2}-b^{2}-c^{2}\right) \\
& =4\left(\mathrm{HA}^{2}+\mathrm{HB}^{2}+\mathrm{HC}^{2}\right)
\end{aligned}
$$

See Proceedings of the Edinburgh Mathematical Society, Vol. I., p. 63 (1894).

The statement that

$$
\mathrm{HA}^{2}+\mathrm{HB}^{2}+\mathrm{HC}^{2}=12 \mathrm{R}^{2}-a^{2}-b^{2}-c^{2}
$$

may be proved as follows.

Frgure 20.

* The value of $\mathrm{HI}^{2}$ is given by William Mawson in the Lady's and Gentleman's Diary for 1843, p. 75 ; the other values are given by William Rutherford and Samuel Bills in the Diary for 1844, p. 52 . 
The triangles $\mathrm{CBZ} \mathrm{AHZ}$ are similar;

$$
\begin{aligned}
& \text { therefore } \quad \mathrm{BC}^{2}: \mathrm{HA}^{2} \quad=\mathrm{CZ}^{2}: \mathrm{AZ}^{2} \text {; } \\
& \text { therefore } \quad \mathrm{BC}^{2}+\mathrm{HA}^{2}: \mathrm{BC}^{2}=\mathrm{CZ}^{2}+\mathrm{AZ}^{2}: \mathrm{CZ}^{2} \\
& =\mathrm{CA}^{2} \quad: \mathrm{CZ}^{2} \\
& \text { therefore } \quad \mathrm{BC}^{2}+\mathrm{HA}^{2}=\frac{\mathrm{BC}^{2} \cdot \mathrm{CA}^{2}}{\mathrm{CZ}^{2}} \\
& =4 \mathrm{R}^{2}
\end{aligned}
$$

by a theorom of Brahmegupta.

$$
\text { Similarly } \quad \mathrm{CA}^{2}+\mathrm{HB}^{2}=\mathrm{AB}^{2}+\mathrm{HC}^{2}=t \mathrm{R}^{2}
$$

For another proof see Feuerbach, Eijenschaften...dcs...Dreiecks, Section VI., Theorem 2.

$$
\$ 7 .
$$

If $\quad \mathbf{A}^{\prime} \mathrm{I} \quad \mathbf{A}^{\prime} \mathrm{I}_{1} \quad \mathbf{A}^{\prime} \mathrm{I}_{2} \quad \mathbf{A}^{\prime} \mathrm{I}_{3}$ intersect $\mathrm{AX}$ at

$\begin{array}{lllll}X_{0} & X_{1} & X_{2} & X_{3} & \text { then }\end{array}$

$$
\begin{array}{llll}
\mathrm{AX}_{0}=r \quad \mathrm{AX}_{1}=r_{1} & \mathrm{AX}_{2}=r_{2} & \mathrm{AX}_{3}=r_{3}
\end{array}
$$

Figure 21.

Join CU, and draw the radius of the incircle IE.

Then $\quad \angle \mathrm{UCA}^{\prime}=\angle \mathrm{IAE}$;

therefore triangles $\mathrm{CUA}^{\prime} \mathrm{AIE}$ are similar ;

therefore $\quad \mathrm{CU}: U \Lambda^{\prime}=\Lambda I: I E$.

Now

$$
\mathrm{CU}: \begin{aligned}
U \Lambda^{\prime} & =\mathrm{IU}: U \Lambda^{\prime} \\
& =\mathrm{AI}: \Lambda \mathrm{X}_{\mathbf{0}} ;
\end{aligned}
$$

therefore $\quad \Delta \mathrm{X}_{0}=\mathrm{IE}=r$

Similarly

$$
A X_{1}=r_{1}
$$

* The first of these properties occurs incidentally in William Walker's proof of a theorem in the Gentleman's Mathematical Companion for 1803, p. 50. 
If $\mathrm{CU}^{\prime}$ be joined, and $\mathrm{I}_{3} \mathrm{E}_{3}$ the radius of the third excircle be drawn, then triangles $\mathrm{CU}^{\prime} \mathrm{A}^{\prime} \mathrm{AI}_{3} \mathrm{E}_{3}$ will be similar, and since

$$
\mathrm{CU}^{\prime}=\mathrm{I}_{3} \mathrm{U}^{\prime} \text {, }
$$

it may be shown that $\quad \mathrm{AX}_{3}=\mathrm{I}_{3} \mathrm{E}_{3}=r_{3}$.

Corresponding to the four $\mathrm{X}$ points situated on $\mathrm{AX}$, there will be four $Y$ points, $Y_{0} Y_{1} Y_{2} Y_{3}$, situated on $B Y$, and four $Z$ points, $Z_{0} Z_{1} Z_{2} Z_{3}$ situated on $\mathrm{CZ}$.

Some of the properties of this collection of points will be found in the Proceedings of the Edinburgh Mathematical Society, Vol. I., pp. 89-96 (1894).

$\$ 8$.

Figure 23.

If the needians $\mathrm{AA}^{\prime} \mathrm{BB}^{\prime} \mathrm{CC}^{\prime}$ be intersected by the radii at the points

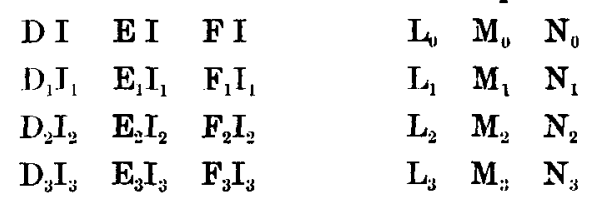

then*
$\mathrm{DL}_{\mathrm{u}}=\frac{2 \Delta}{b+c}$
$\mathrm{E} \mathrm{M}_{0}=\frac{2 \Delta}{c+a}$
$\mathrm{FN}_{0}=\frac{2 \Delta}{a+b}$
$\mathrm{D}_{1} \mathrm{~L}_{1}=-\frac{2 \triangle}{b+c}$
$\mathrm{E}_{1} \mathrm{M}_{1}=-\frac{2 \Delta}{a-c}$
$\mathrm{F}_{1} \mathrm{~N}_{1}=-\frac{2 \Delta}{a-b}$
$\mathrm{D}_{2} \mathrm{~L}_{2}=-\frac{2 \Delta}{b-c}$
$\mathbf{E}_{2} \mathbf{M}_{2}=-\frac{2 \triangle}{c+a}$
$\mathrm{F}_{2} \mathrm{~N}_{2}=\frac{2 \Delta}{a-b}$
$\mathrm{D}_{3} \mathrm{~L}_{\mathrm{s}}=\frac{2 \Delta}{b-c}$
$\mathrm{E}_{3} \mathrm{M}_{3}=\frac{2 \Delta}{a-c} \quad \mathbf{F}_{3} \mathbf{N}_{j}=-\frac{2 \Delta}{a+b}$

the distances of the $\mathrm{L}$ points from $\mathrm{BC}$ being considered positive when $C$, is on the same side of $B C$ as $A$, and negative when

* The first three values are given by W. H. Levy in the Lady's arul Gontle-

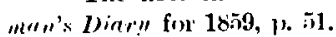


it is on the opposite side from A. A similar convention holds for the $\mathrm{M}$ and the $\mathrm{N}$ points.

\section{Figure 22.}

Let $\mathrm{AI}$ meet $\mathrm{BC}$ at $\mathrm{L}$; draw $\mathrm{LS}$ I,T perpendicular to $\mathrm{AC} \mathrm{AB}$, and $\mathrm{AX}$ perpendicular to $\mathrm{BC}$.

Then

$$
\begin{aligned}
\mathbf{A}^{\prime} \mathrm{L}_{\perp}: \mathbf{A}^{\prime} \mathbf{J} & =\mathbf{A}^{\prime} \mathbf{D}: \mathbf{A}^{\prime} \mathbf{X} \\
& =\mathrm{L}_{0} \mathrm{D}: \mathbf{A} \mathbf{X} .
\end{aligned}
$$

Now

$$
\begin{array}{rlrl}
\mathbf{A}^{\prime} \mathrm{L}: \mathbf{A}^{\prime} \mathbf{D} & =\mathbf{A}^{\prime} \mathbf{D}-\mathbf{A}^{\prime} \mathbf{L}: \mathbf{A}^{\prime} \mathbf{X}-\mathbf{A}^{\prime} \mathbf{D} \\
& =\mathbf{L D} & & : \mathbf{D X} \\
& =\mathbf{L I} & & : \mathbf{I A} \\
& =\mathrm{I} \mathbf{B} & & : \mathbf{B A} \\
& =\mathbf{L} \mathbf{T} & & : \mathbf{A X} ;
\end{array}
$$

therefore

$$
\mathrm{L}_{0} \mathrm{D}=\mathrm{LT}=\mathrm{LS}
$$

Again $\mathrm{LS} \cdot \mathrm{AC}+\mathrm{LT} \cdot \mathrm{AB}=2 \mathrm{ABC}$

therefore $\quad \mathrm{L}_{0} \mathrm{D}(b+c)=2 \triangle$

Similarly for the other equalities

(1) $\mathrm{L}_{0} \quad \mathrm{M}_{0} \mathrm{~N}_{0}$ lie on EF FD DE ; and similarly for

$$
\mathrm{I}_{1} \mathrm{M}_{1} \mathrm{~N}_{1} \ldots
$$

A proof of this will be found in the Proceedings of the Edinburgh Mathematical Society, Vol. I., pp. 57-8 (1894).

(2)

$$
\begin{aligned}
& \frac{1}{\mathrm{DL}_{0}}+\frac{1}{\mathrm{D}_{1} \mathrm{~L}_{1}}+\frac{1}{\mathrm{D}_{2} \mathrm{I}_{2}}+\frac{1}{\mathrm{D}_{3} \mathrm{~L}_{3}} \\
= & \frac{1}{\mathrm{E} \mathrm{M}_{0}}+\frac{1}{\mathrm{E}_{1} \mathrm{M}_{1}}+\frac{1}{\mathrm{E}_{2} \mathrm{M}_{2}}+\frac{1}{\mathrm{E}_{3} \mathrm{M}_{3}} \\
= & \frac{1}{\mathrm{~F} \mathrm{~N}_{0}}+\frac{1}{\mathrm{~F}_{1} \mathrm{~N}_{1}}+\frac{1}{\mathrm{~F}_{2} \mathrm{~N}_{2}}+\frac{1}{\mathrm{~F}_{3} \mathrm{~N}_{3}}=0
\end{aligned}
$$


$(3)^{*}$

$$
\begin{aligned}
& \frac{1}{\mathrm{DI}_{4_{0}}}+\frac{1}{\mathrm{E} \mathrm{M}_{0}}+\frac{1}{\mathrm{E} \mathrm{N}_{0}}=\frac{2}{r} \\
& \frac{1}{\mathrm{D}_{1} \mathrm{~L}_{1}}+\frac{1}{\mathrm{E}_{1} \mathrm{M}_{1}}+\frac{1}{\mathrm{~F}_{1} \mathrm{~N}_{1}}=-\frac{2}{h_{1}} \\
& \frac{1}{\mathrm{D}_{2} \mathrm{~L}_{2}}+\frac{1}{\mathrm{E}_{2} \mathrm{M}_{2}}+\frac{1}{\mathrm{~F}_{2} \mathrm{~N}_{2}}=-\frac{2}{h_{2}} \\
& \frac{1}{\mathrm{D}_{3} \mathrm{~L}_{3}}+\frac{1}{\mathrm{E}_{3} \mathrm{M}_{3}}+\frac{1}{\mathrm{~F}_{3} \mathrm{~N}_{3}}=-\frac{2}{h_{3}}
\end{aligned}
$$

(4) The diagonals of the following pairs of parallelograms

$$
\begin{array}{ccccc}
\mathrm{DL}_{0} \mathrm{D}_{1} \mathrm{I}_{1} & \mathrm{D}_{2} \mathrm{I}_{2} \mathrm{D}_{3} \mathrm{~L}_{3} & \text { intersect } & \text { at } & \mathbf{A}^{\prime} \\
\mathrm{FM}_{0} \mathrm{E}_{2} \mathrm{M}_{2} & \mathrm{E}_{3} \mathrm{M}_{3} \mathrm{E}_{1} \mathrm{M}_{1} & " & " & \mathrm{~B}^{\prime} \\
\mathrm{FN}_{0} \mathrm{~F}_{3} \mathrm{~N}_{3} & \mathrm{~F}_{1} \mathrm{~N}_{1} \mathrm{E}_{2} \mathrm{~N}_{2} & " & & \mathrm{C}^{\prime}
\end{array}
$$

(5) The four LMN triangles are homologous, and their centre of homology is $G$ the centroid of $A B C$.

(6) $\dagger \quad \mathbf{A}^{\prime} \mathrm{U}: \mathbf{A}^{\prime} \mathrm{U}-\mathrm{I}_{\mathrm{L}_{0}}=\mathbf{A}^{\prime} \mathrm{U}: \mathrm{I}_{1} \mathrm{~L}_{1}-\mathbf{A}^{\prime} \mathrm{U}=b+c: a$

$\mathbf{A}^{\prime} \mathrm{U}^{\prime}: \mathrm{I}_{2} \mathrm{I}_{2}+\mathbf{A}^{\prime} \mathrm{U}^{\prime}=\mathbf{A}^{\prime} \mathrm{U}^{\prime}: \mathrm{I}_{3} \mathrm{~L}_{3}-\mathbf{A}^{\prime} \mathrm{U}^{\prime}=b-c: a$

Figure 23.

From I U draw IE US perpendicular to AC.

Then $\quad \mathrm{AS}=\frac{1}{2}(b+c) \quad \mathbf{A E}=\frac{1}{2}(b+c-a)$.

Now

$\mathbf{A}^{\prime} \mathrm{U}: \mathrm{IL}_{0}=\mathrm{UA}: \mathrm{IA}$

$=\mathbf{A S}: \mathbf{A E}$

$=b+c: b+c-a$

therefore

$\mathbf{A}^{\prime} \mathrm{U}: \mathbf{A}^{\prime} \mathrm{U}-\mathrm{IL}_{0}=b+c: a$

$$
\begin{aligned}
2 A^{\prime} U & =I L_{0}+I_{1} L_{1} \\
2 A^{\prime} U^{\prime} & =I_{2} L_{2}-I_{3} L_{3} \\
4 R & =I L_{0}+I_{1} L_{1}+I_{2} L_{2}-I_{3} L_{3}
\end{aligned}
$$

therefore

* The first result in (3) is given by W. H. Levy in the Lady's and Gentleman's Diary for 1858, p. 71.

+ Of the four proportions in (6) the first is given by John Ryley, Teeds, in the Fentleman's Mathematical Companion, for 1802, p. 59. The solution in the tert is that of J. H. Swale, Liverpool. 
(8) If through $\quad I_{1} I_{2} I_{: ;}$parallels be drawn to $B C$, meeting $\mathrm{UU}^{\prime}$ in $\mathrm{K} \mathrm{K}_{1} \mathrm{~K}_{2} \mathrm{~K}_{3}$, then ${ }^{*}$

$$
\begin{aligned}
U \mathrm{~K} & =\mathrm{UK}_{1}=\mathrm{US}^{\prime} \\
U^{\prime} \mathrm{K}_{2} & =\mathrm{U}^{\prime} \mathrm{K}_{3}=U^{\prime} \mathbf{S}^{\prime}
\end{aligned}
$$

where US U'S' are perpendicular to AC.

For the riglit-angled triangles CUS IUK are congruent, since

$$
\mathrm{UC}=\mathrm{UT} \text {, }
$$

and

$$
\angle \mathrm{CUS}=\frac{1}{2}(\mathrm{~B}-\mathrm{C})=\angle \mathrm{IUK} \text {. }
$$

$\$ 9$.

\section{Formulae connected with the Angular Bisectors of a Triangle LIMITED AT THEIK POINTS OF INTARSECTION WITH EACH OTHER.}

The notation

$$
\mathrm{AI}=\alpha \quad \mathrm{AI}=\beta \quad \mathrm{CI}=\gamma, \text { etc., }
$$

was suggested by T. S. Davies in the Lady's und Gentleman's Diary for 1842, p. 77, and adopted by Thomas Weddle in his admirable papers entitled "Symmetrical Properties of Plane Triangles," which appeared in the same publication (1843, 1845̃, 1848).

Neither Davies nor Weddle makes use of the equivalents for $\mathbf{I I}_{1}$, etc., namely $a_{1}-a$, etc. Although the employment of these equivalents somewhat lengthens the formulae, it seems to me that it renders their symmetry a little more apparent.

In connection with the ascription, in the historical notes, of the great majority of the following formulae to Weddle, it is right to call attention to a letter of T. S. Davies in the Lady's and Gentleman's Diary for 1849, pp. 90-1, in which he states that when he undertook to arrange and systematise those properties of the triangle communicated to him, several sets of papers came into his hands, the most ample and elegant of which were those of Messrs Weddle and $J$. W. Elliott. The letter continues :

"I feel it to be due to him [Mr Elliott] to say that the names both of Mr Weddle and $\mathrm{Mr}$ Elliott might fairly have been prefixed to the far greater number of the properties, whilst each gentleman would have had a few properties designated as peculiar to himself."

I might have considerably shortened the lists of the formulae by giving only the leading identities, and referring the reader to Mr Lemoine's scheme of continuous transformation. I have done so here and there, but in general I bave

* The property that UK=US is referred to as well known in the Gentleman's Mathematical Companion for 1803, p. 50. 
either left or made the list complete in order that the reader who consults it may find ready to his hand the particular scrap of information of which he is in search. A table of logarithms which gave the logarithms of the prime numbers only would certainly be of some use, but merely to a select few.

Mr R. F. Muirhead suggests to me $t_{1} t_{2} t_{3}$ as a convenient mathematical translation of Mr Lemoine's transformation continue en $A$, en $B$, en $C$. Here is the $t_{1}$ applicable to the formulae which follow.

$$
\begin{array}{cccccccccccccc}
a & b & r & s & s_{1} & s_{2} & s_{3} & r & r_{1} & r_{2} & r_{3} & h_{1} & h_{2} & h_{3} \\
\text { change into } & \\
a & -b & -c & -s_{1} & -s & s_{3} & s_{2} & r_{1} & r & -r_{3} & -r_{2} & -h_{1} & h_{2} & h_{3}
\end{array}
$$

A

$$
\text { B }
$$

C $\quad$ H

$\mathrm{R} \quad \triangle \quad l_{1} \quad l_{2} \quad l_{3} \lambda_{1} \quad \lambda_{2} \quad \lambda_{3}$ change into

- A $180^{\circ}-\mathrm{B} 180^{\circ}-\mathrm{C}-\mathrm{R}-\triangle-l_{1}-\lambda_{2}-\lambda_{3} \lambda_{1}-l_{2}-l_{3}$

$$
\begin{array}{cccccccccccc}
\alpha & \alpha_{1} & \alpha_{2} & \alpha_{3} & \beta & \beta_{1} & \beta_{2} & \beta_{3} & \gamma & \gamma_{1} & \gamma_{2} & \gamma_{3} \\
\text { change into } & \\
-\alpha_{1}-\alpha & -\alpha_{3} & -\alpha_{2} & \beta_{1} & \beta & -\beta_{3} & -\beta_{2} & \gamma_{1} & \gamma & -\gamma_{3} & -\gamma_{2}
\end{array}
$$

$$
\begin{aligned}
a^{2}=\left(r_{2}-r\right)\left(r_{3}-r\right) & a_{2}^{2}=\left(r_{3}+r_{1}\right)\left(r_{1}+r_{2}\right) \\
\beta^{2}=\left(r_{3}-r\right)\left(r_{1}-r\right) & \beta_{1}^{2}=\left(r_{1}+r_{2}\right)\left(r_{1}-r\right) \\
\gamma^{2}=\left(r_{1}-r\right)\left(r_{2}-r\right) & \gamma_{1}^{2}=\left(r_{1}-r\right)\left(r_{3}+r_{1}\right) \\
a_{2}^{2}=\left(r_{2}-r\right)\left(r_{1}+r_{2}\right) & \alpha_{3}^{2}=\left(r_{3}+r_{1}\right)\left(r_{3}-r\right) \\
\beta_{2}^{2}=\left(r_{1}+r_{2}\right)\left(r_{2}+r_{3}\right) & \beta_{3}^{2}=\left(r_{3}-r\right)\left(r_{2}+r_{3}\right) \\
\gamma_{2}^{2}=\left(r_{2}+r_{3}\right)\left(r_{2}-r\right) & \gamma_{: 3}^{2}=\left(r_{3}+r_{3}\right)\left(r_{3}+r_{1}\right)
\end{aligned}
$$

Weddle remarks that these twelve equations along with the three in (55) of the $r$ formulae* give the values of all the products of every two of the six quantities

$$
r_{1}-r \quad r_{2}-r \quad r_{3}-r \quad r_{2}+r_{: 3} \quad r_{3}+r_{1} \quad r_{1}+r_{2}
$$

* Procedings of the Edinburgh Mathematical Society, Vol. XII., p. 98 (1894). 


$$
\begin{aligned}
& a=\frac{\sqrt{b c r_{1}}}{r_{1}} \quad \beta=\frac{\sqrt{c a r r_{2}}}{r_{2}} \quad \gamma=\frac{\sqrt{a d r r_{3}}}{r_{3}} \\
& \begin{array}{lll}
a_{1}=\frac{\sqrt{b c r r_{1}}}{r} & \beta_{2}=\frac{\sqrt{c a r r_{2}}}{r} & \gamma_{3}=\frac{\sqrt{a b r r_{3}}}{r} \\
a_{2}=\frac{\sqrt{b c r_{2} r_{: 3}}}{r_{;}} & \beta_{3}=\frac{\sqrt{c a r_{i} r_{1}}}{r_{1}} & \gamma_{1}=\frac{\sqrt{a b r_{1} r_{2}}}{r_{2}^{*}}
\end{array} \\
& a_{2}=\frac{\sqrt{b c r_{2} r_{3}}}{r_{:}} \quad \beta_{1}=\frac{\sqrt{\operatorname{car} r_{1}}}{r_{3}} \quad \gamma_{2}=\frac{\sqrt{a b r_{1} r_{2}}}{r_{1}}
\end{aligned}
$$

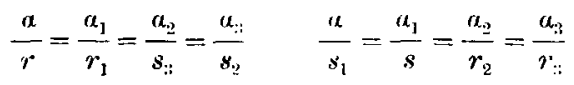

$$
\begin{aligned}
& \frac{\beta}{r}=\frac{\beta_{1}}{s_{3}}=\frac{\beta_{32}}{r_{2}}=\frac{\beta_{3}}{s_{1}} \quad \frac{\beta}{s_{2}}=\frac{\beta_{1}}{r_{1}}=\frac{\beta_{3}}{s}=\frac{\beta_{3}}{r_{3}} \\
& \frac{\gamma}{r}=\frac{\gamma_{1}}{s_{2}}=\frac{\gamma_{2}}{s_{1}}=\frac{\gamma_{: 3}}{r_{: 3}} \quad \frac{\gamma}{s_{3}}=\frac{\gamma_{1}}{r_{1}}=\frac{\gamma_{2}}{r_{2}}=\frac{\gamma_{: 3}}{s} \\
& \alpha \alpha_{1}=\alpha_{2} a_{3}=b c \quad \beta \beta_{2}=\beta_{2} \beta_{1}=c a \quad \gamma \gamma_{: 3}=\gamma_{1} \gamma_{2}=a b
\end{aligned}
$$

$$
a a_{1} a_{2} a_{3}=b^{2} c^{2} \quad \beta \beta_{1} \beta_{2} \beta_{3}=c^{2} a^{2} \quad \gamma \gamma_{1} \gamma_{2} \gamma_{3}=a^{2} b^{2}
$$

$$
a \beta \gamma \alpha_{1} \beta_{1} \gamma_{1} \alpha_{2} \beta_{2} \gamma_{2} \alpha_{3} \beta_{3} \gamma_{3}=(a b c)^{4}
$$$$
\begin{aligned}
a \beta_{1} \gamma_{3} & =a \beta_{3} \gamma_{1}=\alpha_{1} \beta \gamma_{2}=a_{1} \beta_{3} \gamma \\
=\alpha_{2} \beta \gamma_{3}=\alpha_{2} \beta_{3} \gamma_{1} & =\alpha_{3} \beta_{1} \gamma_{2}=a_{3} \beta_{2} \gamma=a b c
\end{aligned}
$$

$$
\begin{aligned}
& a \beta \gamma: a b c=a b c: a_{1} \beta_{2} \gamma_{::} \\
& a_{1} \beta_{1} \gamma_{1}: a b c=a b c: a \beta_{3} \gamma_{2} \\
& a_{2} \beta_{2} \gamma_{2}: a b c=a b c: a_{3} \beta \gamma_{1} \\
& a_{3} \beta_{3} \gamma_{3}: a b c=a b c: a_{2} \beta_{1} \gamma
\end{aligned}
$$




$$
\begin{aligned}
& \frac{\beta \gamma_{2}}{\alpha}=\frac{\beta_{3} \gamma}{a}=\frac{\beta_{1} \gamma_{3}}{a_{1}}=\frac{\beta_{2} \gamma_{1}}{a_{1}} \\
= & \frac{\beta_{1} \gamma_{2}}{a_{2}}=\frac{\beta_{2} \gamma}{a_{2}}=\frac{\beta \gamma_{3}}{\alpha_{3}}=\frac{\beta_{3} \gamma_{1}}{a_{3}}=a \\
& \frac{a \gamma_{1}}{\beta}=\frac{a_{3} \gamma}{\beta}=\frac{a_{1} \gamma}{\beta_{1}}=\frac{a_{2} \gamma_{1}}{\beta_{1}} \\
= & \frac{a_{1} \gamma_{2}}{\beta_{2}}=\frac{a_{3} \gamma_{3}}{\beta_{2}}=\frac{a \gamma_{3}}{\beta_{3}}=\frac{a_{3} \gamma_{2}}{\beta_{3}}=b \\
& \frac{a \beta_{1}}{\gamma}=\frac{a_{2} \beta}{\gamma}=\frac{a_{1} \beta}{\gamma_{1}}=\frac{a_{3} \beta_{1}}{\gamma_{1}} \\
= & \frac{a \beta_{2}}{\gamma_{2}}=\frac{a_{2} \beta_{3}}{\gamma_{2}}=\frac{a_{1} \beta_{3}}{\gamma_{3}}=\frac{a_{3} \beta_{2}}{\gamma_{3}}=c
\end{aligned}
$$

$\alpha_{2}: \beta_{2}=\gamma_{2}: r_{2}+r_{3} \quad \alpha_{3}: \beta_{3}=\gamma_{3}: r_{2}+r_{3}$

$\beta_{2}: \alpha_{2}=\gamma_{2}: r_{2}-r \quad \beta_{3}: \alpha_{3}=\gamma_{3}: r_{3}+r_{1}$ $\gamma_{2}: a_{2}=\beta_{2}: r_{1}+r_{2} \quad \gamma_{3}: a_{3}=\beta_{3}: r_{3}-r$

$\alpha_{1}: \beta_{2}=\gamma_{3}: r_{2}+r_{3} \quad a: \beta_{3}=\gamma_{2}: r_{2}+r_{3}$ $\beta_{2}: a_{1}=\gamma_{3}: r_{3}+r_{1} \quad \beta_{3}: \alpha=\gamma_{2}: r_{2}-r$ $\gamma_{3}: \alpha_{1}=\beta_{2}: r_{1}+r_{2} \quad \gamma_{2}: \alpha=\beta_{3}: r_{3}-r$ $\alpha_{3}: \beta=\gamma_{1}: r_{1}-r \quad \alpha_{2}: \beta_{1}=\gamma: r_{1}-r$ $\beta: a_{3}=\gamma_{1}: r_{3}+r_{1} \quad \beta_{1}: \alpha_{2}=\gamma: r_{2}-r$ $\gamma_{1}: \alpha_{3}=\beta: r_{3}-r \quad \gamma: a_{2}=\beta_{1}: r_{1}+r_{2}$

$$
\begin{array}{ll}
\alpha^{2}: b c=s_{1}: s & \alpha_{1}{ }^{2}: b c=8: s_{1} \\
\beta^{2}: c a=s_{2}: s & \beta_{1}^{2}: c a=8_{3}: s_{1} \\
\gamma^{2}: a b=8_{3}: s & \gamma_{1}^{2}: a b=8_{2}: s_{1} \\
a_{2}^{2}: b c=8_{3}: 8_{2} & \alpha_{3}{ }^{2}: b c=8_{2}: 8_{3} \\
\beta_{2}{ }^{2}: c a=8: 8_{2} & \beta_{3}{ }^{2}: c a=8_{1}: 8_{3} \\
\gamma_{2}{ }^{2}: a b=8_{1}: 8_{2} & \gamma_{3}{ }^{2}: a b=8: s_{3}
\end{array}
$$




$$
\begin{aligned}
& \frac{a^{2}}{b c}+\frac{\beta^{2}}{c a}+\frac{\gamma^{2}}{a b}=1 \\
& \frac{a_{1}^{2}}{b c}-\frac{\beta_{1}^{2}}{c a}-\frac{\gamma_{1}^{2}}{a b}=1 \\
& -\frac{\alpha_{2}^{2}}{b r}+\frac{\beta_{2^{2}}{ }^{2}}{c a}-\frac{\gamma_{2}^{2}}{a b}=1 \\
& -\frac{a_{3}^{2}}{b c}-\frac{\beta_{3}^{2}}{c a}+\frac{\gamma_{: 2}^{2}}{a b}=1
\end{aligned}
$$

$$
\begin{aligned}
& \frac{b c}{a_{1}{ }^{2}}+\frac{c a}{\beta_{2}{ }^{2}}+\frac{a b}{\gamma_{: i^{2}}}=1 \\
& \frac{b c}{a^{2}}-\frac{c a}{\beta_{3^{2}}{ }^{2}}-\frac{a b}{\gamma_{:{ }^{2}}}=1 \\
& -\frac{b c}{a_{: 2}^{2}}+\frac{c a}{\beta^{2}}-\frac{a b}{\gamma_{1}^{2}}=1 \\
& -\frac{b c}{a_{2}{ }^{2}}-\frac{c a}{\beta_{1}^{2}}+\frac{a b}{\gamma^{2}}=1
\end{aligned}
$$

$$
\begin{aligned}
& a^{2}\left(\frac{1}{c}-\frac{1}{b}\right)+\beta^{2}\left(\frac{1}{a}-\frac{1}{c}\right)+\gamma^{2}\left(\frac{1}{b}-\frac{1}{a}\right)=0 \\
& a_{1}{ }^{2}\left(\frac{1}{b}-\frac{1}{c}\right)+\beta_{1}^{2}\left(\frac{1}{a}+\frac{1}{c}\right)-\gamma_{1}^{2}\left(\frac{1}{a}+\frac{1}{b}\right)=0
\end{aligned}
$$

$$
\begin{aligned}
& a a^{2}(b-c)+b \beta^{2}(c-a)+c \gamma^{2}(a-b)=0 \\
& a a_{1}{ }^{2}(c-b)+b \beta_{1}{ }^{2}(c+a)+c \gamma_{1}{ }^{2}(a+b)=0
\end{aligned}
$$

$$
\begin{aligned}
& \frac{b-c}{a a_{1}{ }^{2}}+\frac{c-a}{b{\beta_{2}{ }^{2}}^{2}}+\frac{a-b}{c \gamma_{3}{ }^{2}}=0 \\
& \frac{c-b}{a a^{2}}+\frac{c+a}{b \beta_{3}{ }^{2}}-\frac{a+b}{c \gamma_{2}{ }^{2}}=0
\end{aligned}
$$




$$
\begin{aligned}
& a^{2}+\beta^{2}+\gamma^{2}=\frac{b c s_{1}+c \alpha s_{2}+a b s_{: 3}}{s}=b c+c a+a b-\frac{3 a b c}{s} \\
& a_{1}^{2}+\beta_{1}{ }^{2}+\gamma_{1}{ }^{2}=\frac{b c s+c a s_{3}+a b s_{2}}{s_{1}}=b c-c a-a b+\frac{3 a b c}{s_{1}} \\
& a_{2}^{2}+\beta_{2}^{2}+\gamma_{2}^{2}=\frac{b c s_{;}+c a s+a b s_{1}}{s_{3}}=-b c+c a-a b+\frac{3 a b c}{s_{2}} \\
& u_{3}{ }^{2}+\beta_{i 3}{ }^{2}+\gamma_{i 3}{ }^{2}=\frac{b r s_{2}+c a s_{1}+r b s_{s}}{s_{3}}=-b c-c a+a b+\frac{3 a b c}{s_{3}} \\
& \alpha_{1}^{2}+\beta_{2}^{2}+\gamma_{: 3}^{2}=\left(r_{1}+r_{2}+r_{: 3}\right)^{2}+s^{2} \\
& a^{2}+\beta_{3}{ }^{2}+\gamma_{2}^{2}=\left(r-r_{3}-r_{2}\right)^{2}+s_{1}^{2} \\
& \alpha_{: 3}^{2}+\beta^{2}+\gamma_{1}^{2}=\left(r-r_{1}-r_{0}\right)^{2}+s_{2}^{2} \\
& \alpha_{2}{ }^{2}+\beta_{1}{ }^{2}+\gamma^{2}=\left(r-r_{2}-r_{1}\right)^{2}+s_{::}{ }^{2}
\end{aligned}
$$

Compare (15) of the $r$ formulae*

$$
\begin{aligned}
& \alpha \beta \gamma: a b c=r: s \\
& a_{1} \beta_{1} \gamma_{1}: a b c=r_{1}: s_{1} \\
& a_{2} \beta_{2} \gamma_{2}: a b c=r_{2}: s_{2} \\
& \alpha_{3} \beta_{: 3} \gamma_{3}: a b c=r_{::}: s_{3}
\end{aligned}
$$

Other proportions may be obtained by substituting for $a b c$ its equivalents in ( 7 ). Matthes (p. 49) gives

$$
\alpha_{1} \beta_{1} \gamma_{2}: \alpha \beta \gamma=\triangle: r^{2}
$$

which may be reduced to

$$
\begin{gathered}
a b c: a \beta \gamma=s: r \\
a_{1} \beta_{2} \gamma_{3}: a b c=s: r \\
\alpha \beta_{3} \gamma_{2}: a b c=s_{1}: r_{1} \\
\alpha_{3} \beta \gamma_{1}: a b c=s_{2}: r_{2} \\
a_{2} \beta_{1} \gamma: a b c=s_{3}: r_{3}
\end{gathered}
$$

and so on.

$$
\left.\begin{array}{ll}
h_{1} h_{2} h_{3} \alpha \beta \gamma=8 \triangle^{2} r^{2} & h_{1} h_{2} h_{3} a_{1} \beta_{2} \gamma_{3}=8 \triangle^{2} s^{2} \\
h_{1} h_{2} h_{3} \alpha_{1} \beta_{1} \gamma_{1}=8 \triangle^{2} r_{1}^{2} & h_{1} h_{2} h_{3} a \beta_{3} \gamma_{2}=8 \triangle^{2} s_{1}{ }^{2}
\end{array}\right\}
$$

* Proceedings of the Edinburgh Mathematical Society, Vol. XII., p. 91 (1894). 


$$
\begin{gathered}
a \alpha^{2}+b \beta^{2}+c \gamma^{2}= \\
a a_{1}{ }^{2}-b \beta_{1}{ }^{2}-c \gamma_{1}{ }^{2}= \\
-a a_{2}{ }^{2}+b{\beta_{2}}^{2}-c \gamma_{2}{ }^{2}= \\
-a{a_{3}}^{2}-b{\beta_{3}}^{2}+c{\gamma_{3}}^{2}=a b c
\end{gathered}
$$

$$
\begin{aligned}
& \alpha \beta \gamma=\left(r_{1}-r\right)\left(r_{2}-r\right)\left(r_{3}-r\right) \\
& \alpha_{1} \beta_{1} \gamma_{1}=\left(r_{1}-r\right)\left(r_{3}+r_{1}\right)\left(r_{1}+r_{2}\right) \\
& \alpha_{2} \beta_{2} \gamma_{2}=\left(r_{2}+r_{3}\right)\left(r_{2}-r\right)\left(r_{1}+r_{2}\right) \\
& \alpha_{3} \beta_{3} \gamma_{3}=\left(r_{2}+r_{3}\right)\left(r_{3}+r_{1}\right)\left(r_{3}-r\right) \\
& \alpha_{1} \beta_{2} \gamma_{3}=\left(r_{2}+r_{: 3}\right)\left(r_{3}+r_{1}\right)\left(r_{1}+r_{3}\right) \\
& \text { a } \beta_{3} \gamma_{2}=\left(r_{2}+r_{3}\right)\left(r_{2}-r\right)\left(r_{;:}-r\right) \\
& u_{: 3} \beta \gamma_{1}=\left(r_{1}-r\right)\left(r_{::}+r_{1}\right)\left(r_{::}-r\right) \\
& \alpha_{1} \beta_{1} \gamma=\left(r_{1}-r\right)\left(r_{2}-r\right)\left(r_{1}+r_{2}\right) \\
& a \beta \beta_{3}=\left(r_{2}+r_{i j}\right)\left(\dot{r}_{i j}-r\right)\left(r_{1}-r\right) \\
& \text { a } \gamma \gamma_{2}=\left(r_{2}+r_{3}\right)\left(r_{1}-r\right)\left(r_{2}-r\right) \\
& b \gamma \gamma_{1}=\left(r_{3}+r_{1}\right)\left(r_{1}-r\right)\left(r_{2}-r\right) \\
& \text { b a } a_{3}=\left(r_{3}+r_{1}\right)\left(r_{2}-r\right)\left(r_{3}-r^{2}\right) \\
& \text { c } \alpha a_{2}=\left(r_{1}+r_{2}\right)\left(r_{2}-r\right)\left(r_{3}-r\right) \\
& c \beta \beta_{1}=\left(r_{1}+r_{2}\right)\left(r_{3}-r\right)\left(r_{1}-r\right) \\
& a \beta_{1} \beta_{2}=\left(r_{1}-r\right)\left(r_{1}+r_{2}\right)\left(r_{2}+r_{33}\right) \\
& \text { a } \gamma_{3} \gamma_{1}=\left(r_{1}-r^{*}\right)\left(r_{2}+r_{i j}\right)\left(r_{3}+r_{1}\right) \\
& \text { b } \gamma_{2} \gamma_{33}=\left(r_{2}-r\right)\left(r_{2}+r_{3}\right)\left(r_{3}+r_{1}\right) \\
& b a_{1} \alpha_{2}=\left(r_{2}-r\right)\left(r_{3}+r_{1}\right)\left(r_{1}+r_{3}\right) \\
& c a_{3} \alpha_{1}=\left(r_{3}-r\right)\left(r_{3}+r_{1}\right)\left(r_{1}+r_{2}\right) \\
& c \beta_{2} \beta_{3}=\left(r_{3}-r\right)\left(r_{2}+r_{2}\right)\left(r_{2}+r_{3}\right)
\end{aligned}
$$

Weddle remarks that $(24)$ and (25) exhibit the twenty products of every three of the six quantities

$$
r_{1}-r, \quad r_{2}-r, \quad r_{i 3}-r, \quad r_{2}+r_{3}, \quad r_{3}+r_{1}, \quad r_{1}+r_{2}
$$

6 Vol. 13 


$\left.\begin{array}{rr}a a_{2}=\left(r_{2}-r\right) c & a_{3} \alpha_{1}=\left(r_{3}+r_{1}\right) c \\ \alpha a_{3}=\left(r_{3}-r\right) b & \alpha_{1} \alpha_{2}=\left(r_{1}+r_{2}\right) b \\ \beta \beta_{3}=\left(r_{3}-r\right) a & \beta_{1} \beta_{2}=\left(r_{1}+r_{2}\right) a \\ \beta \beta_{1}=\left(r_{1}-r\right) c & \beta_{2} \beta_{3}=\left(r_{2}+r_{3}\right) c \\ \gamma \gamma_{1}=\left(r_{1}-r\right) b & \gamma_{2} \gamma_{3}=\left(r_{2}+r_{3}\right) b \\ \gamma \gamma_{2}=\left(r_{2}-r\right) a & \gamma_{3} \gamma_{1}=\left(r_{3}+r_{1}\right) a\end{array}\right\}$




$$
\begin{aligned}
& \left(a_{1}-\alpha\right) s_{2}=a_{3}\left(r_{1}-r\right)=\beta \gamma_{1} \\
& \left(\alpha_{1}-a\right) \varepsilon_{3}=u_{2}\left(r_{1}-r\right)=\beta_{1} \gamma \\
& \left(\beta_{2}-\beta\right) s_{3}=\beta_{1}\left(r_{2}-r\right)=\gamma \alpha_{2} \\
& \left(\beta_{2}-\beta\right) s_{1}=\beta_{3}\left(r_{2}-r\right)=\gamma_{2} a \\
& \left(\gamma_{3}-\gamma\right) s_{1}=\gamma_{2}\left(r_{3}-r\right)=\alpha \beta_{3} \\
& \left(\gamma_{3}-\gamma\right) s_{2}=\gamma_{1}\left(r_{3}-r\right)=\alpha_{3} \beta \\
& \left(\alpha_{2}+\alpha_{3}\right) s=\alpha_{1}\left(r_{2}+r_{3}\right)=\beta_{2} \gamma_{3} \\
& \left(\alpha_{2}+\alpha_{3}\right) s_{1}=a\left(r_{2}+r_{3}\right)=\beta_{3} \gamma_{2} \\
& \left(\beta_{3}+\beta_{1}\right) s=\beta_{2}\left(r_{3}+r_{1}\right)=\gamma_{3} a_{1} \\
& \left(\beta_{3}+\beta_{1}\right) s_{2}=\beta\left(r_{3}+r_{1}\right)=\gamma_{1} \alpha_{3} \\
& \left(\gamma_{1}+\gamma_{2}\right) s=\gamma_{3}\left(r_{1}+r_{2}\right)=a_{1} \beta_{2} \\
& \left(\gamma_{1}+\gamma_{2}\right) s_{3}=\gamma\left(r_{1}+r_{2}\right)=u_{2} \beta_{1}
\end{aligned}
$$

$$
\begin{aligned}
& \left(a_{1}-u\right) h_{1}=2 u r_{1}=2 u_{1} r=2 \alpha_{2} s_{2}=2 u_{3} s_{3} \\
& \left(\beta_{2}-\beta\right) h_{2}=2 \beta r_{2}=2 \beta_{2} r=2 \beta_{1} s_{1}=2 \beta_{v} s_{3} \\
& \left(\gamma_{33}-\gamma\right) h_{3}=2 \gamma r_{i 3}=2 \gamma_{3} r=2 \gamma_{2} s_{1}=2 \gamma_{2} s_{2} \\
& \left(u_{2}+\alpha_{\mathrm{j}}\right) h_{1}=2 u s=2 u_{1} s_{1}=2 u_{2} r_{3}=2 u_{s} r_{2} \\
& \left(\beta_{3}+\beta_{1}\right) h_{2}=2 \beta s=2 \beta_{2} s_{2}=2 \beta_{1} r_{;}=2 \beta_{: 1} r_{1} \\
& \left(\gamma_{1}+\gamma_{2}\right) h_{3}=2 \gamma s=2 \gamma_{j} s_{3 j}=2 \gamma_{1} r_{2}=2 \gamma_{2} r_{1}
\end{aligned}
$$

$$
\begin{aligned}
& \left(u_{1}-u\right) a=\left(u_{2}+u_{3}\right)\left(r_{1}-r\right) \\
& \left(\beta_{3}-\beta\right) b=\left(\beta_{3}+\beta_{1}\right)\left(r_{2}-r\right) \\
& \left(\gamma_{3}-\gamma\right) c=\left(\gamma_{1}-\gamma_{2}\right)\left(r_{3}-r\right) \\
& \left(u_{2}+\alpha_{3}\right) a=\left(u_{1}-u\right)\left(r_{1}+r_{3}\right) \\
& \left(\beta_{3}+\beta_{1}\right) b=\left(\beta_{2}-\beta\right)\left(r_{3}+r_{1}\right) \\
& \left(\gamma_{1}+\gamma_{3}\right) c=\left(\gamma_{3}-\gamma\right)\left(r_{1}+r_{3}\right)
\end{aligned}
$$




$$
\begin{aligned}
& \left(a_{1}-a\right) b=\left(\beta_{2}-\beta\right) \gamma_{1}=\left(\beta_{3}+\beta_{1}\right) \gamma \\
& \left(\alpha_{1}-a\right) c=\left(\gamma_{3}-\gamma\right) \beta_{1}=\left(\gamma_{1}+\gamma_{2}\right) \beta \\
& \left(\beta_{2}-\beta\right) c=\left(\gamma_{3}-\gamma\right) a_{2}=\left(\gamma_{1}+\gamma_{2}\right) a \\
& \left(\beta_{2}-\beta\right) a=\left(\alpha_{1}-a\right) \gamma_{2}=\left(\alpha_{2}+a_{3}\right) \gamma \\
& \left(\gamma_{3}-\gamma\right) a=\left(\alpha_{1}-a\right) \beta_{3}=\left(\alpha_{2}+\alpha_{3}\right) \beta \\
& \left(\gamma_{3}-\gamma\right) b=\left(\beta_{2}-\beta\right) \alpha_{3}=\left(\beta_{3}+\beta_{1}\right) a \\
& \left(\alpha_{2}+\alpha_{3}\right) b=\left(\beta_{3}+\beta_{1}\right) \gamma_{2}=\left(\beta_{2}-\beta\right) \gamma_{3} \\
& \left(\alpha_{2}+a_{3}\right) c=\left(\gamma_{1}+\gamma_{2}\right) \beta_{3}=\left(\gamma_{3}-\gamma\right) \beta_{2} \\
& \left(\beta_{3}+\beta_{1}\right) c=\left(\gamma_{1}+\gamma_{2}\right) a_{3}=\left(\gamma_{3}-\gamma\right) \alpha_{2} \\
& \left(\beta_{3}+\beta_{1}\right) a=\left(\alpha_{2}+\alpha_{3}\right) \gamma_{1}=\left(a_{1}-a\right) \gamma_{3} \\
& \left(\gamma_{1}+\gamma_{2}\right) a=\left(a_{2}+\alpha_{3}\right) \beta_{1}=\left(\alpha_{1}-a\right) \beta_{2} \\
& \left(\gamma_{1}+\gamma_{2}\right) b=\left(\beta_{3}+\beta_{1}\right) \alpha_{2}=\left(\beta_{2}-\beta\right) \alpha_{1}
\end{aligned}
$$

$$
\begin{aligned}
& \left(\alpha_{1}-\alpha\right) \beta=\left(\gamma_{3}-\gamma\right)\left(r_{1}-r\right) \\
& \left(\alpha_{1}-a\right) \gamma=\left(\beta_{2}-\beta\right)\left(r_{1}-r\right) \\
& \left(\alpha_{1}-\alpha\right) \beta_{1}=\left(\gamma_{1}+\gamma_{2}\right)\left(r_{1}-r\right) \\
& \left(\alpha_{1}-\alpha\right) \gamma_{1}=\left(\beta_{3}+\beta_{1}\right)\left(r_{1}-r\right) \\
& \left(\beta_{2}-\beta\right) \gamma=\left(\alpha_{1}-\alpha\right)\left(r_{2}-r\right) \\
& \left(\beta_{2}-\beta\right) a=\left(\gamma_{3}-\gamma\right)\left(r_{2}-r\right) \\
& \left(\beta_{2}-\beta\right) \gamma_{2}=\left(\alpha_{2}+a_{3}\right)\left(r_{2}-r\right) \\
& \left(\beta_{2}-\beta\right) \alpha_{2}=\left(\gamma_{1}+\gamma_{2}\right)\left(r_{2}-r\right) \\
& \left(\gamma_{3}-\gamma\right) a=\left(\beta_{2}-\beta\right)\left(r_{3}-r\right) \\
& \left(\gamma_{3}-\gamma\right) \beta=\left(\alpha_{1}-\alpha\right)\left(r_{3}-r\right) \\
& \left(\gamma_{3}-\gamma\right) \alpha_{33}=\left(\beta_{3}+\beta_{1}\right)\left(r_{3}-r\right) \\
& \left(\gamma_{3}-\gamma\right) \beta_{3}=\left(\alpha_{2}+\alpha_{3}\right)\left(r_{3}-r\right)
\end{aligned}
$$




$$
\begin{aligned}
& \left(\mu_{2}+\alpha_{3}\right) \beta_{.2}=\left(\gamma_{1}+\gamma_{2}\right)\left(r_{2}+r_{3}\right) \\
& \left(\alpha_{2}+\alpha_{3}\right) \gamma_{2}=\left(\beta_{2}-\beta\right)\left(r_{2}+r_{3}\right) \\
& \left(\alpha_{2}+\alpha_{3 ;}\right) \beta_{33}=\left(\gamma_{3}-\gamma\right)\left(r_{32}+r_{33}\right) \\
& \left(\alpha_{2}+u_{3}\right) \gamma_{i 3}=\left(\beta_{3}+\beta_{1}\right)\left(r_{2}+r_{3}\right) \\
& \left(\beta_{i j}+\beta_{1}\right) \gamma_{1}=\left(\mu_{1}-u\right)\left(r_{; ;}+r_{1}\right) \\
& \left(\beta_{3}+\beta_{1}\right) a_{1}=\left(\gamma_{1}+\gamma_{2}\right)\left(r_{33}+r_{1}\right) \\
& \left(\beta_{33}+\beta_{1}\right) \gamma_{3}=\left(\alpha_{.2}+\alpha_{i 3}\right)\left(r_{3}+r_{1}\right) \\
& \left(\beta_{: 3}+\beta_{1}\right) \alpha_{3}=\left(\gamma_{3}-\gamma_{1}\right)\left(r_{i 3}+r_{1}\right) \\
& \left(\gamma_{1}+\gamma_{2}\right) u_{1}=\left(\beta_{3 j}+\beta_{1}\right)\left(r_{1}+r_{2}\right) \\
& \left(\gamma_{1}+\gamma_{2}\right) \beta_{1}=\left(\alpha_{1}-a\right)\left(r_{1}+r_{2}\right) \\
& \left(\gamma_{1}+\gamma_{2}\right) \alpha_{2}=\left(\beta_{2}-\beta\right)\left(r_{1}+r_{2}\right) \\
& \left(\gamma_{1}+\gamma_{2}\right) \beta_{2}=\left(\alpha_{2}+u_{3}\right)\left(r_{1}+r_{2}\right)
\end{aligned}
$$

$$
\begin{aligned}
& \left(\alpha_{1}-\alpha\right) r_{1 .}=\left(\alpha_{.2}+\alpha_{3}\right) s_{3}=a u_{2}=\beta_{1} \gamma_{2}=\beta_{2} \gamma \\
& \left(\alpha_{1}-a\right) r_{3}=\left(\alpha_{.2}+\alpha_{: 3}\right) s_{3}=a u_{3}=\beta \gamma_{3}=\beta_{: 3} \gamma_{1}
\end{aligned}
$$

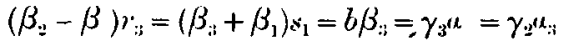

$$
\begin{aligned}
& \left(\beta_{3_{2}}-\beta\right) r_{1}=\left(\beta_{3}+\beta_{1}\right) s_{3}=b / \beta_{1}=\gamma_{,} \alpha_{1}=\gamma_{1} \alpha_{12} \\
& \left(\gamma_{::}-\gamma\right) r_{1}=\left(\gamma_{1}+\gamma_{2}\right) s_{2}=c \gamma_{1}=u_{1} \beta=\alpha_{3 ;} \beta_{1} \\
& \left(\gamma_{: 3}-\gamma\right) r_{22}=\left(\gamma_{1}+\gamma_{3}\right) s_{1}=c \gamma_{2}=a \beta_{: 2}=a_{22} \beta_{3} \\
& \left(\alpha_{2}+\alpha_{i j}\right) r=\left(\alpha_{1}-\alpha\right) s_{1}=a \alpha=\beta \gamma_{2}=\beta_{i j} \gamma \\
& \left(u_{2}+a_{3}\right) r_{1}=\left(\alpha_{1}-a\right) s=a \alpha_{1}=\beta_{1} \gamma_{j}=\beta_{2} \gamma_{1} \\
& \left(\beta_{3}+\beta_{1}\right) r=\left(\beta_{2}-\beta\right) \varepsilon_{2}=b / \beta=\gamma_{1} a=\gamma u_{3} \\
& \left(\beta_{3}+\beta_{1}\right) r_{2}=\left(\beta_{2}-\beta\right) s=b \beta_{2}=\gamma_{2} \alpha_{1}=\gamma_{,} \alpha_{2} \\
& \left(\gamma_{1}+\gamma_{2}\right) r=\left(\gamma_{j}-\gamma\right) s_{i 3}=c \gamma=a \beta_{1}=\alpha_{2} \beta \\
& \left(\gamma_{1}+\gamma_{:}\right) r_{::}=\left(\gamma_{::}-\gamma\right) s=c \gamma_{3}=a_{1} \beta_{: 3}=\alpha_{3} \beta
\end{aligned}
$$




$$
\begin{aligned}
& \left(a_{1}-a\right)^{2}=a^{2}+\left(r_{1}-r\right)^{2}=\frac{a^{2} b c r r_{1}}{\Delta^{2}}=\frac{a^{2} b c}{s s_{1}} \\
& =\left(r_{1}-r\right) \frac{\left(r_{2}+r_{3}\right)\left(r_{3}+r_{1}\right)}{r_{2} r_{3}+r_{3} r_{1}+r_{1} r_{2}} \\
& \left(\beta_{2,}-\beta\right)^{2}=b^{2}+\left(r_{2} \cdots r\right)^{2}=\frac{a b^{2} c r r_{2}}{\triangle^{2}}=\frac{a b^{2} c}{s s_{2}} \\
& =\left(r_{2}-r\right)[] \\
& \left(\gamma_{3}-\gamma\right)^{2}=c^{2}+\left(r_{3}-r\right)^{2}=\frac{a b c^{2} r r_{3}}{\triangle^{2}}=\frac{a b c^{2}}{s s_{3}} \\
& =\left(r_{3}-r\right)[] \\
& \left(u_{13}+u_{3}\right)^{\prime \prime}=a^{2}+\left(r_{2}+r_{3}\right)^{2}=\frac{a^{2} / b c r_{2} r_{3}}{\triangle^{2}}=\frac{a^{2} b c}{s_{x^{2} ;}} \\
& =\left(r_{2}+r_{i:}\right)[] \\
& \left(\beta_{3}+\beta_{1}\right)^{2}=b^{2}+\left(r_{i 3}+r_{1}\right)^{2}=\frac{a b^{2} c r_{3} r_{1}}{\Delta^{2}}=\frac{a b^{2} c}{s_{3: s_{1}}} \\
& =\left(r_{3}+r_{1}\right)[] \\
& \left(\gamma_{1}+\gamma_{2}\right)^{2}=c^{2}+\left(r_{1}+r_{2}\right)^{2}=\frac{a b c^{2} r_{1} r_{2}}{\Delta^{2}}=\frac{a b c^{2}}{s_{1} s_{2}} \\
& =\left(r_{1}+r_{2}\right)[
\end{aligned}
$$

In Grunert's Archiv, XXIX., 436 (1857), Franz Unferdinger gives for $\left(u_{1}-u\right)^{n}$, etc., the values

$$
r_{2}^{2}\left(r_{2}+r_{33}\right) \frac{\left(r_{2}+r_{3}\right)\left(r_{3}+r_{1}\right)\left(r_{1}+r_{3}\right)}{\left(r_{2} r_{3}+r_{3} r_{1}+r_{1} r_{3}\right)^{2}} \text { ete. }
$$

See $(56)$ of the $r$ formulae.*

$$
\begin{array}{r}
\left(\alpha_{1}-\alpha\right)^{2}+\left(\beta_{2}-\beta\right)^{2}+\left(\gamma_{3}-\gamma\right)^{2} \\
+\left(\alpha_{2}+\alpha_{33}\right)^{2}+\left(\beta_{3}+\beta_{1}\right)^{2}+\left(\gamma_{1}+\gamma_{2}\right)^{2} \\
=3\left(-r+\gamma_{1}+r_{2}+r_{33}\right)^{2}
\end{array}
$$

\footnotetext{
* Procedings of the Edinburyh Mathcmatical Socicty, Vol. XII., p. 98 (1894).
} 


$$
\begin{aligned}
\left(\alpha_{1}-\alpha\right)^{2} & =\left(\beta_{3}+\beta_{1}\right) \beta_{1}-\left(\beta_{2}-\beta\right) \beta \\
& =\left(\gamma_{1}+\gamma_{2}\right) \gamma_{2}-\left(\gamma_{3}-\gamma\right) \gamma \\
\left(\beta_{2}-\beta\right)^{2} & =\left(\gamma_{1}+\gamma_{2}\right) \gamma_{2}-\left(\gamma_{3}-\gamma\right) \gamma \\
& =\left(\alpha_{2}+\alpha_{3}\right) \alpha_{2}-\left(\alpha_{1}-\alpha\right) \alpha \\
\left(\gamma_{3}-\gamma\right)^{2} & =\left(\alpha_{2}+\alpha_{3}\right) \alpha_{3}-\left(\alpha_{1}-\alpha\right) \alpha \\
& =\left(\beta_{3}+\beta_{1}\right) \beta_{3}-\left(\beta_{2}-\beta\right) \beta_{1} \\
\left(u_{2}+u_{3}\right)^{2} & =\left(\beta_{3}+\beta_{1}\right) \beta_{3}+\left(\beta_{2}-\beta\right) \beta_{2} \\
& =\left(\gamma_{1}+\gamma_{2}\right) \gamma_{2}+\left(\gamma_{3}-\gamma\right) \gamma_{3} \\
\left(\beta_{3}+\beta_{1}\right)^{2} & =\left(\gamma_{1}+\gamma_{2}\right) \gamma_{1}+\left(\gamma_{3}-\gamma\right) \gamma_{3} \\
& =\left(u_{2}+u_{33}\right) \alpha_{3}+\left(u_{1}-\alpha\right) \alpha_{1} \\
\left(\gamma_{1}+\gamma_{2}\right)^{2} & =\left(\alpha_{2}+\alpha_{33}\right) u_{2}+\left(\alpha_{1}-\alpha\right) \alpha_{1} \\
& =\left(\beta_{33}+\beta_{1}\right) \beta_{1}+\left(\beta_{2}-\beta\right) \beta_{2}
\end{aligned}
$$

$$
\begin{aligned}
\left(\alpha_{1}-a\right)\left(\alpha_{2}+\alpha_{3}\right) & =\left(\beta_{3}+\beta_{1}\right) \beta_{2}-\left(\beta_{2}-\beta\right) \beta_{: 1} \\
& =\left(\gamma_{1}+\gamma_{2}\right) \gamma_{3}-\left(\gamma_{: 3}-\gamma_{1}\right) \gamma_{2} \\
& =\left(\beta_{3}+\beta_{1}\right) \beta+\left(\beta_{2}-\beta\right) \beta_{1} \\
& =\left(\gamma_{1}+\gamma_{2}\right) \gamma+\left(\gamma_{: 3}-\gamma_{1}\right) \gamma_{1}
\end{aligned}
$$

$$
\begin{aligned}
\left(\beta_{2}-\beta\right)\left(\beta_{3}+\beta_{1}\right) & =\left(\gamma_{1}+\gamma_{2}\right) \gamma_{3}-\left(\gamma_{3}-\gamma\right) \gamma_{1} \\
& =\left(u_{2}+u_{3 j}\right) u_{1}-\left(u_{1}-u\right) u_{i j} \\
& =\left(\gamma_{1}+\gamma_{2}\right) \gamma+\left(\gamma_{3}-\gamma\right) \gamma_{2} \\
& =\left(u_{2}+u_{3}\right) u+\left(\alpha_{1}-u\right) u_{i 2}
\end{aligned}
$$

$$
\begin{aligned}
\left(\gamma_{3}-\gamma\right)\left(\gamma_{1}+\gamma_{2}\right) & =\left(\alpha_{2}+\alpha_{3}\right) \alpha_{1}-\left(\alpha_{1}-a\right) \alpha_{2} \\
& =\left(\beta_{33}+\beta_{1}\right) \beta_{2 .}-\left(\beta_{2}-\beta\right) \beta_{1} \\
& =\left(\alpha_{2}+\alpha_{33}\right) \alpha+\left(\alpha_{1}-a\right) \alpha_{33} \\
& =\left(\beta_{3}+\beta_{1}\right) \beta+\left(\beta_{2}-\beta\right) \beta_{3}
\end{aligned}
$$

$$
\begin{aligned}
& \left(\alpha_{1}-a\right)\left(\beta_{2}-\beta\right)\left(\gamma_{3}-\gamma\right):\left(\alpha_{2}+\alpha_{3}\right)\left(\beta_{3}+\beta_{1}\right)\left(\gamma_{1}+\gamma_{2}\right)=r: s \\
& \left(\alpha_{1}-a\right)\left(\beta_{3}+\beta_{1}\right)\left(\gamma_{1}+\gamma_{2}\right):\left(\alpha_{2}+\alpha_{3}\right)\left(\beta_{2}-\beta\right)\left(\gamma_{3}-\gamma\right)=r_{1}: s_{1} \\
& \left(\alpha_{2}+\alpha_{3}\right)\left(\beta_{2}-\beta\right)\left(\gamma_{1}+\gamma_{2}\right):\left(\alpha_{1}-\alpha\right)\left(\beta_{i 3}+\beta_{1}\right)\left(\gamma_{i 3}-\gamma\right)=r_{: 2}: s_{: 1} \\
& \left(\alpha_{2}+\alpha_{3}\right)\left(\beta_{3}+\beta_{1}\right)\left(\gamma_{i 3}-\gamma\right):\left(\alpha_{1}-\alpha\right)\left(\beta_{2}-\beta\right)\left(\gamma_{1}+\gamma_{2}\right)=r_{i 3}: s_{: ;}
\end{aligned}
$$


By combining (41) with (8) and (20) other proportions may be obtained which it is needless to write down. T. S. Davies (in the Ladies'Diary for 1835 , p. 53) gives one of them :

$$
\left.\begin{array}{c}
\left(\alpha_{1}-\alpha\right)\left(\beta_{2}-\beta\right)\left(\gamma_{3}-\gamma\right):\left(\alpha_{2}+u_{3}\right)\left(\beta_{3}+\beta_{1}\right)\left(\gamma_{1}+\gamma_{2}\right)=a \beta \gamma: a b c \\
\left(\alpha_{2}+\alpha_{33}\right)\left(\beta_{3}+\beta_{1}\right)\left(\gamma_{1}+\gamma_{2}\right) \\
=\left(\alpha_{2}+u_{3}\right)\left(\beta_{2}-\beta\right)\left(\gamma_{3}-\gamma\right)+\left(\alpha_{1}-a\right)\left(\beta_{3}+\beta_{1}\right)\left(\gamma_{3}-\gamma\right) \\
+\left(\alpha_{1}-\alpha\right)\left(\beta_{2}-\beta\right)\left(\gamma_{1}+\gamma_{2}\right)
\end{array}\right\}
$$

These equalities are merely particular cases of more general ones stated by Gergonne in his dunales, IX., 116. 284 (1818-9). 


$$
\begin{gathered}
\frac{a_{1}-\alpha}{\alpha_{1}}+\frac{\beta_{2}-\beta}{\beta_{3}}+\frac{\gamma_{3}-\gamma}{\gamma_{3}}=2 \\
-\frac{a_{1}-a}{\alpha}+\frac{\beta_{3}+\beta_{1}}{\beta_{3}}+\frac{\gamma_{1}+\gamma_{2}}{\gamma_{2}}=2 \\
\frac{a_{2}+\alpha_{3}}{\alpha_{3}}-\frac{\beta_{2}-\beta}{\beta}+\frac{\gamma_{1}+\gamma_{2}}{\gamma_{2}}=2 \\
\frac{a_{3}+\alpha_{3}}{\alpha_{3}}+\frac{\beta_{3}+\beta_{1}}{\beta_{1}}-\frac{\gamma_{3}-\gamma}{\gamma}=2
\end{gathered}
$$

The first of these equations is a particular case of a theorem given by Vecten in Gergonne's Annales, IX., 277-9 (1819).

$$
\begin{aligned}
& \frac{1}{u^{2}}+\frac{1}{a_{1}^{2}}+\frac{1}{a_{v_{2}^{2}}^{2}}+\frac{1}{a_{i_{i}^{2}}^{2}}=\frac{4}{h_{1}^{2}} \\
& \frac{1}{\beta^{2}}+\frac{1}{\beta_{1}^{2}}+\frac{1}{\beta_{2}^{2}}+\frac{1}{\beta_{3}^{2}}=\frac{4}{h_{2}^{2}} \\
& \frac{1}{\gamma^{2}}+\frac{1}{\gamma_{1}^{2}}+\frac{1}{\gamma_{2}{ }^{2}}+\frac{1}{\gamma_{3}^{2}}=\frac{4}{h_{3}^{2}} \\
& \Sigma\left(\frac{1}{a^{2}}\right)+\Sigma\left(\frac{1}{\beta^{2}}\right)+\Sigma\left(\frac{1}{\gamma^{2}}\right)=\frac{1}{r^{2}}+\frac{1}{r_{1}{ }^{2}}+\frac{1}{r_{2}^{2}}+\frac{1}{r_{3^{2}}{ }^{2}}
\end{aligned}
$$

See $(35)$ of the $r$ formulae.*

$$
\left.\begin{array}{rl}
4 \triangle_{11} & =2\left(a_{3}+a_{3}\right) a_{1}=2\left(\beta_{3}+\beta_{3}\right) \beta_{2}=2\left(\gamma_{1}+\gamma_{2}\right) \gamma_{3} \\
& =\left(a_{1}-a\right)\left(a_{2}+a_{3}\right)+\left(\beta_{2}-\beta\right)\left(\beta_{3}+\beta_{1}\right)+\left(\gamma_{3}-\gamma\right)\left(\gamma_{1}+\gamma_{2}\right) \\
4 \triangle_{1} & =2\left(a_{1}+a_{3}\right) a=2\left(\beta_{2}-\beta\right) \beta_{3}=2\left(\gamma_{3}-\gamma\right) \gamma_{2} \\
& =-\left(a_{1}-a\right)\left(a_{2}+a_{3}\right)+\left(\beta_{2}-\beta\right)\left(\beta_{3}+\beta_{1}\right)+\left(\gamma_{3}-\gamma\right)\left(\gamma_{1}+\gamma_{2}\right) \\
4 \triangle_{2} & =2\left(a_{1}-a\right) a_{3}=2\left(\beta_{3}+\beta_{1}\right) \beta \quad=2\left(\gamma_{3}-\gamma\right) \gamma_{1} \\
& =\left(a_{1}-a\right)\left(a_{2}+a_{2}\right)-\left(\beta_{2}-\beta\right)\left(\beta_{3}+\beta_{1}\right)+\left(\gamma_{3}-\gamma\right)\left(\gamma_{1}+\gamma_{2}\right) \\
4 \triangle_{3} & =2\left(a_{1}-a\right) a_{2}=2\left(\beta_{2}-\beta\right) \beta_{1}=2\left(\gamma_{1}+\gamma_{2}\right) \gamma \\
& =\left(a_{1}-a\right)\left(a_{2}+a_{3}\right)+\left(\beta_{2}-\beta\right)\left(\beta_{3}+\beta_{1}\right)-\left(\gamma_{3}-\gamma\right)\left(\gamma_{1}+\gamma_{2}\right)
\end{array}\right\}
$$

$\begin{array}{lcccc}\text { where } & \triangle_{1} & \triangle_{1} & \triangle_{2} & \triangle_{3} \\ \text { triangles } & \mathrm{I}_{1} \mathrm{I}_{2} \mathrm{I}_{3} & \mathrm{II}_{3} \mathrm{I}_{2} & \mathrm{I}_{3} \mathrm{II}_{1} & \mathrm{I}_{2} \mathrm{I}_{1} \mathrm{I}\end{array}$

* Proceedings of the Edinburgh Mathematical Society, Vol. XII., p. 94 (1894). 
Historigal Notes.

In 1811 the Ladics' Dirry, which first :tppeared in 1704, and the Gentleman's Diary, which first appeared in 1741, were united and published under the title of the Lredy's and Gentlenures's Disry, which canns to an end in 1871. This title will in the notes be shortened? to Diary.

(1) The values of $\alpha_{1} \beta_{2} \gamma_{3}$ are given by J. Lowry in the Ladies' Diary for for 1836 , p. 52 ; T. S. Davies alds six more in the Diary for 1842 , 1. 79) and Weddle completes the duan by giving the values of $a \beta \gamma$ in the Diary for 1843, p. 80 .

(2) C. J. Matthes in his Conmentatio de Proprietatibus Quinque Cirrulorum, pp. 46,49 (1831).

(3) Weddle in the Diary for 1843, p. 81.

(4) Lhuilier in his Élémens d'Analyse, p. 215 (1809). The values of $\alpha a_{1} \beta \beta_{2} \gamma \gamma_{; ;}$ were however given by.J. Lowry in Leylourn's Mathematiral Rcpository, old series, I. 394 (1799).

(5) T. T. Wilkinson in Mathematical Questions from the Elucational Times, XIX. 107 (1873).

(6) C. Adams in Dic merkwïrdigsten Eigensehaften des geradlinigen Dreierks, p. $36(1846)$.

(7)--(12) Weddle in the Diary for 1843, pl, s1, 22, s8. The first three proportions of (12) are however inplicitly given by Matthes in his Commentatio, p. 46 (1831).

(13) The first property was proposed for proof at the Concours Académique de Clermont, 1875; the others were given by Mr H. Van Aubel in Nourelle Correspondance Mathématique, IV. 364 (1878).

(14), (17) First property given in Todhunter's Plane Trigonometry, Chap. XVI., Ex. 37 (18כy).

(15), (18) First property given in Hind's Trifonometry, 4th ed., pp. 304, 309 (1841).

(19) First property given in a slightly different form by Adams in his Eigenschaften des...Dreiccks, p. 40 (1846).

(20) First property given by C. F. A. Jacobi in his De Triangulorum Rectilineorum Proprietatibus, p. 10 (1825).

(21) First proportion given by J. Lowry in the Ladics' Diary for 1836, p. 52.

(22) First property on the left side given hy Adams in his Eiygenschaften des ...Dreiechs, p. $62(1846)$.

(23) The first property was proposed for proof at the Concours Académique de Clermmt, 1875. A geometrical solution of it occurs in 3ourget's Jomenal de Mathémutiques Élémcntaires, II. 54-5 (1878). 
(24)-(26) Weddle in the Diary for $1845,13.69$.

$(2 i)-(29) \quad, \quad, \quad, \quad, \quad, \quad, \quad$ p. 70.

(30) , , , , , , , , p.

$(31)-(35) \quad, \quad, \quad, \quad, \quad, \quad, \quad$ p. 71.

(36) The first values of $\left(a_{1}-\alpha\right)^{2}$, etc., occur in the Diary for 1847, p). 49-50, in answer to a question proposed the previous year by the editor, W. S. B. Woulhouse. The second values are given by Matthes in his Commentatio, pp. 53-4 (1831); the third values by Weddle in the Dictry for 1845, p. 74. The last values of $\left(\alpha_{2}+\alpha_{3}\right)^{2}$, etc., are given by Franz Unferdinger in Grumert's Archiv, XXIX., 436 (1857).

(38) Weddle in the Diary for 1843, p. 83 .

(39), (40) , , , , , , 1845, p. 73.

(41) The first proportion is given by Adams in his Eiglenschaften des...Dreiecks, p. 34 (1846). All four follow at once from eight expressions given by Werdde in the Diary for 1843, p. 82.

(43) Weddle in the Diary for 1S43. p. 82.

(46) ", , , , , 1845, p. 76.

(47) J. W. Ellintt in the Diary for 1847 , p. 73.

(48) Weddle , , , , 1845, p. 75.

(49) , , ., ., ., ., 1845, p. 76 .

(50) , , , , , , , ,

$\$ 10$.

Formulate connected with the Angular Bisectors of a Triangle LIMITED AT THEIR POINTS OF INTRRSECTION WITH THE SIDES.

The uniliteral notation for these bisectors

$$
\begin{array}{llllll}
l_{1} & l_{2} & l_{3} & \lambda_{1} & \lambda_{2} & \lambda_{3}
\end{array}
$$

was suggested by T. S. Davies in the Lady's and Gentleman's Diary for 1842, p. 77. In the expressions for them it has been assumed that the sides $\mathrm{BC} C A \mathrm{AB}$ are in decreasing order of magnitude. Hence it will follow that

BL is less than CL, and $\mathrm{BI}^{\prime}$ is less than $\mathrm{CL}^{\prime}$

$\mathrm{CM}$ is greater than $\mathrm{AM}$, and $\mathbf{C M}^{\prime}$ is greater than $\mathbf{A M}^{\prime}$

$A N$ is less than $B N$, and $A N^{\prime}$ is less than $B N^{\prime}$. 
The asaumption "canses the sign of $\lambda_{2}$ (corresponding to the mean aide $b$ ) to be contrary to those of $\lambda_{1}$ and $\lambda_{3}$. This must be borne in mind, otherwise the symmetry of the expressions in which these functions $\left(\begin{array}{lll}\lambda_{1} & \lambda_{2} & \lambda_{3}\end{array}\right)$ are involved will not be seen." (Weddle in the Diary for 1848, p. 76.)

Two fundamental theorems* regarding two sides of a triangle and the bisectors of the angles between them give the following proportions :

$$
\begin{gathered}
b: c=u_{2}: u_{1}=u_{2}^{\prime}: u_{1}^{\prime} \\
b c=u_{1} u_{2}+l_{2}{ }^{2}=u_{1}^{\prime} u_{2}^{\prime}-\lambda_{1}{ }^{2}
\end{gathered}
$$

Hence are derived

$$
\left.\begin{array}{l}
b^{2}=u_{2}^{2}+l_{1}^{2} \cdot \frac{u_{2}}{u_{1}}=u_{2}^{\prime 2}-\lambda_{1}^{2} \cdot \frac{u_{2}^{\prime}}{u_{1}^{\prime}} \\
c^{2}=u_{1}^{2}+l_{1}^{2} \cdot \frac{u_{1}}{u_{2}}=u_{1}^{\prime 2}-\lambda_{1}^{2} \cdot \frac{u_{1}^{\prime}}{u_{2}^{\prime}}
\end{array}\right\}
$$

Segments of the sides in terms of the sides

$$
\begin{aligned}
& u_{1}=\frac{c a}{b+c} \quad v_{1}=\frac{a b}{c+a} \quad w_{1}=\frac{b c}{a+b} \\
& u_{1}^{\prime}=\frac{c a}{b-c} \quad v_{1}^{\prime}=\frac{a b}{a-c} \quad u_{1}^{\prime}=\frac{b c}{a-b} \\
& u_{2}=\frac{a b}{b+c} \quad v_{2}=\frac{b c}{c+a} \quad w_{2}=\frac{c a}{a+b} \\
& u_{2}^{\prime}=\frac{a b}{b-c} \quad v_{2}^{\prime}=\frac{b c}{a-c} \quad w_{2}^{\prime}=\frac{c a}{a-b} \\
& u_{1}^{\prime}+u_{1}=u_{2}^{\prime}-u_{2}=\mathrm{L} \mathrm{L}=\frac{2 a b c}{b^{2}-c^{2}} \\
& v_{2}^{\prime}+v_{2}=v_{1}^{\prime}-v_{1}=\mathrm{MM}^{\prime}=\frac{2 a b c}{a^{2}-c^{2}} \\
& w_{1}^{\prime}+w_{1}=u_{2}^{\prime}-w_{2}=\mathrm{N} \mathrm{N}^{\prime}=\frac{2 a b c}{a^{2}-b^{\prime 2}}
\end{aligned}
$$

* The first is Euclid VI. 3 and its extension, which also was known to the Greeks, $2 s$ is evident from Pappus's Mathematical Collection, VII. 39, second proof. The first part of the second fundamental theorem is given in Schooten's Exercitationes Mathemuticue, p. 65 (1657). 


$$
\frac{1}{\mathrm{LI}^{\prime}}-\frac{1}{\mathrm{MM}^{\prime}}+\frac{1}{\mathrm{NN}^{\prime}}=0
$$

$$
\frac{a^{2}}{\mathrm{LL}^{\prime}}-\frac{b^{2}}{\mathrm{MM}^{\prime}}+\frac{c^{2}}{\mathrm{NN}^{\prime}}=0
$$

$$
\frac{a}{\mathrm{LL}^{\prime}}-\frac{b}{\mathrm{M} \mathrm{M}^{\prime}}+\frac{c}{\mathrm{NN}^{\prime}}=\frac{(b-c)(c-a)(a-b)}{2 a b c}
$$

The segments of the sides in terms of each other.

and so on.

$$
u_{1}=u_{1}^{\prime} \frac{u_{2}^{\prime}-u_{1}^{\prime}}{u_{2}^{\prime}+u_{1}^{\prime}} \quad u_{2}=u_{2}^{\prime} \frac{u_{2}^{\prime}-u_{1}^{\prime}}{u_{2}^{\prime}+u_{1}^{\prime}}
$$

and so on.

$$
u_{1}^{\prime}=u_{1} \frac{u_{2}+u_{1}}{u_{2}-u_{1}} \quad u_{2}^{\prime}=u_{2} \frac{u_{2}+u_{1}}{u_{2}-u_{1}}
$$

and so on.

$$
u_{1}^{\prime}+u_{1}=u_{2}^{\prime}-u_{2}=\mathrm{I} \mathrm{J}_{1}^{\prime}=\frac{2 u_{1} u_{2}}{u_{2}-u_{1}}
$$

$$
\begin{aligned}
& l_{1}=\frac{2 \sqrt{b c s s_{1}}}{(b+c)}=\frac{2 \Delta \sqrt{b c r r_{1}}}{(b+c) r r_{1}} \\
& l_{2}=\frac{2 \sqrt{c a s s_{2}}}{(c+a)}=\frac{2 \Delta \sqrt{c a r r_{2}}}{(c+a) r r_{2}} \\
& l_{3}=\frac{2 \sqrt{a b s s_{3}}}{(a+b)}=\frac{2 \Delta \sqrt{a b r r_{3}}}{(a+b) r r_{3}}
\end{aligned}
$$




$$
\begin{aligned}
& \lambda_{\mathrm{r}}=\frac{2 \sqrt{b\left(r_{0} v_{::}\right.}}{(b-c)}=\frac{2 \Delta \sqrt{b r_{2} r_{:}}}{(b-c) r_{2} r_{::}} \\
& \lambda_{2}=\frac{2 \sqrt{c a s_{3} x_{1}}}{(a-c)}=\frac{2 \Delta \sqrt{c a r_{3} r_{1}}}{(a-c) r_{: 3} r_{1}} \\
& \lambda_{i:}=\frac{2 \sqrt{a b s_{1} s_{2}}}{(a-b)}=\frac{2 \Delta \sqrt{a b r_{2} r_{2}}}{(a-b) r_{1} r_{2}}
\end{aligned}
$$

$$
\left.\begin{array}{l}
\frac{l_{1}^{2}}{b c}+\frac{a^{2}}{(b+c)^{2}}=1 \\
\frac{l_{2}^{2}}{c a}+\frac{b^{2}}{(c+a)^{2}}=1 \\
\frac{l_{3}^{2}}{(e l)}+\frac{c^{2}}{(a+b)^{2}}=1
\end{array}\right\}
$$

$$
\left.\begin{array}{c}
\frac{a^{2}}{(b-c)^{2}}-\frac{\lambda_{1}{ }^{2}}{b c}=1 \\
\frac{b^{2}}{(a-c)^{2}}-\frac{\lambda_{2}{ }^{2}}{c a}=1 \\
\frac{c^{2}}{(a-b)^{2}}-\frac{\lambda_{:}^{2}}{a b}=1
\end{array}\right)
$$

$$
\begin{aligned}
& l_{1}{ }^{2}(b+c)^{2}+\lambda_{1}{ }^{2}(b-c)^{2}=4 b^{2} c^{2} \\
& l_{0}{ }^{2}(c+a)^{2}+\lambda_{2}{ }^{2}(a-c)^{2}=4 c^{2} a^{2} \\
& l_{3^{2}}{ }^{2}(a+b)^{2}+\lambda_{i:}{ }^{2}(a-b)^{2}=4 a^{2} b^{2}
\end{aligned}
$$

$$
-\frac{l_{1}^{2}}{b c}(b+c)^{2}+\frac{l_{2^{2}}^{2}}{c a}(c+a)^{2}+\frac{l_{3^{2}}^{2}}{a b}(a+b)^{2}=4 s^{2}
$$$$
\frac{l_{1}^{2}}{b_{c} c}(b+c)^{2}-\frac{\lambda_{2}^{2}}{c a}(a-c)^{2}-\frac{\lambda_{2}^{2}}{a b}(a-b)^{2}=4 s_{1}^{2}
$$$$
-\frac{\lambda_{1}^{2}}{b c}(b-c)^{2}+\frac{l_{2^{2}}^{2}}{c a}(c+a)^{2}-\frac{\lambda_{a^{2}}{ }^{2}}{a b}(a-b)^{2}=4 s_{2}^{2}
$$$$
\left.-\frac{\lambda_{1}{ }^{2}}{b c}(b-c)^{2}-\frac{\lambda_{2}{ }^{2}}{c a}(a-c)^{2}+\frac{l^{2}{ }^{2}}{r b}-(a+b)^{2}=4 s_{3}{ }^{2} \quad\right)
$$

$$
l_{1}^{2} b c\left(\frac{1}{b}+\frac{1}{c}\right)^{2}+l_{2}^{2} c a\left(\frac{1}{c}+\frac{1}{a}\right)^{2}+l_{a^{2}}^{2} a b\left(\frac{1}{a}+\frac{1}{b}\right)^{2}=4 s^{2}
$$

and so on.

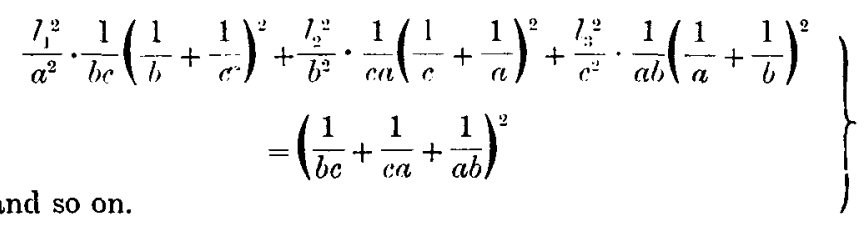




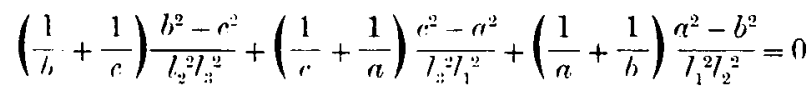

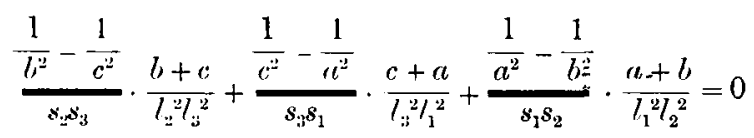

$$
\begin{aligned}
& u_{1} u_{2}+v_{1} v_{2}+w_{1} w_{2}=a b c\left\{\frac{a}{(b+c)^{2}}+\frac{b}{(c+a)^{2}}+\frac{c}{(a+b)^{2}}\right\} \\
& \left.u_{1}^{\prime} u_{2}^{\prime}+v_{1}^{\prime} v_{2}^{\prime}+w_{1}^{\prime} w_{2}^{\prime}=a b c\left\{\frac{a}{(b-c)^{2}}+\frac{b}{(a-c)^{2}}+\frac{c}{(a-b)^{2}}\right\}\right\} \\
& u_{1} u_{2}+v_{1} u_{2}+u_{1} u_{2}+\left(l_{1}^{2}+l_{2}^{2}+l_{3}^{2}\right)=b c+c a+a b \\
& u_{1}^{\prime} u_{2}^{\prime}+v_{1}^{\prime} u_{2}^{\prime}+u u_{1}^{\prime} u_{2}^{\prime}-\left(\lambda_{1}{ }^{2}+\lambda_{2}{ }^{2}+\lambda_{3}{ }^{2}\right)=b c+c a+a l \\
& l_{1} u+l_{2} \beta+l_{:} \gamma=a v_{1}+2 u_{1}+m u_{1} \\
& l_{1}\left(l_{1}-\alpha\right)+l_{2}\left(l_{2}-\beta\right)+l_{3}\left(l_{: 3}-\gamma\right) \\
& =\left(a-r_{1}\right) r_{2}+\left(l-u_{1}\right) u_{2}+\left(c-u_{1}\right) u_{2} \\
& u^{2}+\beta^{2}+\gamma^{2}-\left\{\left(l_{1}-a\right)^{2}+\left(l_{2}-\beta\right)^{2}+\left(l_{3}-\gamma\right)^{\prime \prime}\right\} \\
& =\left(u_{1}+v_{1}+w_{1}\right)\left(u_{2}+v_{2}+u_{2}\right)-2\left(u_{1} v_{2}+v_{1} u_{2}+w_{1} n_{2}\right) j \\
& \frac{1}{u_{1} v_{1} v_{1}}=\left(\frac{1}{b}+\frac{1}{c}\right)\left(\frac{1}{c}+\frac{1}{a}\right)\left(\frac{1}{a}+\frac{1}{b}\right) \\
& \frac{1}{u_{1} v_{1}^{\prime} w_{1}^{\prime}}=\left(\frac{1}{b}+\frac{1}{c}\right)\left(\frac{1}{c}-\frac{1}{a}\right)\left(\frac{1}{b}-\frac{1}{a}\right) \\
& \frac{1}{u_{1}^{\prime} v_{1} w_{1}^{\prime}}=\left(\frac{1}{c}-\frac{1}{b}\right)\left(\frac{1}{c}+\frac{1}{a}\right)\left(\frac{1}{b}-\frac{1}{a}\right) \\
& \frac{1}{u_{1}^{\prime} v_{1}^{\prime} w_{1}}=\left(\frac{1}{c}-\frac{1}{b}\right)\left(\frac{1}{c}-\frac{1}{a}\right)\left(\frac{1}{a}+\frac{1}{b}\right)
\end{aligned}
$$

These may be put into the forms

and so on; or

$$
u_{1} v_{1} w_{1}: a b c=a b c:(b+c)(c+a)(a+b)
$$

$\mathrm{BL} \cdot \mathrm{CM} \cdot \mathrm{AN}: a b c=a b c: \mathrm{D}_{2} \mathrm{D}_{3} \cdot \mathrm{E}_{3} \mathrm{E}_{3} \cdot \mathrm{F}_{1} \mathrm{~F}_{2}$ and so on. 


$$
\begin{aligned}
& u_{1} r_{1} u_{1}=u_{12} r_{2} u_{2}=\frac{4 \triangle R_{r}}{h_{1}+h_{2}+h_{; 3}-r} \\
& u_{1} v_{1}^{\prime} w_{1}^{\prime}=u_{2} v_{2}^{\prime} w_{2}^{\prime}=\frac{4 \triangle \mathrm{R} r_{1}}{h_{1}-h_{2}-h_{3}+r_{1}} \\
& u_{1}^{\prime} v_{1} u_{1}^{\prime}=u_{2}^{\prime} v_{2} u u_{2}^{\prime}=\frac{4 \Delta \mathrm{R} r_{2}}{h_{1}-h_{2}+h_{3}-r_{2}} \\
& u_{1}^{\prime} v_{1}^{\prime} w_{1}=u_{2}^{\prime} v_{2}^{\prime} w_{2}=\frac{4 \triangle R_{3}}{-h_{1}-h_{2}+h_{: 3}+r_{:}} \\
& u_{1}^{\prime} v_{1}^{\prime} w_{1}^{\prime}=u_{2}^{\prime} v_{2}^{\prime} w_{2}^{\prime}=\frac{a^{2} b^{2} c^{\prime \prime}}{(b-c)(a-c)(a-b)} \\
& u_{1}^{\prime} v_{1} w_{1}=u_{2}^{\prime} v_{2} u_{2}=\frac{a^{2} l b^{2} r^{2}}{(b-c)(c+a)(a+b)} \\
& u_{1} v_{1}^{\prime} w_{\mathrm{I}}=u_{2} r_{2}^{\prime} w_{2}=\frac{a^{3} b^{2} c^{2}}{(b+c)(a-c)(a+b)} \\
& u_{1} v_{1} w_{1}^{\prime}=u_{2} v_{2} u_{2}^{\prime}=\frac{a^{2} b^{2} c^{2}}{(b+c)(c+a)(a-b)}
\end{aligned}
$$

These may be put into the forms

$$
\mathrm{BL}^{\prime} \cdot \mathrm{CM}^{\prime} \cdot \mathrm{AN}^{\prime}: a b c=a b c: \mathrm{IDD}_{1} \cdot \mathrm{EE}_{2} \cdot \mathrm{FF}_{z}
$$

and so on.

$$
\begin{aligned}
& l_{1} l_{2} l_{3}=\frac{8 a b c s \triangle}{(b+c)(c+a)(a+b)} \quad \lambda_{1} \lambda_{2} \lambda_{: 3}=\frac{8 a b c r \Delta}{(b-c)(a-c)(a-b)} \\
& l_{1} \lambda_{2} \lambda_{3}=\frac{8 a b c s_{1} \Delta}{(b+c)(a-c)(a-b)} \quad \lambda_{1} l_{2} l_{: ;}=\frac{8 a b c r_{1} \triangle}{(b-c)(c+a)(a+b)} \\
& \lambda_{1} l_{2} \lambda_{3}=\frac{8 a b c s_{2} \triangle}{(b-c)(c+a)(a-b)} \quad l_{1} \lambda_{2} l_{::}=\frac{8 a b c r_{2} \triangle}{(b+c)(a-c)(a+b)} \\
& \left.\lambda_{1} \lambda_{2} l_{3}=\frac{8 a b r_{3} \Delta}{(b-c)(a-c)(a+b)} \quad l_{1} l_{2} \lambda_{: ;}=\frac{8 a b c r_{3} \triangle}{(b+c)(c+a)(a-b)}\right) \\
& l_{1} l_{2} l_{:}=\frac{32 \mathrm{R} \triangle^{*}}{r(b+c)(c+a)(a+b)}=\frac{8 \triangle^{*}}{h_{1}+h_{: 2}+h_{: 3}-r}
\end{aligned}
$$


and so on.

$$
\lambda_{1} \lambda_{2} \lambda_{3}=\frac{32 \mathrm{R} \triangle}{s(b-c)(a-c)(a-b)}
$$

$$
\begin{aligned}
& \mathrm{BL} \cdot \mathrm{CM} \cdot \mathrm{AN}: l_{1} l_{2} l_{2}=\mathrm{R}: 2 s \\
& \mathrm{BL}^{\prime} \cdot \mathrm{CM}^{\prime} \cdot \mathrm{AN}^{\prime}: \lambda_{1} \lambda_{2} \lambda_{3}=\mathrm{R}: 2 r \\
& \left.\begin{array}{c}
l_{1} l_{2} l_{3}(b+c)(c+a)(a+b) \\
=8 a \beta \gamma s^{3}=8 a_{1} \beta_{1} \gamma_{1} s s_{1}{ }^{2}=8 a_{2} \beta_{2} \gamma_{2} s s_{2}^{2}=8 a_{-3} \beta_{3} \gamma_{j s} s s_{3}{ }^{2} \\
=8 a_{1} \beta_{2} \gamma_{3} s r^{2}=8 a \beta_{3} \gamma_{2} s r_{1}{ }^{2}=8 a_{3} \beta \gamma_{1} s r_{2}{ }^{2}=8 a_{2} \beta_{1} \gamma s r_{3}{ }^{2}
\end{array}\right\} \\
& \left.\begin{array}{c}
\lambda_{1} \lambda_{2} \lambda_{3}(b-c)(a-c)(a-b) \\
=8 u_{1} \beta_{2 .} \gamma_{3} r^{3}=8 u \beta_{3} \gamma_{2} r r_{1}^{2}=8 a_{3} \beta \gamma_{1} r r_{2}^{2}=8 a_{2} \beta_{1} \gamma r r_{3}^{2} \\
=8 a \beta \gamma r s^{2}=8 a_{1} \beta_{1} \gamma_{1} r s_{1}^{2}=8 a_{2} \beta_{2} \gamma_{2} r s_{2}^{2}=8 a_{3} \beta_{3} \gamma_{3} \cdot s_{3}{ }^{2}
\end{array}\right\} \\
& \left.\begin{array}{rl}
l_{1} l_{2} l_{3} \lambda_{1} \lambda_{2} \lambda_{3} & =\frac{64 a^{2} b^{2} c^{2} \triangle^{3}}{\left(b^{2}-c^{2}\right)\left(a^{2}-c^{2}\right)\left(a^{2}-b^{2}\right)} \\
& =\frac{1024 \mathrm{R}^{2} \triangle^{5}}{\left(b^{2}-c^{2}\right)\left(a^{2}-c^{2}\right)\left(a^{2}-b^{2}\right)}
\end{array}\right\} \\
& \frac{2 a}{l_{1} \lambda_{1}}=\frac{h_{3}^{\prime 2}-h_{2}^{2}}{h_{1} h_{2} h^{2}} \quad \frac{2 b}{l_{2} \lambda_{2}}=\frac{h_{3}: h_{1}^{2}}{h_{1} h_{2} h_{3}} \quad \frac{2_{c}}{l_{3} \lambda_{3}}=\frac{h_{2}: h_{1}^{2}}{h_{1} h_{2} h_{3}} \\
& \frac{2 h_{1}}{l_{1} \lambda_{1}}=\frac{b^{2}-c^{2}}{a b c} \quad \frac{2 h_{2}}{l_{2} \lambda_{2}}=\frac{a^{2}-c^{2}}{a b c} \quad \frac{2 h_{; i}}{l_{3} \lambda_{3}}=\frac{a^{2}-b^{2}}{a b c} \\
& l_{1} \lambda_{1}=\frac{4 b c \triangle}{b^{2}-c^{2}} \quad l_{2} \lambda_{2}=\frac{4 c a \triangle}{a^{2}-c^{2}} \quad l_{3} \lambda_{3}=\frac{4 a b \triangle}{a^{2}-b^{2}} \\
& \frac{a}{l_{1} \lambda_{1}}-\frac{b}{l_{2} \lambda_{2}}+\frac{c}{l_{3} \lambda_{3}}=0 \\
& \frac{h_{1}}{l_{1} \lambda_{1}}-\frac{h_{22}}{l_{2} \lambda_{2}}+\frac{l_{i 3}}{l_{3} \lambda_{;}}=0
\end{aligned}
$$




$$
\begin{aligned}
& \frac{1}{a l_{1} \lambda_{1}}-\frac{1}{b l_{2} \lambda_{2}}+\frac{1}{c l_{3} \lambda_{3}}=0 \\
& \frac{1}{h_{1} l_{1} \lambda_{1}}-\frac{1}{h_{2} l_{2} \lambda_{2}}+\frac{1}{h_{3} l_{3} \lambda_{3}}=0 \\
& a: l_{1}=r(b+c): 2 \triangle=b+c: 2 s \\
& \beta: l_{2}=r(c+a): 2 \Delta=c+a: 2 s \\
& \gamma: l_{3}=r(a+b): 2 \triangle=a+b: 2 s \\
& u_{1}: l_{1}=r_{1}(b+c): 2 \triangle=b+c: 2 s_{1} \\
& \beta_{2}: l_{2}=r_{2}(c+a): 2 \triangle=c+a: 2 s_{2} \\
& \gamma_{i ;}: l_{;}=r_{3}(a+b): 2 \Delta=a+b: 2 s_{; 3} \\
& \alpha_{.2}: \lambda_{1}=r_{2}(b-c): 2 \triangle=b-c: 2 s_{1 .} \\
& u_{i j}: \lambda_{1}=r_{s}(b-c): 2 \triangle=b-c: 2 s_{; j} \\
& \beta_{3}: \lambda_{2}=r_{3}(a-c): 2 \Delta=a-c: 2 s_{; 3} \\
& \beta_{1}: \lambda_{2}=r_{1}(a-c): 2 \triangle:=a-c: 2 s_{1} \\
& \gamma_{1}: \lambda_{3}=r_{1}(a-b): 2 \triangle=a-b: 2 s_{1} \\
& \gamma_{2}: \lambda_{: 3}=r_{s}(a-b): 2 \triangle=a-b: 2 s_{2}
\end{aligned}
$$

$$
\begin{aligned}
& a: \mathrm{I} \mathrm{L}=b+c: a \\
& \beta: \mathrm{I} \mathrm{M}=c+a: b \\
& \gamma: \mathrm{I} \mathrm{N}=a+b: c \\
& a_{1}: \mathrm{I}_{1} \mathrm{~L}=b+c: a \\
& \beta_{3:}: \mathrm{I}_{2} \mathrm{M}=c+a: b \\
& \gamma_{: 3}: \mathrm{I}_{3} \mathrm{~N}=a+b: c \\
& u_{22}: \mathrm{I}_{2} \mathrm{~L}^{\prime}=b-c: a \\
& a_{3}: \mathrm{I}_{3} \mathrm{~L}^{\prime}=b-c: a \\
& \beta_{3}: \mathrm{I}_{3} \mathrm{M}^{\prime}=a-c: b \\
& \beta_{1}: \mathrm{I}_{1} \mathrm{M}^{\prime}=a-c: b \\
& \gamma_{1}: \mathrm{I}_{1} \mathrm{~N}^{\prime}=a-b: c \\
& \gamma_{2}: \mathrm{I} \mathbf{N}^{\prime}=a-b: c
\end{aligned}
$$

$$
\begin{aligned}
& l_{1}: \mathrm{I} \mathrm{L}=2 s: \alpha \\
& I_{2,2}: \mathbf{I} \mathbf{M I}=2 s: l \\
& l_{: i}: \mathrm{I} \mathrm{N}=2 s: c \\
& I_{1}: I_{1} L_{1}=2 s_{1}: a \\
& l_{2}: \mathbf{I}_{2} \mathbf{M}=2 s_{2,}: b \\
& l_{: 3}: \mathrm{I}_{3 ;} \mathrm{N}=2 s_{: 3}: c \\
& \lambda_{1}: \mathrm{I}_{2} \mathrm{~L}^{\prime}=2 s_{2,}: a \\
& \lambda_{1}: I_{3} L^{\prime}=2 s_{3}: a \\
& \lambda_{2}: I_{3} \mathbf{M}^{\prime}=2 s_{3}: b \\
& \lambda_{2}: \mathbf{I}_{1} \mathbf{M}^{\prime}=2 s_{1}: b \\
& \lambda_{3}: \mathrm{I}_{1} \mathrm{~N}^{\prime}=2 s_{1}: c \\
& \lambda_{\mathrm{s}}: \mathrm{I}_{2} \mathbf{N}^{\prime}=2 s_{12}: c
\end{aligned}
$$


Values such as

$$
\begin{aligned}
& l_{1}=\frac{2 \Delta}{r} \cdot \frac{a}{\mathrm{D}_{2} \mathrm{D}_{3}}=\frac{2 \Delta}{r_{1}} \cdot \frac{\alpha_{1}}{\mathrm{D}_{2} \mathrm{D}_{3}} \\
& \lambda_{1}=\frac{2 \Delta}{r_{2}} \cdot \frac{a_{2}}{\mathrm{DD}_{1}}=\frac{2 \Delta}{r_{3}} \cdot \frac{a_{3}}{\mathrm{DD}_{1}} \\
& \text {...................... } \\
& \mathrm{IL}=\frac{a \sqrt{b c r r_{1}}}{(b+c) r_{1}} \quad \mathrm{I}_{1} \mathrm{~L}=\frac{a \sqrt{b c r r_{1}}}{(b+c) r} \\
& \mathrm{I}_{2} \mathrm{~L}^{\prime}=\frac{a \sqrt{b c r_{2} r_{3}}}{(b-c) r_{3}} \quad \mathrm{I}_{3} \mathrm{~L}^{\prime}=\frac{a \sqrt{b c r_{2} r_{3}}}{(b-c) r_{3}}
\end{aligned}
$$

need not be written out at length.

$$
\begin{aligned}
& \mathrm{I} \mathrm{L} \cdot \mathrm{I} \mathrm{M} \cdot \mathrm{I} \mathrm{N}=\frac{16 \Delta \mathrm{R}^{2} r^{2}}{(b+c)(c+a)(a+b)} \\
& \mathrm{I}_{1} \mathrm{~L} \cdot \mathrm{I}_{2} \mathrm{M} \cdot \mathrm{I}_{3} \mathrm{~N}=\frac{16 \Delta \mathrm{R}^{2} s^{2}}{(b+c)(c+a)(a+b)} \\
& \mathrm{I}_{1} \mathrm{~L} \cdot \mathrm{I}_{1} \mathrm{M}^{\prime} \cdot \mathrm{I}_{1} \mathrm{~N}^{\prime}=\frac{16 \Delta \mathrm{R}^{2} r_{1}{ }^{2}}{(b+c)(a-c)(a-b)} \\
& \mathrm{I} \mathrm{L} \cdot \mathrm{I}_{8} \mathrm{M}^{\prime} \cdot \mathrm{I}_{2} \mathrm{~N}^{\prime}=\frac{16 \Delta \mathrm{R}^{2} s_{1}{ }^{2}}{(b+c)(a-c)(a-b)} \\
& \mathrm{I}_{2} \mathrm{~L} \cdot \mathrm{I}_{2} \mathrm{M} \cdot \mathrm{I}_{2} \mathrm{~N}^{\prime}=\frac{16 \Delta \mathrm{R}^{2} r_{2}{ }^{2}}{(b-c)(c+a)(a-b)} \\
& \mathrm{I}_{3} \mathrm{~L}^{\prime} \cdot \mathrm{I} \mathrm{M} \cdot \mathrm{I}_{1} \mathrm{~N}^{\prime}=\frac{16 \Delta \mathrm{R}^{2}{ }_{s_{2}}{ }^{2}}{(b-c)(c+a)(a-b)} \\
& \mathrm{I}_{3} \mathrm{~L}^{\prime} \cdot \mathrm{I}_{3} \mathrm{M}^{\prime} \cdot \mathrm{I}_{3} \mathrm{~N}=\frac{16 \Delta \mathrm{R}^{2} r_{3}{ }^{2}}{(b-c)(a-c)(a+b)} \\
& \mathrm{I}_{2} \mathrm{~L}^{\prime} \cdot \mathrm{I}_{1} \mathrm{M}^{\prime} \cdot \mathrm{I} \mathrm{N}=\frac{16 \Delta \mathrm{R}^{2} s_{3}{ }^{2}}{(b-c)(a-c)(a+b)}
\end{aligned}
$$




$$
\left.\begin{array}{l}
\mathrm{I} \mathrm{L} \cdot \mathrm{I} \mathrm{M} \cdot \mathrm{I} \mathrm{N}=\frac{4 \mathrm{R} r^{3}}{h_{1}+h_{3}+h_{3}-r} \\
\mathrm{I}_{1} \mathrm{~L} \cdot \mathrm{I}_{2} \mathrm{M} \cdot \mathrm{I}_{3} \mathrm{~N}=\frac{4 \mathrm{R} r s^{2}}{h_{1}+h_{2}+h_{3}-r}
\end{array}\right\}
$$

$a \beta \gamma: \mathrm{IL} \cdot \mathrm{IM} \cdot \mathrm{IN}=(b+c)(c+a)(a+b): a b c$

$$
\begin{aligned}
& =a b c: \mathrm{BL} \cdot \mathrm{CM} \cdot \mathrm{AN} \\
& =h_{1}+h_{2}+h_{3}-r: r \\
& =u_{1} \beta_{3} \gamma_{3} \cdot \mathrm{I}_{1} \mathrm{~L}: \mathrm{I}_{2} \mathrm{M} \cdot \mathrm{I}_{3} \mathrm{~N}
\end{aligned}
$$

$$
\begin{aligned}
& \mathrm{I} \mathrm{L} \cdot \mathrm{I} \mathrm{M} \cdot \mathrm{I} \mathrm{N}: l_{1} l_{2} l_{3}=\mathrm{R} r: 28^{2} \\
& \mathrm{I}_{1} \mathrm{~L} \cdot \mathrm{I}_{2} \mathrm{M} \cdot \mathrm{I}_{3} \mathrm{~N}: l_{1} l_{2} l_{3}=\mathrm{R}: 2 r
\end{aligned}
$$

$$
\begin{aligned}
& \frac{l_{1}}{\mathrm{LL}^{\prime}} \cdot \frac{l_{2}}{\mathrm{MM}^{\prime}} \cdot \frac{l_{3}}{\mathrm{NN}^{\prime}}=\frac{(b-c)(a-c)(a-b)}{16 \mathrm{R}^{2} r}=\frac{h_{1} h_{2} h_{3}}{\lambda_{1} \lambda_{2} \lambda_{3}} \\
& \frac{\lambda_{1}}{\mathrm{LL}^{\prime}} \cdot \frac{\lambda_{2}}{\mathrm{M} \overline{\mathbf{I}}^{\prime}} \cdot \frac{\lambda_{3}}{\mathrm{NN}^{\prime}}=\frac{(b+c)(c+a)(a+b)}{16 \mathrm{R}^{2} 8}=\frac{h_{1} h_{2} h_{: 3}}{l_{1} l_{2} l_{3}}
\end{aligned} ;
$$

$$
\begin{aligned}
& l_{1}^{2}=\frac{4 r r_{1}\left(r r_{1}+r_{2} r_{i 3}\right)}{\left(r_{1}+r\right)^{2}} \quad \lambda_{1}^{2}=\frac{4 r_{2} r_{3}\left(r r_{1}+r_{2} r_{i 3}\right)}{\left(r_{2}-r_{3}\right)^{2}} \\
& I_{2}^{2}=\frac{4 r r_{3}\left(r r_{3}+r_{3} r_{1}\right)}{\left(r_{2}+r\right)^{2}} \quad \lambda_{2}^{2}=\frac{4 r_{3} r_{1}\left(r r_{3}+r_{3} r_{1}\right)}{\left(r_{1}-r_{3}\right)^{2}} \\
& l_{3}{ }^{\prime}=\frac{4 r_{i}\left(r r_{i i}+r_{1} r_{i 2}\right)}{\left(r_{3}+r\right)^{2}} \quad \lambda_{3}{ }^{2}=\frac{4 r_{1} r_{3}\left(r r_{3}+r_{1} r_{2}\right)}{\left(r_{1}-r_{2}\right)} \\
& \frac{1}{l_{1}^{2}}+\frac{1}{\lambda_{1}^{2}}=\frac{1}{h_{1}^{2}} \\
& \frac{1}{l_{2}^{2}}+\frac{1}{\lambda_{2}{ }^{2}}=\frac{1}{h_{2}^{2}} \\
& \frac{1}{h_{: 2}^{2}}+\frac{1}{\lambda_{i:}^{2}}=\frac{1}{h_{i:}^{2}}
\end{aligned}
$$




$$
\begin{aligned}
& \frac{l_{1}}{l_{2} l_{3}}+\frac{l_{1}}{\lambda_{2} \lambda_{3}}=\frac{\lambda_{1}}{\lambda_{2} l_{3}}-\frac{\lambda_{3}}{l_{3} \lambda_{3}}=\frac{h_{1}}{h_{2} h_{3}}=\frac{2 \mathrm{R}}{a^{2}} \\
& \frac{l_{3}}{l_{3} l_{1}}-\frac{l_{2}}{\lambda_{3} \lambda_{1}}=\frac{\lambda_{2}}{l_{3} \lambda_{1}}+\frac{\lambda_{2}}{\lambda_{3} l_{1}}=\frac{h_{2}}{h_{3} h_{1}}=\frac{2 \mathrm{R}}{b^{2}} \\
& \frac{l_{3}}{l_{1} l_{2}}+\frac{l_{3}}{\lambda_{1} \lambda_{2}}=\frac{\lambda_{3}}{l_{1} \lambda_{2}}-\frac{\lambda_{3}}{\lambda_{2} l_{2}}=\frac{h_{3}}{h_{1} h_{2}}=\frac{2 \mathrm{R}}{c^{2}}
\end{aligned}
$$

$$
\begin{aligned}
& \frac{l_{1}}{\lambda_{1}}=\frac{l_{3} \lambda_{3}-\lambda_{2} l_{3}}{l_{2} l_{3}+\lambda_{2} \lambda_{3}} \\
& \frac{l_{2}}{\lambda_{3}}=\frac{l_{3} \lambda_{1}+\lambda_{3} l_{1}}{\lambda_{3} \lambda_{1}-l_{3} l_{1}} \\
& \frac{l_{3}}{\lambda_{3}}=\frac{\lambda_{1} l_{2}-l_{2} \lambda_{2}}{l_{1} l_{2}+\lambda_{1} \lambda_{2}}
\end{aligned}
$$

Weddle remarks that the three preceding relations between $\begin{array}{lllllllll}l_{1} & l_{2} & l_{3} & \lambda_{1} & \lambda_{2} & \lambda_{3} & \text { all reduce to }\end{array}$

$$
l_{1} l_{2} l_{3}=\lambda_{1} l_{2} \lambda_{3}-\lambda_{1} \lambda_{2} l_{3}-l_{1} \lambda_{2} \lambda_{3}
$$

$$
\left.\begin{array}{lll}
l_{1}=\frac{2 \alpha \alpha_{1}}{\alpha+\alpha_{1}} & l_{2}=\frac{2 \beta \beta_{2}}{\beta+\beta_{2}} & l_{3}=\frac{2 \gamma \gamma_{3}}{\gamma+\gamma_{3}} \\
\frac{2}{l_{1}}=\frac{1}{a}+\frac{1}{\alpha_{1}} & \frac{2}{l_{2}}=\frac{1}{\beta}+\frac{1}{\beta_{3}} & \frac{2}{l_{3}}=\frac{1}{\gamma}+\frac{1}{\gamma_{3}} \\
\lambda_{1}=\frac{2 a_{3} a_{3}}{\alpha_{3}-a_{3}} & \lambda_{2}=\frac{2 \beta_{1} \beta_{3}}{\beta_{1}-\beta_{3}} & \lambda_{3}=\frac{2 \gamma_{1} \gamma_{2}}{\gamma_{1}-\gamma_{2}} \\
\frac{2}{\lambda_{1}}=\frac{1}{a_{3}}-\frac{1}{a_{2}} & \frac{2}{\lambda_{2}}=\frac{1}{\beta_{3}}-\frac{1}{\beta_{1}} & \frac{2}{\lambda_{3}}=\frac{1}{\gamma_{2}}-\frac{1}{\gamma_{1}}
\end{array}\right\}
$$




$$
\begin{aligned}
& \operatorname{AU}\left(a_{2}+a_{3}\right)=2 \mathrm{R}(b+c) \\
& \mathrm{BV}\left(\beta_{3}+\beta_{1}\right)=2 \mathrm{R}(c+a) \\
& \mathrm{CW}\left(\gamma_{1}+\gamma_{2}\right)=2 \mathbf{R}(a+b) \\
& \mathrm{AU}^{\prime}\left(a_{1}-\alpha\right)=2 \mathrm{R}(b-c) \\
& \mathrm{BV}^{\prime}\left(\beta_{2}-\beta\right)=2 \mathrm{R}(a-c) \\
& \mathrm{CW}^{\prime}\left(\gamma_{3}-\gamma\right)=2 \mathrm{R}(a-b) \\
& \mathrm{AU} \cdot l_{1}=\mathrm{AU}^{\prime} \cdot \lambda_{1}=b c \\
& \mathrm{BV} \cdot l_{2}=\mathrm{BV}^{\prime} \cdot \lambda_{2}=c a \\
& \mathrm{CW} \cdot l_{3}=\mathrm{CW}^{\prime} \cdot \lambda_{3}=a b \\
& \mathrm{CW}^{2}=\frac{a b(a+b)^{2}}{4 s s_{3}} \quad \mathrm{CW}^{\prime 2}=\frac{a b(a-b)^{2}}{4 s_{1} s_{2}} \\
& \begin{aligned}
\mathrm{UA}^{\prime} & =\frac{r^{2}}{h_{1}-2 r}=\frac{r_{1}}{h_{1}+2 r_{1}} \\
\mathrm{VB}^{\prime} & =\frac{r^{2}}{h_{2}-2 r}=\frac{r_{2}^{2}}{h_{2}+2 r_{2}} \\
\mathrm{WC}^{\prime} & =\frac{r^{2}}{h_{33}-2 r}=\frac{r_{3}^{2}}{h_{3}+2 r_{3}}
\end{aligned} \\
& \frac{b c\left(b^{2}-c^{2}\right)}{4 \mathrm{AU} \cdot \mathrm{AU}^{\prime}}=\frac{a c\left(a^{2}-c^{2}\right)}{4 \mathrm{BV} \cdot \mathrm{BV}},=\frac{a b\left(a^{2}-\dot{b}^{2}\right)}{4 \mathrm{CW} \cdot \mathrm{CW}^{\prime}}=\Delta \\
& l_{1}(b+c)=h_{1}\left(a_{2}+a_{3}\right) \quad \lambda_{1}(b-c)=h_{1}\left(a_{1}-a\right) \\
& l_{2}(c+a)=h_{2}\left(\beta_{3}+\beta_{1}\right) \quad \lambda_{2}(a-c)=h_{2}\left(\beta_{2}-\beta\right) \\
& l_{3}(a+b)=h_{3}\left(\gamma_{1}+\gamma_{2}\right) \quad \lambda_{3}(a-b)=h_{3}\left(\gamma_{3}-\gamma\right)
\end{aligned}
$$




$$
\begin{aligned}
& \frac{4}{l_{1}{ }^{2}}+\frac{4}{\lambda_{1}{ }^{2}}=\frac{1}{a^{2}}+\frac{1}{{\alpha_{1}{ }^{2}}^{2}}+\frac{1}{{a_{2}{ }^{2}}^{2}}+\frac{1}{\alpha_{3}{ }^{2}} \\
& \frac{4}{l_{2}{ }^{2}}+\frac{4}{\lambda_{1}{ }^{2}}=\frac{1}{\beta^{2}}+\frac{1}{\beta_{1}{ }^{2}}+\frac{1}{\beta_{2}{ }^{2}}+\frac{1}{\beta_{3}{ }^{2}} \\
& \frac{4}{l_{3}{ }^{2}}+\frac{4}{\lambda_{3}{ }^{2}}=\frac{1}{\gamma^{2}}+\frac{1}{\gamma_{1}{ }^{2}}+\frac{1}{\gamma_{2}{ }^{2}}+\frac{1}{\gamma_{3}{ }^{2}}
\end{aligned}
$$

$$
\left.\begin{array}{l}
\frac{a}{l_{1}}+\frac{\beta}{l_{2}}+\frac{\gamma}{l_{3}}=2 \\
\frac{\alpha_{1}}{l_{1}}-\frac{\beta_{1}}{\lambda_{2}}+\frac{\gamma_{1}}{\lambda_{3}}=2 \\
\frac{\beta_{2}}{l_{2}}+\frac{\gamma_{2}}{\lambda_{3}}-\frac{\alpha_{2}}{\lambda_{1}}=2 \\
\frac{\gamma_{3}}{l_{3}}+\frac{\alpha_{3}}{\lambda_{2}}+\frac{\beta_{3}}{\lambda_{2}}=2
\end{array}\right\}(67) \quad \begin{aligned}
& \frac{a_{1}}{\lambda_{1}}-\frac{\beta_{2}}{\lambda_{2}}+\frac{\gamma_{3}}{\lambda_{3}}=0 \\
& \frac{a}{\lambda_{1}}+\frac{\beta_{3}}{l_{2}}-\frac{\gamma_{2}}{l_{3}}=0 \\
& \frac{\alpha_{3}}{l_{1}}+\frac{\beta}{\lambda_{2}}-\frac{\gamma_{1}}{l_{3}}=0 \\
& \frac{a_{2}}{l_{1}}-\frac{\beta_{1}}{l_{2}}+\frac{\gamma}{\lambda_{3}}=0
\end{aligned}
$$

Let AI BI CI meet MN NL LM respectively at

$\begin{array}{lll}\mathrm{L}_{1} & \mathrm{M}_{1} & \mathrm{~N}_{1}\end{array}$

$$
\left.\begin{array}{c}
\mathrm{AL}_{1}: \mathrm{IL}_{1}=\mathrm{AL}: \mathrm{IL}=h_{1}: r \\
\mathrm{BM}_{1}: \mathrm{IM}_{1}=\mathrm{BM}: \mathrm{IM}=h_{2}: r \\
\mathrm{CN}_{1}: \mathrm{IN}_{1}=\mathrm{CN}: \mathrm{IN}=h_{3}: r
\end{array}\right\}
$$

Matthes (p. 47) gives the values

$$
\begin{aligned}
\mathrm{AL}_{1} & =\frac{h_{1} \sqrt{b c r r_{1}}}{\left(h_{1}+r\right) r_{1}}, \text { etc., } \\
\mathrm{IL}_{1} & =\frac{r \sqrt{b c r r_{1}}}{\left(h_{1}+r\right) r_{1}}, \text { etc. }
\end{aligned}
$$


Expressions for the sides of $\triangle \mathrm{LMN}$.

$$
\left.\begin{array}{l}
\mathrm{MN}^{2}=\frac{a b c}{(c+a)^{2}(a+b)^{2}} \times \\
\left(b^{2} c+b c^{2}-c^{2} a+c a^{2}+a^{2} b-a b^{2}+a^{3}-b^{2}-c^{3}+3 a b c\right)
\end{array}\right\}
$$

$\mathrm{NL}^{2}$ and $\mathrm{LM}^{2}$ can be obtained by cyclical permutations of the letters $a \quad b c$.

These expressions can be put into shorter forms, by help of Landen's theorem that

$$
\mathrm{I}_{1} \mathrm{O}^{2}=\mathrm{R}^{2}+2 \mathrm{R} r_{1}
$$

$$
\text { For } \begin{gathered}
\quad 4 \Delta\left(\mathrm{R}+2 r_{1}\right)=4 \Delta \mathrm{R}+\frac{16 \triangle^{2}}{2 s_{\mathrm{l}}} \\
=a b c+(a+b+c)(a-b+c)(a+b-c) \\
=b^{2} c+b c^{2}-c^{2} a+c a^{2}+a^{2} b-a b^{2}+a^{3}-b^{3}-c^{3}+3 a b c
\end{gathered}
$$

Hence

$$
\mathrm{MN}=\frac{4 \Delta \cdot \mathrm{I}_{1} \mathrm{O}}{(c+a)(a+b)} \quad \mathrm{NL}=\frac{4 \Delta \cdot \mathrm{I}_{2} \mathrm{O}}{(a+b)(b+c)} \quad \mathrm{LM}=\frac{4 \Delta \cdot \mathrm{I}_{3} \mathrm{O}}{(b+c)(c+a)}
$$

Matthes (p. 45) in transforming the ten-term factor which occurs in the expression for $\mathrm{MN}^{2}$ does not appear to have observed the simplification that would result from introducing $\mathrm{R}+2 r_{r}$. $\mathrm{He}$ introduces $R+2 r$, and obtains for $M N$ the following ralue:

$$
\frac{4 \Delta}{(c+a)(a+b) r_{2} r_{3}} \sqrt{\left\{\left(\mathbf{R}^{2}+2 \mathrm{R} r\right) r_{2} r_{3}+2 a \Delta \mathbf{R}\right\} r_{2} r_{3}}
$$

The points $L^{\prime} M^{\prime} N^{\prime}$ do not form the vertices of a triangle, but are collinear.

Expressions for the distances $M^{\prime} N^{\prime} N^{\prime} L^{\prime} L^{\prime} M^{\prime}$.

$$
\left.\begin{array}{l}
\mathrm{M}^{\prime} \mathrm{N}^{\prime 2}=\frac{a b c}{(a-c)^{2}(a-b)^{2}} \times \\
\left(-b^{2} c-b c^{2}-c^{2} a-c a^{2}-a^{2} b-a b^{2}+a^{3}+b^{3}+c^{3}+3 a b c\right)
\end{array}\right\}
$$

$\mathrm{N}^{\prime} \mathrm{L}^{\prime 2}$ and $\mathrm{L}^{\prime} \mathrm{M}^{\prime 2}$ can be obtained by cyclical permutations of the letters $a b c$. 
These expressions can be put into shorter forms, by help of Chapple's theorem that

$$
\mathrm{IO}^{2}=\mathrm{R}^{2}-2 \mathrm{R} r
$$

For

$$
\begin{gathered}
4 \Delta(\mathrm{R}-2 r)=4 \Delta \mathrm{R}-\frac{16 \triangle^{2}}{2 s} \\
=a b c+(-a+b+c)(a-b+c)(a+b-c) \\
=-b^{2} c-b c^{2}-c^{2} a-c a^{2}-a^{2} b-a b^{2}+a^{3}+b^{3}+c^{3}+3 a b c
\end{gathered}
$$

Hence

$$
\mathbf{M}^{\prime} \mathbf{N}^{\prime}=\frac{4 \Delta \cdot \mathrm{IO}}{(a-c)(a-b)} \quad \mathbf{N}^{\prime} \mathbf{L}^{\prime}=\frac{4 \Delta \cdot \mathrm{IO}}{(a-b)(b-c)} \quad \mathbf{L}^{\prime} \mathbf{M}^{\prime}=\frac{4 \Delta \cdot \mathrm{IO}}{(b-c)(a-c)}
$$

In deducing the expressions for $M^{\prime} N^{\prime} N^{\prime} L^{\prime} L^{\prime} M^{\prime}$ it has been assumed that $a b c$ are in descending order of magnitude. If the figure do not correspond to this supposition, care must be taken in verifying the equation

$$
L^{\prime} \mathbf{M}^{\prime}=\mathbf{M}^{\prime} \mathbf{N}^{\prime}+\mathbf{N}^{\prime} \mathbf{L}^{\prime}
$$

to affix the proper sigus to the values of these magnitudes.

\section{Historical Notrs.}

(3) Crelle's Eigenschaften des...Dreieclis, p. 39 (1816). The property is probably much older.

(4) Weddle in the Diary for 1843, p. 75 .

(10) The first values of $l_{1} l_{2} l_{3}$ are given by Vecten in Gergonne's Annales, IX., $304(1818-9)$; the second values by Matthes in his Commentatio, p. 42 (1831).

(11) The first values are given by Weddle in the Diary for 1848, p. 78 ; the second values by Matthes in his Commentatio, p. 58 (1831).

(12) Mr Robert E. Anderson.

(14) The first equality is given by Mr Launoy in Bourget's Journal de Mathematiques Élementaires, III. 160 (1879).

(15) The first equality is given in J. A. Grunert's article "Dreieck" in Supplemente zu Khügel's Wörterbuche der reinen Mathematik, I. 709 (1833). In this article Grunert gives also (20). 
(16)-(19) Mr Robert E. Anderson.

(21) First part in Jacobi's De Triangulorum...Proprietatibus, p. 8 (1825). Both parts certainly much older.

(22)-(24) Jacobi, p. 13 (1825).

(25) Jacobi, p. 12 (1825), gives the first equality in the first alternative form.

(26) First equality given by Matthes in his Commentatio, p. 42 (1831).

(27) First equality given by Marsano in his Considerazioni sul Triangolo Retti. lineo, p. 29 (1863).

(28) The value of $l_{1} l_{2} l_{3}$ is given by Vecten in Gergonne's Annales, IX. 304 (1819); that of $\lambda_{1} \lambda_{2} \lambda_{3}$ by Weddle in the Diary for 1848, p. 78.

(29) The first value is given by Vecten in Gergonne's Arnales, IX. 305 (1819).

(31), (32) J. W. Elliott in the Diary for 1851, p. 58.

(33) The first of these eight values is given by Jacobi, p. 10 (1825).

(35) Weddle in the Diary for 1848, p. 78.

(36) , , , , , , , p. $\$ 1$.

(37) , ,, , , , , " p. 80.

(38) Nouvelles Annales, 2nd series, IX. 548 (1870).

(39)-(42) Weddle in the Diary for 1848, pp. 81-2.

(43)-(45) Matthes, pp. 46, 48, 50 (1831), gives several of these proportions, but they must all have been known long previonsly.

(46) Matthes, p. 58 (1831), gives the values of $\lambda_{1} \lambda_{2} \lambda_{3}$, but he does not seem to have observed the corresponding ones for $l_{1} l_{2} l_{3}$.

(47) Matthes, pp. 48, 51, gives the first half of these values, the first two of (48), and the first of (49).

(50) The first two proportions are given by Jacobi, pp. 11, 19 (1825); the last two by Matthes, pp. 48, 51 (1831).

(51) The last proportion is given by Matthes, p. 51 .

(52) J. W. Elliott in the Diary for 1851, p. 58. The equality of the last two expressions is given by Vecten in Gergonne's Annales, IX. 305 (1819).

(53) - (58) Weddle in the Diary for 1848, pp. 76-7S, 82 . The values in (58) are probably much older than this.

(61) Weddle in the Diary for 1848, p. 82.

(62) Value of $\mathrm{AU}^{2}$ is given by William Mawson in the Diary for 1845, p. 67.

(63) Adams's Eigenschaften des... Dreiecks, p. 75 (1846).

(65)-(68) Weddle in the Diary for 1848, p. 83 . The first equality in (67) is given by Adams in his Eigenschaften des...Dreiecks, p. 61 (1846).

(69), (71), (72), (74), (75) Matthes, pp. 47, 44, 59 (1831). 